\title{
Demonstration of Innovative Monitoring- Technologies at the Savannah River Integrated Demonstration Site ${ }^{(U)}$
}




\section{Demonstration of Innovative Monitoring Technologies at the Savannah River Integrated Demonstration Site ${ }^{(U)}$}

Authors:

J. Rossabi, WSRC, Technical Coordinator

R. A. Jenkins, ORNL, Characterization and Monitoring Technical Support Group (TSG) Leader

M. B. Wise, ORNL

M. R. Guerin, ORNL

P. M. Kearl, ORNL

S. Ballard, SNL

G. J. Elbring, SNL

G. Frye, SNL

F. P. Milanovich, LLNL

P. F. Daley, LLNL

A. L. Ramirez, LLNL

W. D. Daily, LLNL

E. Kaplan, BNL

B. Neilsen, USAF

J. Evans, PNL

K. B. Olsen, PNL

Technical Support Group Members:

D. S. Kaback, CCEM

A. D. Henriksen, LANL

T. M. Brouns, PNL

G. V. Last, PNL

S. D. Tomich, PNL

V. J. Rohay, WHC

C. A. Eddy Dilek, WSRC

G. R. Olhoeft, USGS

C. Keller, Eastman/Cherrington

F. K. Heacker, HAZWRAP

G. Junk, Ames Lab

D. A. Emilia, Geo Tech

K. J. Koegler, WHC 


\title{
Contents
}

\author{
Executive Summary 1
}

Introduction 3

Background 5

Savannah River Site 7

Savannah River Integrated Demonstration Site

Physical Parameters 11

In Situ Permeable Flow Sensor 12

Background 12

Operation and Methods 12

Results 14

Conclusions 16

Seismic Tomography 16

Background 16

Operation and Methods 17

Results 17

Conclusions 17

Electrical and Electromagnetic Tomography 19

Background 19

Operation and Methods 20

Results 20

Conclusions 20

Colloidal Borescope 22

Background 22

Operations and Methods 23

Results 23

Conclusions 23 


\section{Chemical Sampling and Monitoring 27}

Sampling Technologies 29

Passive Groundwater Sampling 29

Background 29

Operation and Methods 29

Results 29

Conclusions 30

Arrayed Vadose Zone Sampler $\mathbf{3 0}$

Background 30

Operation and Methods 32

Results 34

Conclusions 34

Tech Transfer 35

\section{Compound Selective Technologies 37}

Fiber Optic TCE Sensor 37

Background 37

Operation and Methods 38

Results 38

Conclusions 41

\section{Class Selective Technologies 43}

Portable Acoustic Wave Sensor 43

Background 43

Operation and Methods 44

Results 44

Conclusions 45

HaloSnif'M 45

Background 47

Operation and Methods 47

Results 48

Conclusions 48

\section{Broadly Applicable Technologies 51}

Direct Sampling Ion Trap Mass Spectrometer 51

Background

51

Operations and Methods 51

Results 54

Conclusions 56 


\section{Summary 57 \\ Physical Parameter Technologies 59 \\ Sampling Technologies $\mathbf{5 9}$ \\ Chemical Analysis Technologies $\quad 59$ \\ Other Technologies 60 \\ Technology Status 60 \\ Acquisition and Use of Data 60}

\section{References 61}

\section{Bibliography 63}

Appendix-Field Monitoring Test Platform 73 


\section{List of Figures}

Figure 1. Savannah River Site and Surrounding Area 8

Figure 2. Theoretical surface temperature as a function of vertical distance from the midpoint of probe 13

Figure 3. Temperature as a function of azimuth for probe buried in a horizontal flow field 13

Figure 4. Vertical temp srature distribution on surface of probe before air injection began and then later when air injection was taking place 15

Figure 5. Surface temperature of probe as a function of azimuth both before and after the in situ bioremediation air injection started 15

Figure 6. Velocity difference tomogram resulting from inversion of S-wave travel time differences 18

Figure 7. Cross-sectional view of the sampled region at SRIDS 21

Figure 8. Differential resistivity tomograph representing changes in resistance observed during the high-rate air injection phase 21

Figure 9. Diagram of the Colloidal Borescope 24

Figure 10. Groundwater Flow Directions at the Integrated Site Demonstration as Measured by the Colloidal Borescope 25

Figure 11. Mechanical sampler results indicating the existence of weak vertical profiles in dissolved oxygen, temperature, and $\mathrm{pH} 31$

Figure 12. Membrane apparatus results indicating a horizontal specific discharge of about $6 \mathrm{~cm} /$ year 31

Figure 13. Schematic Diagram of Arrayed Sampler 33

Figure 14. Fiber optic TCE sensor design 39

Figure 15. Scatter plnt comparing results of fiber optic sensor analyses with independent, EPAapproved sampling and analysis techniques 40

Figure 16. Results from penetrometer insertion test performed in May 1992 (DON'T HAVE) 40

Figure 17. On-line analysis of contaminant concentrations in the offgas stream from the vacuum extraction process at SRIDS using the PAWS system 46

Figure 18. Monitoring of gas sample from monitoring well at SRIDS 46

Figure 19. Test I and II results using HaloSnif ${ }^{\mathrm{TM}} \quad 49$

Figure 20. DSITMS Sample Introduction System 53

Figure 21. Real time Measurements of TCE and PCE in Well Headspace 55 


\title{
Demonstration of Innovative Monitoring Technologies at the Savannah River Integrated Demonstration Site
}

\author{
J. Rossabi, Technic?l Coordinator/Author-Environmental Sciences Section, Westinghouse Savannah River Company
}

\section{Executive Summary}

Innovative site characterization and monitoring technologies are integral to the objective of reducing environmental restoration costs and long-term, post-closure monitoring. As part of the Department of Energy's (DOE) Integrated Demonstration Program at the Savannah River Site (SRS), new technologies in the areas of drilling, characterization, monitoring, and remediation are being demonstrated and evaluated for their technical performance and cost effectiveness in comparison with baseline technologies.

Present site characterization and monitoring methods are costly, time-consuming, overly invasive, and often imprecise. Better technologies are required to accurately describe the subsurface geophysical and geochemical features of a site and the nature and extent of contamination. More efficient, nonintrusive characterization and monitoring techniques are also necessary for understanding and predicting subsurface transport.

DOE is focusing on site characterization, sampling, and monitoring as areas in which significant technological advances are possible. Relatively small investments in better characterization and monitoring systems will provide cost payback many times over.

This report summarizes the results of field demonstrations of technologies that address the measurement of both physical and chemical parameters related to subsurface characterization and monitoring as well as in situ sampling methods. Several different platforms were targeted for the deployment of these sensors including placement directly in the subsurface, in wells, and at the surface.The following three categories of instruments have been demonstrated as part of the DOE's OTD integrated demonstrations:

- instruments that monitor physical parameters by measuring surrogate parameters i.e., colloidal particle movement (ORNL colloidal borescope) or temperature change (SNL In Situ Permeable Flow Sensor) for groundwater flow velocity; electrical resistivity (LLNL Electrical and electromagnetic tomography) or seismic velocity (SNL Seismic Tomography) for three dimensional imaging of saturation changes.

- instruments that capture liquid (BNL Multilevel Mechanical and Membrane Samplers) or vapor (ORNL Arrayed Vadose Zone Sampler) subsurface samples with minimal invasiveness

- instruments that analyze chemical concentration (LLNL Fiber Optic TCE Sensor for remote detection of vapor-phase TCE and chloroform in a borehole; SNL Portable Acoustic Wave Sensor for the detection of vapor-phase contaminants; PNL Halosnif for the detection of vapor-phase chlorinated organic species; ORNL Direct Sampling Ion Trap Mass Spectrometer for compound specific determination of contaminants in the vapor, liquid, or solid phases).

All of the technologies were successful in completing the sampling or monitoring objectives of their field demonstrations. Many of the technologies are licensed to private industry and all are mature enough to begin technology transfer and to initiate progress toward regulatory acceptance. Not only are several of the technologies cost competitive with existing technologies, but they can provide information that is not obtainable by the existing methods. 


\section{Introduction}

The Department of Energy's (DOE) Office of Technology Development (OTD) initiated an Integrated Demonstration Program at the Savannah River Site (SRS) in 1989. The objective of this program is to develop, demonstrate, and evaluate innovative technologies that can improve present-day environmental restoration methods. The Integrated Demonstration Program at SRS is entitled "Cleanup of Organics in Soils and Groundwater at Non-Arid Sites" (Walton, 1991). New technologies in the areas of drilling, characterization, monitoring, and remediation are being demonstrated and evaluated for their technical performance and cost effectiveness in comparison with baseline technologies.

Present site characterization and monitoring methods are costly, time-consuming, overly invasive, and often imprecise. Better technologies are required to accurately describe the subsurface geophysical and geochemical features of a site and the nature and extent of contamination. More efficient, nonintrusive characterization and monitoring techniques are necessary for understanding and predicting subsurface transport. More reliable procedures are also needed for interpreting monitoring and characterization data (e.g., How clean is "clean"?).

Site characterization and monitoring are key elements in preventing, identifying, and restoring contaminated sites. The remediation of a site cannot be determined without characterization data, and monitoring may be required for 30 years after site closure. Environmental characterization and monitoring is mandated by various legislation, including, but not limited to the following:

- Clean Water Act

- Resource Conservation and Recovery Act

- Superfund Amendments and Reauthorization Act

- Comprehensive Environmental Response, Compensation, and Liability Act

DOE is focusing on site characterization, sampling, and monitoring as areas in which significant technological advances are possible. Advances in these areas will decrease cost, reduce risk, and shorten schedules for achieving restoration goals.

This report describes the interim status of the monitoring technologies that have been demonstrated as part of the Savannah River Integrated Demonstration Program. 
WSRC-TR-93-671 


\section{Background}

Chlorinated volatile organic compounds (CVOCs) were commonly used before the mid-1980s by many industrial facilities as metal-degreasing solvents. The use of these solvents was discontinued at that time because of their risk to human health and the environment (Looney et al. 1992). These solvents can be particularly insidious once introduced into the environment for several reasons:

- Their density is greater than water $(>1.0)$, often resulting in greater vertical migration relative to groundwater flow.

- They are refractory to most biological processes.

- They tend to be held in the vadose zone by sorptive and other processes, which makes them a long-term source of contamination to water that comes in contact with them.

The heterogeneity of the subsurface at all sites and the number of paths available to CVOC movement make the prediction of the fate and transport of these solvents an intractable problem. This in turn makes the remediation of CVOC contamination extremely difficult.
To accurately and economically assess the degree and extent of CVOC contamination at a site, it is necessary to have a good conceptual model of the site and a complete and accurate spatio-temporal database of the contaminant concentrations and physical parameters affecting the transport of the contaminant. The ideal method for analysis of the subsurface would give a precise and accurate, threedimensional distribution of the chemical and physical parameters without disturbing the subsurface. This technology is not yet available. The best available technologies have involved the acquisition of grab samples that are later quantitatively analyzed in the laboratory. Relatively few field screening methods are currently available and in situ monitoring is virtually nonexistent (Eddy et al., 1992; Rossabi, 1993a). The objective of the Savannah River Integrated Demonstration Monitoring Program has been to develop and field test new monitoring methods that attempt to fill this field data need with technologies that are better, faster, and more economical than baseline technologies. 
WSRC-TR-93-671 


\section{Savannah River Site}

SRS encompasses a 300-square-mile area near Aiken, South Carolina (Figure 1), and is located on the upper Atlantic Coastal Plain. The site is underlain by a thick wedge (approximately 1000 feet) of unconsolidated Tertiary and Cretaceous sediments that overlay the basement, which consists of preCambrian and Paleozoic metamorphic rocks and consolidated Triassic sediments (siltstones and sandstones). The Cretaceous and younger sedimentary section consists predominantly of sand, clayey sand, and sandy clay (Eddy et al., 1991).

The site contains several nuclear material production facilities that began operating in 1951. As with many large production facilities, the SRS facilities released chemicals into the environment, which has resulted in the contamination of the subsurface of many onsite areas by a number of different compounds used in or resulting from the production process. The largest volume of contamination has been from CVOCs (Looney et al., 1992). SRS used trichloroethylene (TCE) and tetrachloroethylene (PCE) until the early 1980s as metal-degreasing solvents (Marine and Bledsoe, 1984). Elevated levels of these compounds have been measured in the groundwater in several areas onsite. One area has a plume that extends over one square mile. Conventional groundwater pump-and-treat systems have been installed in two locations onsite; however, this type of system does not effectively remediate contamination in the vadose zone, where it is believed that most of the contaminants reside.

Groundwater flow at the site is controlled by the following hydrologic boundaries:

- at and immediately below the water table-to local tributaries

- in the lower Tertiary aquifer-to the Savannah River or one of its major tributaries

- in the Cretaceous aquifers-toward the Savannah River.

Flow in the shallow aquifers in the immediate vicinity of the Savannah River Integrated Demonstration Site (SRIDS) is highly influenced by an eleven-well recovery network (pump and treat). The demonstration program is focusing on contamination in the shallow Tertiary sediments (Kaback et al. 1989a). 


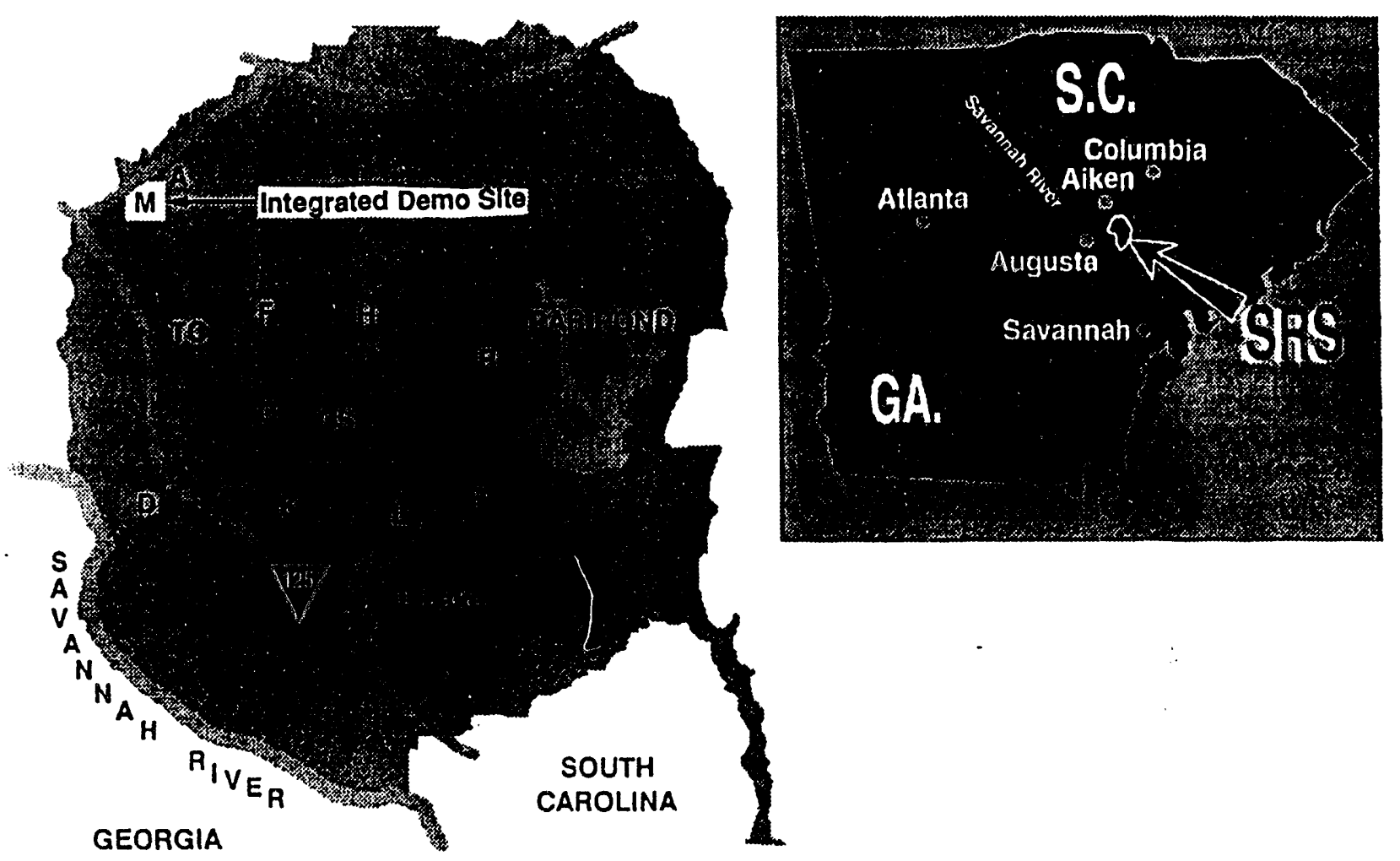

SRSSE

Figure 1. Savannah River Site and Surrounding Area 


\section{Savannah River Integrated Demonstration Site}

The area selected for the SRIDS is along the former site of a process sewer line that carried nonradioactive solvent waste to a seepage basin for 27 years beginning in 1958 (Looney et al, 1991). Characterization data indicated that several leaks existed in the sewer line $(\approx 20$-ft depth), serving as localized sources of contamination. Over one million pounds of solvent were released to the sewer line, and a significant portion of this solvent is estimated to be in the subsurface at the SRIDS. Two horizontal wells were installed at the site at depths of approximately 160 and 70 feet along the trace of the excavated sewer line. The lower well (AMH-1) was designed for gas injection below the water table ( $\approx 135-\mathrm{ft}$ depth), and the upper well (AMH-2) was used for vapor extraction (Kaback et al., 1989b).

Ten clusters of monitoring wells were initially installed at the SRIDS. Each cluster consisted of two wells, one screened at the water table and one screened in the upper sand of the Tertiary aquifer. Fifteen boreholes were continuously cored at the SRIDS to depths greater than 130 feet.
Samples for chemical and microbiological analyses were collected from the cores and used to characterize the site. Geophysical logs of the 10 deepest boreholes ( $190 \mathrm{ft}$ ) were used along with the core to create geologic cross sections (Eddy et al, 1991).

Five clusters of vadose zone piezometers were installed at the site, each consisting of three wells screened in different lithologies in the unsaturated zone. In addition, several wells designed to suit the needs of the various characterization and monitoring technologies tested at the site were installed. Using the headspace gas chromatography (GC) method, SRS personnel sampled the monitoring wells bimonthly for aqueous-phase analysis of CVOC concentrations (Looney et al., 1993). Gas samples from the vadose zone were also taken periodically from the piezometer and analyzed using GC for CVOC concentrations. The results from both of these sampling efforts have been used as a baseline for comparison with the analytical results from new monitoring technology demonstrations. Those monitoring technologies tested at the SRIDS are described in the following sections. 


\section{WSRC-TR-93-671}

$\because$ 


\section{Physical Parameters}

A variety of innovative geophysical techniques are being tested at the SRIDS. The primary objective of these technologies is to characterize the dynamics of the air injection process. During the in situ air-stripping demonstration, the air was used to strip contaminants from the groundwater and the vadose zone as it traveled from one well to the other. Air was injected into the deeper horizontal well and extracted from the upper horizontal well (Looney et al., 1991/1992; Looney et al., 1991). During the in situ bioremediation demonstration, a mixture of methane and air was injected to stimulate biological activity to the point where additional quantities of the contaminant were consumed by microorganisms (Hazen et al., 1992). In both cases, it is important to understand how the injected gas travels from the injection well to the extraction well to estimate the zone of influence of the remediation process.

In an ideal, perfectly homogeneous medium, the injected gas would emanate uniformly from the injection well along the screened length and permeate upward through the groundwater and the unsaturated zone to the extraction well. The subsurface, however, is composed of heterogeneous materials. Although there is evidence that the gas does emanate from most of the screened sections of the injection well, it is highly unlikely that injection into the subsurface occurs in a perfectly uniform fashion along the entire length of the well. Once in the subsurface the air is likely to travel along very tortuous pathways from the injection to the extraction well. The air may become trapped beneath relatively impermeable clay layers in the saturated environment, then migrate up along high-permeability pathways through these layers. Under these conditions, the areas that have the greatest volumes of gas moving through them will be remediated the most because of both the physical air-stripping process and biological degradation. The bacteria in these areas are exposed to the largest flux of air and nutrients and multiply and metabolize the contaminants more rapidly than in areas with less air and nutrients. Therefore, to estimate the effectiveness of the remediation process and to design full-scale remediation systems, it is necessary to know the zone of influence for the air injection.

Three new monitoring technologies were demonstrated to address this issue. The first of these, the in situ permeable flow sensor, is a new technology for measuring the magnitude and direction of the groundwater flow velocity at a specific point in permeable geologic materials. Developed by Sandia National Laboratory (SNL), this instrument was installed to monitor changes in the groundwater flow field around the injection well in an attempt to identify pathways with the greatest air flux. The other two technologies involve cross-hole geophysical tomography. Similar to medical tomographic techniques, these state-of-the-art geophysical methods are used to obtain two- or three-dimensional (3-D) images of the variations in a relevant geophysical parameter in the region between boreholes. SNL used seismic tomography to image changes in the seismic velocity between the injection and extraction wells. Lawrence Livermore National Laboratory (LLNL) measured induced voltage and current to probe changes in the electrical resistivity in the same region. In the following sections, each of these technologies is discussed in greater detail. 


\section{In Situ Permeable Flow Sensor}

SNL has developed a sensor that measures thermal perturbations induced by groundwater flow to determine the 3-D groundwater flow velocity vector in permeable geologic formations. Groundwater flow is one of the most important mechanisms for the dispersal of contaminants once they have been released into the subsurface. Accurate information about the groundwater flow field is critical to the characterization of waste sites, the monitoring of waste remediation activities, and the monitoring of the post-closure performance of remediated waste sites. This technology should find widespread applications in all of these areas.

\section{Background}

The basic principle of the in situ permeable flow sensor relies on the perturbation of a uniformly heated volume by a fluid flux (water or air) past the instrument. The temperature distribution within the heated volume will change in response to the magnitude and direction of the flow field.

The first groundwater flow sensor based on this principle was developed (with funding from the USDOE's Basic Energy Sciences) for scientific studies in thermally active regions of the shallow crust of the Earth. This instrument, called the convective heat flow probe, was designed to be used as a logging tool in open boreholes that penetrate hard rock or consolidated sediments. DOE holds a U. S. patent on the convective heat flow probe $(\# 4,547,080)$. This complicated instrument had motors to make the temperature sensors and heater pads contact the walls of the borehole, as well as packers to seal off the hole above and below the instrument. The instrument was successful in some geothermal applications; however, deployment in a borehole where the flow can be quite different from the flow in the surrounding, undisturbed formation may provide inaccurate flow values. The convective heat flow probe in its original configuration could not be used in unconsolidated formations that require a cased borehole because the casing disrupted the thermal field. This prevented the use of the sensor for environmental remediation objectives at most hazardous waste sites.

Beginning in FY 90, the deployment strategy for the flow sensor technology was reevaluated. With funding from DOE OTD, the sensor was redesigned for use in environmental characterization and monitoring. The new design uses a simple, inexpensive probe that can be permanently buried in saturated, unconsolidated sediments. To deploy the sensor, a hollow stem auger is used to drill to the depth where the measurement is to be made. The probe is then lowered down the center of the auger and the auger is retracted from the hole, leaving the probe in the ground. In unconsolidated formations, the hole quickly collapses around the probe. The resulting measured flows are more representative of in situ conditions than measurements made when the instrument is installed in a cased hole or in an open borehole in consolidated formations. Although the probes cannot be recovered after being deployed, they can continue to provide flow measurements for extended periods of time. Ideally, the probes should last until the waterproof coatings leak (several years). An alternative method for emplacing the device is to push the instrument into the ground with a cone penetrometer. Installation using the cone penetrometer may be preferred because the diameter of the cylinder of disturbed soil is minimized and the costs of installation is reduced. This type of deployment will require further development.

\section{Operation and Methods}

The sensor-a thin cylindrical heater surrnunded by an array of thermistors-is buried in the ground at the point where the groundwater flow velocity is to be measured. The heat flux out of the cylinder is assumed to be uniform over its surface. In the absence of any flow past the device. the only mechanism for heat transfer is by diffusion. Therefore, the temperature on the surface of the probe would be independent of azimuth and symmetric about the vertical midpoint of the probe (Figure $2,0 \mathrm{~m} / \mathrm{yr}$ ). The vertical midpoint would be warmer than the ends of the probe because of end effects. Fluid (groundwater or subsurface air) flow past the device perturbs the temperature distribution on the surface of the cylinder. Warmer temperatures are observed on the downstream side of the probe than on the upstream side because the heat introduced into the formation by the heater is advected around the instrument.

Figure 2 illustrates the theoretical surface temperature as a function of vertical distance from the midpoint of the probe for a variety of flow velocities directed vertically upward. The vertical temperature distribution on the surface of the probe is no longer symmetric about the vertical midpoint of the probe but rather is skewed in the direction of the flow. The downstream end of the probe is warmer than the upstream end. Figure 3 illustrates the temperature as a function of azimuth for a probe buried in a horizontal flow field where the groundwater is flowing in a direction $90^{\circ}$ from the reference direction on the probe. The temperature distribution is no longer independent of azimuth but varies as the cosine of the azimuth with the downstream side of the probe being warmer than the upstream side. In a groundwater flow field with both vertical and horizontal components, a combination of these effects would be observed. The magnitude and direction of the 3-D flow velocity vector are determined from the magnitude and the pattern of the temperature variations on the surface of the probe. 


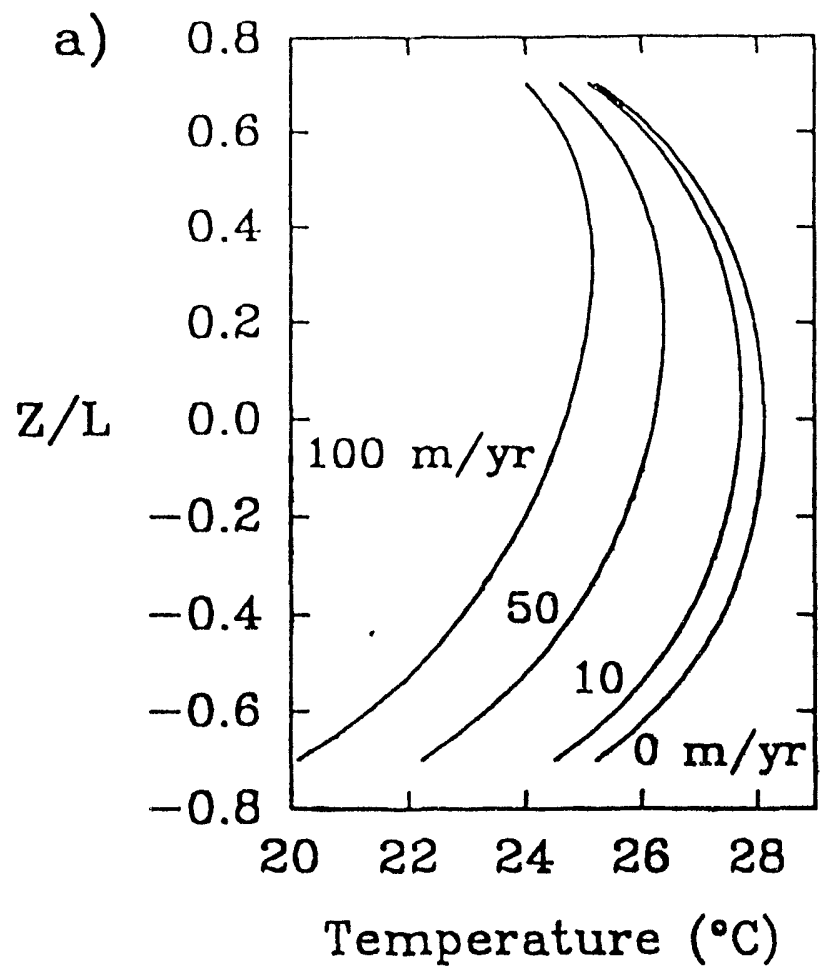

Figure 2. Theoretical surface temperature as a function of vertical distance from the midpoint of probe (Z/L)

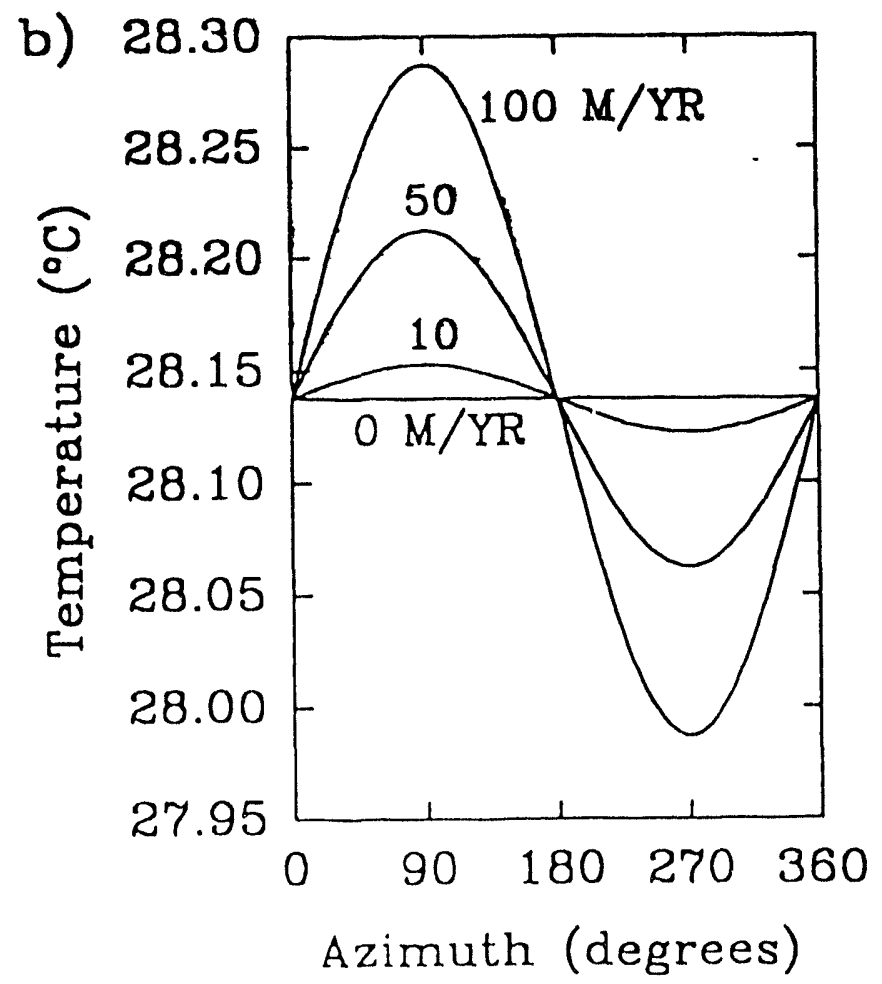

Figure 3. Temperature as a function of azimuth for probe buried in a horizontal flow field (Groundwater was flowing in a direction $90^{\circ}$ from the reference direction on the probe.) 
The sensors can resolve horizontal groundwater flows of about $10 \mathrm{~m} / \mathrm{yr}$ or more, depending on the thermal diffusivity of the subsurface medium. Because of the long aspect ratio in the vertical direction, the instruments are more sensitive to vertical than horizontal flows.

The first in situ permeable flow sensors intended specifically for environmental applications were designed, fabricated, and tested during the in situ air-stripping demonstration at the SRIDS. Each sensor consisted of a rod of G-11 epoxy laminate $75 \mathrm{~cm}$ long and $5 \mathrm{~cm}$ in diameter. A long hole was drilled along the axis of the rod to accept a cylindrical heater $(60 \mathrm{~cm}$ long and $1.9 \mathrm{~cm}$ in diameter). An array of 30 carefully calibrated thermistors was deployed on the outside of the probe.

\section{Results}

In May 1990, flow sensors were placed between the injection and extraction wells (just below the water table) at the SRIDS to monitor the area that would be affected most by the remediation. These sensors were unable to measure the horizontal component of the flow velocity for two reasons. First, the laminated material from which the probes were fabricated had a significant thermal anisotropy, resulting in heat flux out of the probe that varied with azimuth. Second, the thermal anisotropy with respect to azimuth was compounded by mechanical problems encountered when installing the cylindrical heater. It was impossible to drill the heater holes along the axis of the rods with adequate precision. The resulting concentricity error led to the central heater being slightly closer to one side of the rod than the other, again resulting in heat flux from the probe that varied with azimuth.

While the probes did not yield data relevant to the horizontal component of the flow velocity, they were able to resolve the vertical component. Figure 4 is a plot of the vertical temperature distribution on the surface of one of the probes before air injection began and then later when air injection was taking place. The symbols represent the measured deviation from the average surface temperature of the probe while the curves illustrate the theoretical distribution that best fits the data. The data suggest that an upwardly directed flow of about $30 \mathrm{~m} / \mathrm{yr}$ was induced by the air injection process.

To correct the problems encountered with the sensors first developed, each new sensor now consists of a rod of polyuretha.ze foam approximately $75 \mathrm{~cm}$ long and $5 \mathrm{~cm}$ in diameter. A thin-film, flex circuit heater and an array of 30 calibrated thermistors are mounted on the surface of the rod. Deploying the heaters on the surface of the rod effectively eliminates the heater concentricity problems encountered in the earlier version. The proximity of the heater to the surface of the probe, along with the very low thermal conductivity of the polyurethane foam, ensures a high degree of uniformity in the heat flux from the surface of the probe.

Five of these improved sensors were deployed at the SRIDS in December 1991, approximately two months before the initiation of the in situ bioremediation demonstration. Some of them are located above the injection well and just below the water table similar to the earlier deployed instruments. Other sensors were installed at the same elevation as the injection well but horizontally offset from 5 to 30 feet. These sensors are located several feet further along the trace of the horizontal injection well from where the earlier sensors were deployed. These sensors are providing excellent data on the full 3-D groundwater flow velocity at the site. When the air injection for the in situ bioremediation was initiated, the sensors detected large changes in the flow field around the injection well. Figure 5 is a plot of surface temperature of one of the probes as a function of azimuth both before and after the in situ bioremediation air injection started.

The pattern of the changes in the flow velocity that occur when the air injection system is turned on is extremely complex. Detailed analysis of these changes, which are still being evaluated and analyzed, will lead to a better understanding of the dynamics of the air-stripping remediation process. This will in turn yield constraints on the effectiveness and efficiency of using this technique to remediate VOC-contaminated sites.

Other tests of the flow sensor technology are also underway. Two flow sensors have been deployed in a confined aquifer at the Savannah River TNX site, where the subsurface hydrology has been very well characterized using standard hydrologic techniques. A number of wells at the site are screened in this aquifer. An aquifer test was recently conducted, during which different flow velocities were induced at the locations of the flow sensors. The colloidal borescope was also used during this test. Conventional methods (pressure transducers) to measure drawdown were used as a baseline method to determine flow in the aquifer. The data from this test are being analyzed. Additional tests are planned for 1994 in which the flow will be measured using the flow sensors, colloidal borescope, standard hydrologic techniques (dye tracer study and draw down measurements), and a novel technique using in situ fiber optic absorption sensors that were emplaced in the aquifer. The results will then be compared with those of other methods to provide a definitive test of the accuracy of the SNL flow sensor technology. 


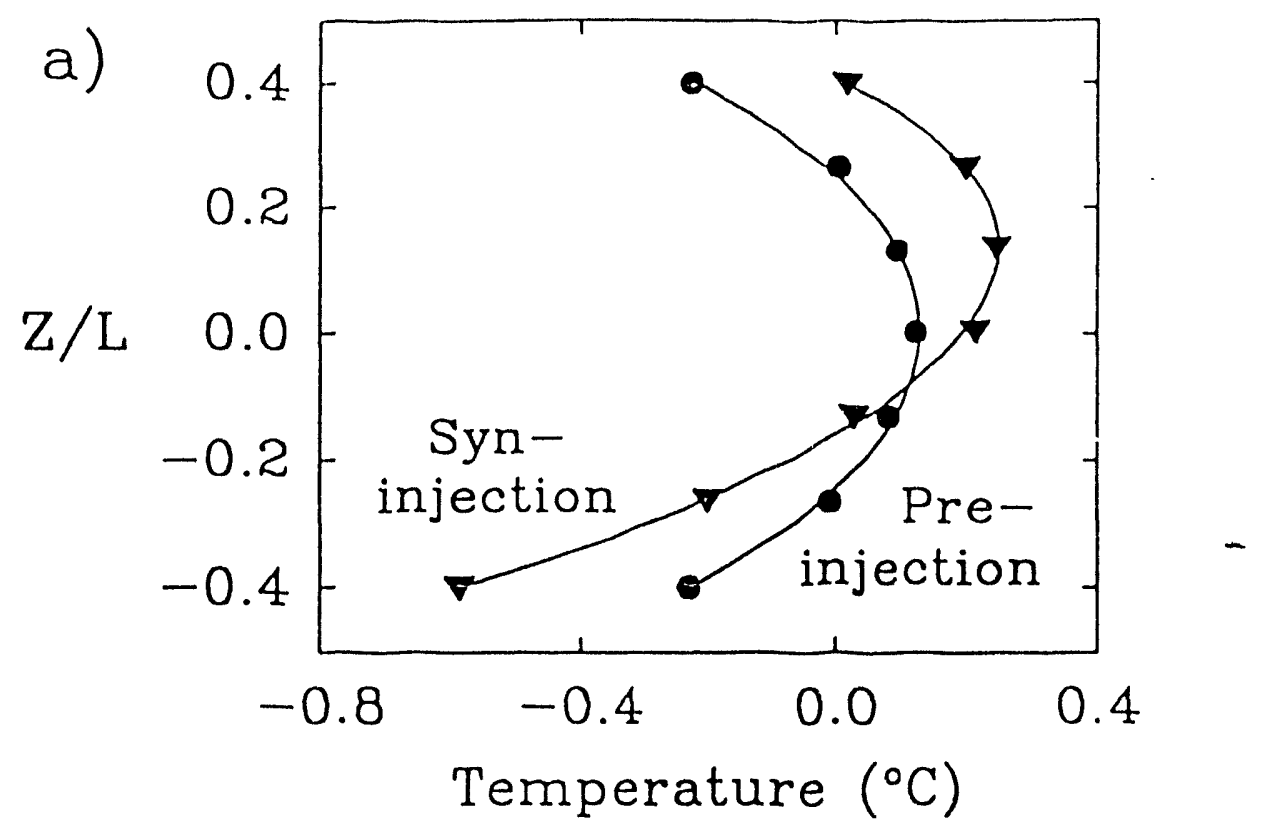

Figure 4. Vertical temperature distribution on surface of probe before air injection began and then later when air injection was takin place

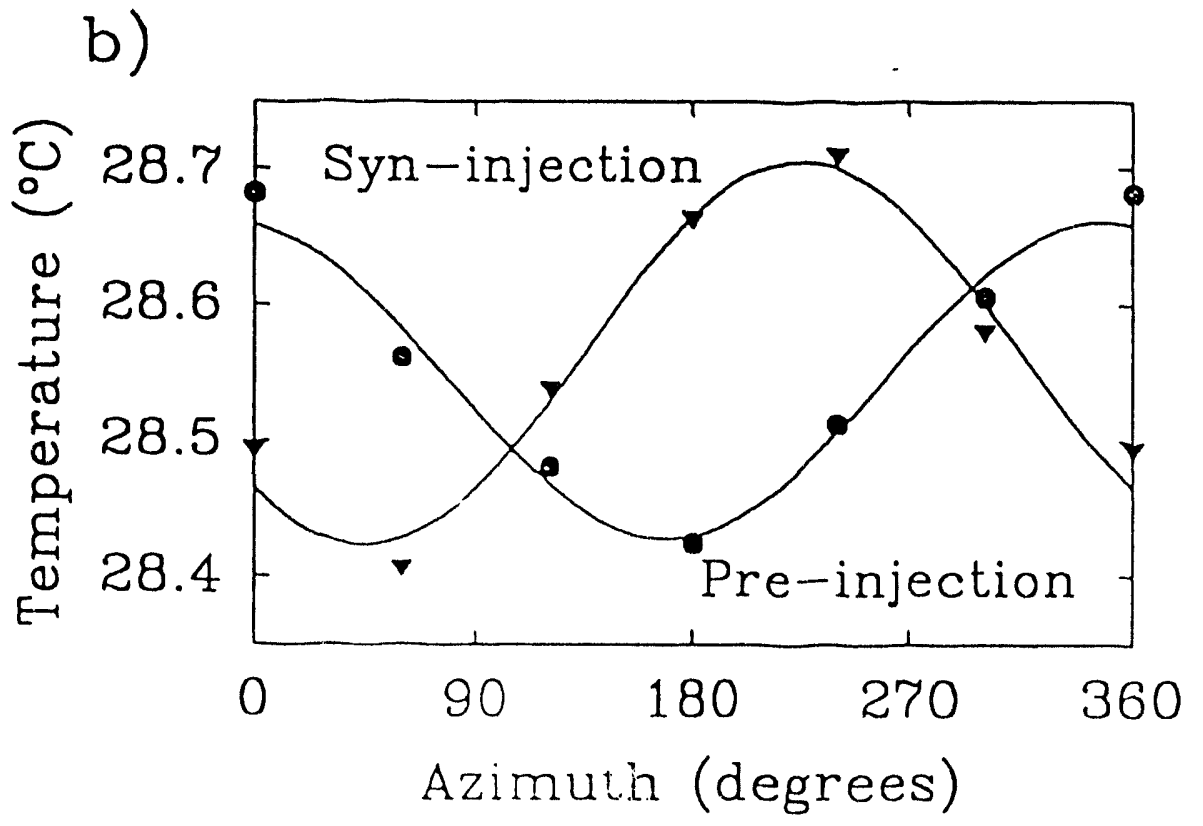

Figure 5. Surface temperature of probe as a function of azimuth both before and after the in situ bioremediation air injection started 


\section{Conclusions}

The SNL In Situ Permeable Flow Sensor has a number of advantages over the current standard techniques for measuring groundwater flow velocity (e.g., measuring the hydraulic head in a number of monitoring wells and determining the hydraulic conductivity distribution in the formation of interest). The measurement of hydraulic conductivity typically requires performing an aquifer test in which large volumes of purge water are produced. In areas with significant groundwater contamination, disposal of this water can be a difficult and expensive problem. The SNL In situ Permeable Flow Sensors can measure the groundwater flow velocity vector without the installation of additional wells or performing an aquifer test. In addition, the sensors can monitor the magnitude and direction of air flows in the subsurface. This capability can help determine the zone of influence of the air injection process.

The development of this technology is progressing well. At this point, only minor changes in the design of the probes and in the fabrication techniques are anticipated. The technology will soon be ready for more widespread application. To that end, technology transfer will be pursued in the coming year. It is anticipated that the route to technology transfer with the highest probability of success is to identify a private company to undertake commercialization of the technology. At least one company has plans to manufacture these probes by 1994 .

Additional information on this work can be found in publications by Ballard in the Bibliography section.

\section{Seismic Tomography}

Seismic tomography is one of the less intrusive geophysical techniques available for both site characterization and remediation process monitoring. At the SRIDS, cross-hole seismic tomography using both $S$ and $P$ seismic waves was used to map subsurface structure and to monitor the extent of the air-stripping remediation process. Tomngraphic methods provide a detailed 2-D or 3-D image of the measured parameter (seismic wave travel time), which can be used to infer physical properties of the studied region.

\section{Background}

For characterization of waste sites and the monitoring of waste remediation processes, borehole data from well logs, coring, and sampling are often used. These data provide information on the type and extent of contamination in the subsurface and on the lithologic structure. This information is then used to help predict contaminant migration rates and pathways so that appropriate remediation actions can be taken. Unfortunately, the drilling required for these coring and sampling methods is expensive and often cannot be done with close enough spacing to give a continuous image of the subsurface. Furthermore, drilling is not possible in some areas because of physical interferences (e.g., structures and difficult terrain) or other limitations. For this reason, the development of less intrusive methods is needed to fill this characterization gap.

Surface seismic methods have been used to map the shallow subsurface in several areas at SRS, but these methods lack fine resolution. Cross-hole seismic imaging has three main advantages over surface seismic methods. They are as follows:

- By avoiding near-surface attenuation problems, a much clearer image of the subsurface is provided.

- The seismic signal travel paths are shortened to preserve the high frequencies needed for greater resolution.

- A wide range of ray-path directions are used, allowing for tomographic inversion imaging of the data.

The lone drawback to this method is that it requires drilling, although fewer holes are needed than would be required for coring and sampling methods.

In cross-hole tomography, both the source generating the seismic energy and the receiver are placed in boreholes on either side of the region to be imaged. The travel times for the seismic waves moving through the formation between the source and receiver are then measured for a large number of source-to-receiver ray paths. The mathematical process of tomographic inversion uses the measured travel times to construct a velocity model for the region between the holes. Such a velocity model can be used in conjunction with other information (e.g., well logs or coring data) to interpret the geology in areas that have not or cannot be drilled.

Seismic velocities are affected by other factors than just the formation type encountered. The degree of water saturation can have a great effect on both $P$ and $S$ waves, although the effect is different for the two wave types. When air is injected into the subsurface beneath the water table, changes in saturation should occur. These in turn will give rise to changes in seismic velocities that can be imaged using cross-hole tomography.

\section{Operation and Methods}

The primary objective of this study was to image changes in saturation resulting from the injection of air during the 
air-stripping remediation process at the SRIDS. These saturation changes should correspond to the travel paths taken by the injected air from the injection to the extraction well.

In addition to imaging the air-stripping zone of influence, imaging of the geology between the boreholes has been done using $\mathrm{P}$ and $\mathrm{S}$ wave data. The comparison of the $\mathrm{P}$ and $S$ velocity images may provide additional information about the geology and rock properties of the study area.

During the injection of air for the in situ air-stripping demonstration at the SRIDS, saturation changes were expected, but where these changes might occur and their magnitude was unknown. Cross-hole seismic tomographic data sets were collected before the air injection began and again during the air injection. Any differences in travel time between the survey sets can be attributed to saturation changes resulting from injected air from the injection to the extraction well. The travel time differences can then be tomographically inverted to obtain velocity changes corresponding to saturation changes. This results in a map of the pathways of air traveling from the injection to the extraction well.

The seismic tomography study was conducted in two stages corresponding to the phases of the air-stripping operation. During the in situ air-stripping demonstration, $S$-wave cross-hole data sets were collected before the air stripping began and again during the air injection. The source used was a swept-frequency, down-hole pneumatic vibrator and the receiver was a three-component, clamped borehole receiver, both of which were developed at SNL. The source and receiver boreholes were $27 \mathrm{~m}$ apart. Data were collected at $1-\mathrm{m}$ vertical spacings for both the source and receiver from a depth of 30 to $56 \mathrm{~m}$. This provided 648 different ray paths. Processing of these data consisted of the following steps:

1. field tape playback
2. filtering
3. deconvolution
4. cross-correlation
5. phase shift removal

Travel times were selected from the processed data for input into the tomographic inversion. Travel time differences between the pre-injection survey data and the data collected during injection were chosen by directly overlaying the data sets and selecting time differences between corresponding points on the wavelets. These travel time differences were then inverted tomographically to obtain velocity changes.
In tomographic inversion, the region to be imaged (between the boreholes) is divided into a grid with either velocity or, when inverting travel time changes, velocity difference assigned to each grid point. Rays are traced through this model to obtain calculated travel times or travel time differences. The calculated values are compared to the measured values and the model is updated to reduce this difference. This process is repeated until the difference between the measured and calculated values is minimized. The final models produced are then interpreted in terms of geology for the velocity model or in saturation change for the velocity difference model.

P-wave data have been collected for Phase II of the airstripping process both before and during injection in much the same manner as the S-wave data. The primary difference is in the source used. For P-wave data, a pneumatic impact-type source developed at SNL was used. These data are being analyzed.

\section{Results}

Analysis and inversion of the S-wave data have yielded both a velocity model and a velocity difference model. The velocity model has been interpreted in conjunction with well $\log$ and coring data and shows predominantly horizontal layers of interbedded sands and clays.

The velocity difference model indicates significant changes in saturation around the horizontal injection well and along paths between the injection and extraction wells (Figure 6). Another interesting feature of the velocity difference model is the lack of significant saturation changes in the more clay-rich layers, indicating less air is penetrating into these layers.

An SNL report detailing the experiment, analysis, and results has been published (Elbring, 1992).

\section{Conclusions}

S-wave data was collected during the in situ air-stripping demonstration, and analysis of these data are complete. Tomographic inversion of the travel time data resulted in a velocity structure corresponding to a geology consisting of sands and clays. The interpreted structure is consistent with well log data. Inversion of the travel time difference data indicated saturation changes surrounding the injection well and a plume extending toward the extraction well. Clay layers showed significantly less saturation change than sandy layers. P-wave cross-hole data sets have been collected during the in situ bioremediation demonstration. Analysis of these data is not yet complete. 

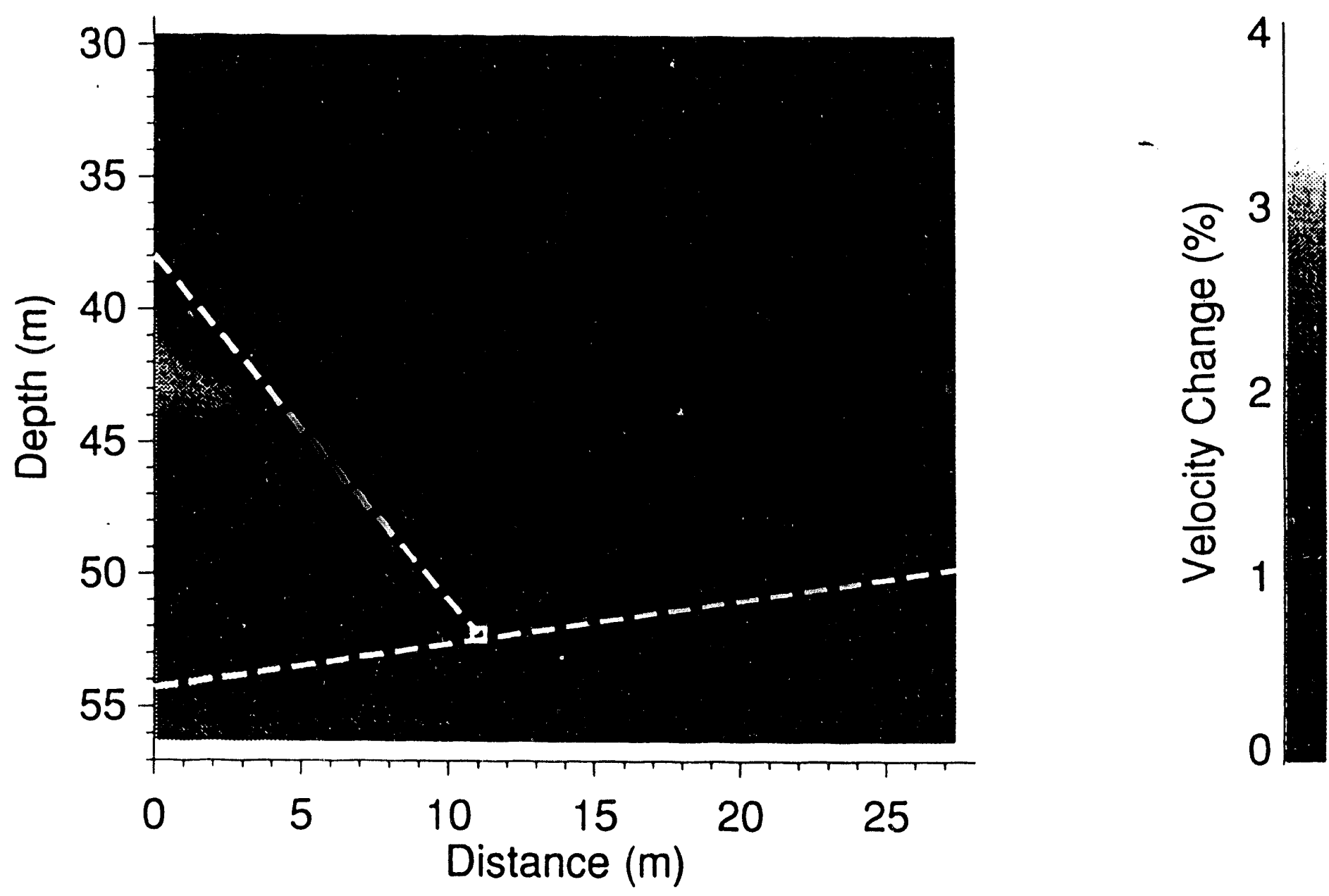

Figure 6. Velocity difference tomogram resulting from inversion of S-wave travel time differences. Solid circle represents intersection of injection well. Sub-horizontal dashed line represents projection of injection well onto the plane of the tomogram. Diagonal dashed line represents the intersection of the plane containing the injection and extraction wells with the plane of the tomogram. Clay-rich layers are at 40-m and 51-m depths. 
The S-wave results show that the cross-hole seismic tomographic method used in this experiment is a viable means for modeling subsurface geology. The method can also be used to model subsurface saturation changes by analyzing seismic velocity differences. Although other conventional methods exist for determining geology (e.g., coring, well logs, and surface geophysical methods), there are no established techniques available for monitoring the saturation changes caused by air injeccion processes. Electrical resistivity tomography is being developed for this purpose (following section). As with any geophysical technique, it is best to use these two new technologies together to remove ambiguities inherent in any one of the methods.

Cross-hole seismic tomography also has advantages over surface seismic techniques in the mapping of the subsurface geology. Greater resolution is obtained through crosshole seismics because high-frequency information is preserved and tomographic imaging can be performed on the data.

Cross-hole measurements of $\mathrm{P}$ - and $\mathrm{S}$-wave velocities can be applied at any site for general geological site characterization. Having both the $P$ and $S$ velocities can provide information concerning rock properties and fluid saturation levels. Such information is important when dealing with isolated contaminant plumes, perched water tables, or localized tank leaking. A well-characterized site geology is critical for determining the placement of sampling or recovery wells for use in subsurface flow and contaminant transport modeling and remediation.

Portions of the data collection system for the cross-hole seismic system, specifically the downhole S-wave source, have been transferred out to private industry (Santerra, Inc.) for use in both environmental and oil and gas exploration applications.

Additional information on this work by Elbring can be found in the Bibliography section.

\section{Electrical and Electromagnetic Tomography}

Researchers from LLNL have evaluated electrical and electromagnetic imaging (tomography) techniques to map the behavior of subsurface fluids as they change in response to natural or remedial processes. Natural processes (e.g., surface water infiltrating the vadose zone) and remedial processes (e.g., air injection in the saturated zone and steam injection) can create changes in fluid distribution that change a soil's electrical and electromagnetic properties. The information derived from these new imaging techniques can be used by remediation projects to characterize hydrologic processes affecting contaminant transport, to select appropriate cleanup alternatives, to demonstrate regulatory compliance, and to monitor the effectiveness of cleanup processes.

\section{Background}

Both high-frequency electromagnetic (HFEM) tomography and electrical resistance tomography (ERT) are similar to the medical tomography that inspired them. A region to be studied is sampled by transmitting energy through it along many paths of known orientations. A cross-sectional image of the region of interest is then constructed from these transmission data. In these two electromagnetic tomographic techniques, induced voltage and current are measured to probe changes in the electricalresistivity of a subsurface region. Tomographic images are obtained before and after a subsurface event (e.g., air injection). The difference between the two images yields information about the location and magnitude of changes in the electrical resistivity. This information is then correlated to changes in the degree of partial saturation in the subsurface, which is used to evaluate the effectiveness of the air injection process.

The HFEM technique involves the measurement of phase change and signal attenuation in the frequency range of 34-38 $\mathrm{MHz}$. For a given subsurface path length, the phase change is a function of the water content of the medium. Additional details of this technique can be found in Daily and Ramirez (1989).

The second technique, ERT, uses measurements of the electrical resistivity in the soil mass to infer the quantity of water present. As in the case of the dielectric constant, the bulk resistivity is correlated to water content (i.e., resistivity decreases with increasing amounts of water). To make ERT measurements, lines of electrodes, which can act as both sources and receivers, are placed at discrete depths in boreholes. The resistivity is then determined by passing current between multiple pairs of electrodes. The electrical potential differences are measured at each electrode location. The values of these measured potential differences reflect the distribution of current density within the medium and, consequently, the distribution of electrical resistivity.

\section{Operation and Methods}

Underground HFEM tomography and ERT were used to determine the effectiveness of the SRIDS's air injection and vacuum extraction process in removing VOCs from subsurface water and soils. Because the injected air displaces water in the soil's pore space, the region of air per- 
meation can be detected by inferring changes in the quantity of moisture present. The ubjective was to use HFEM tomography and ERT to map the changes in moisture content in a plane between the tomographic measurement boreholes, and then to compare the different data sets and examine the changes in the spatial distribution of moisture content over time.

Measurements were made between a series of three vertical boreholes drilled in the vicinity of the injection and extraction wells (Figure 7). These coplanar boreholes (MHM-3, MHM-4, MHM-5) were constructed with sections of polyvinyl chloride casing for the HFEM measurements. Alternate steel sections, used as electrodes for the ERT measurements, were installed with the PVC casing in boreholes MHM-3 and MHM-5 every $3.66 \mathrm{~m}$ between 30.48 and $61.0 \mathrm{~m}$ (every $12 \mathrm{ft}$ between 100 and $200 \mathrm{ft}$ ). The three boreholes were spaced $11 \mathrm{~m}(\approx 35 \mathrm{ft})$ apart and the monitoring plane was located roughly perpendicular to the horizontal air injection well. The HFEM measurements were made between boreholes MHM-3 and MHM4, and between MHM-4 and MHM-5. The ERT measurements were made between boreholes MHM-3 and MHM5.

Tomographs from the ERT measurements represent changes in resistivity relative to initial conditions (i.e., the tomographs are generated by subtracting values of pixels in one tomograph from values of pixels in another tomograph). These differential tomographs should show only those features that have changed between the time the two data sets were taken. Each tomograph represents an area approximately $21.95 \mathrm{~m}$ wide $\times 25.6 \mathrm{~m}$ tall $(=72 \times 84 \mathrm{ft}$; pixel size is $3.66 \times 3.66 \mathrm{~m}$ ).

Similarly, the HFEM data were used to calculate the differences between the soil's initial permittivity and its permittivity measured during the remediation process.

\section{Results}

Figure 8 shows a resistivity differential tomograph representing the changes observed during high-rate air injection. A tomograph from July 30, 1990 (before the start of air injection and vacuum extraction), was subtracted pixel by pixel from a tomograph dated October 11,1990 (during high-rate air injection). The differential tomograph shows a region of increased resistivity to the right and above the approximate location of the injection point. This region probably represents the decreases in moisture content caused by the air plume as it propagated from the injection point to the water table. Note that the anomaly is located near borehole MHM-3. There are also indications of increased resistivity near the $51.8-\mathrm{m}(170-\mathrm{ft})$ depth near borehole MHM-5. In addition, a general increase in resistivity is observed near the $42.7-\mathrm{m}$ (140-ft) depth, which would imply a decrease in the moisture content at the water table interface. This type of behavior was also observed during the medium-rate air injection phase, but here the lateral extent of the dewatered region is substantially larger. The dewatering near the water table may be due to the presence of an aquitard located near the original water table location.

Decreases in relative permittivity (from the HFEM technique) as large as -1.2 were detected near the injection well at a depth of $50.3 \mathrm{~m}(\approx 165 \mathrm{ft})$. These changes were concentrated between MHM-3 and MHM-4 and showed an approximately horizontal trend. They imply that a detectable decrease in moisture content occurred as a resuit of air injection. The HFEM data were more difficult to interpret than the ERT data because of diffraction effects encountered in the HFEM data collection.

\section{Conclusions}

The results to date have indicated that the HFEM and ERT tcchniques can be used successfully to monitor air injection and extraction remediation processes. However, the HFEM technique will require a new data collection method and a tomography algorithm that can correctly account for diffraction under high contrast conditions. The ERT technique was demonstrated to be in a more mature stage of development requiring only minor modifications; therefore, ERT was chosen for continued demonstration and development. Additional details of this work can be found in Ramirez et al. (1991).

The advantages of ERT are as follows:

- The technology minimizes the need for drilling monitoring wells while providing unprecedented detail of subsurface structures and processes.

- The data acquisition rate is sufficient to allow detailed sampling of large subsurface regions in reasonable amounts of time (e.g., measurement sets were obtained in 2-6 hours). 


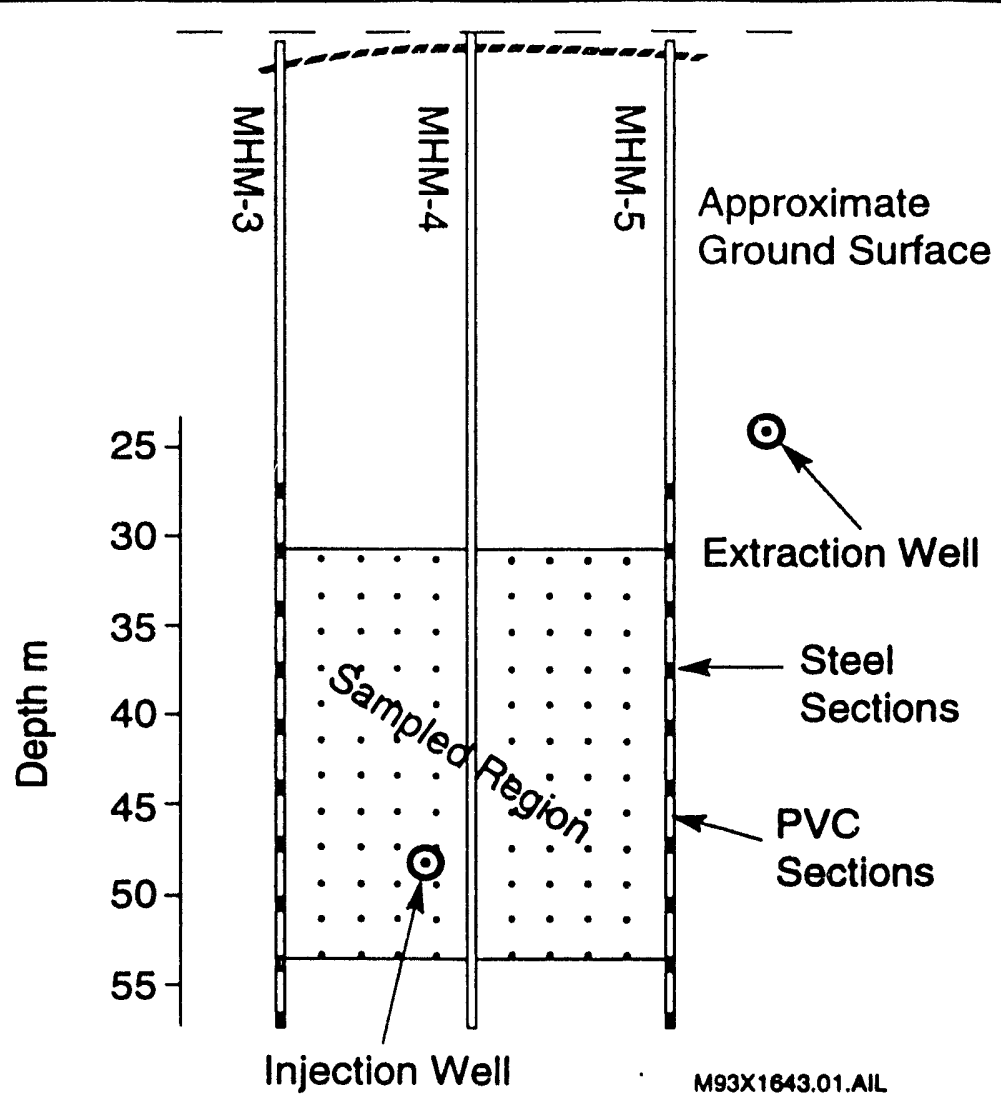

Figure 7. Cross-sectional view of the samples region at SRIDS

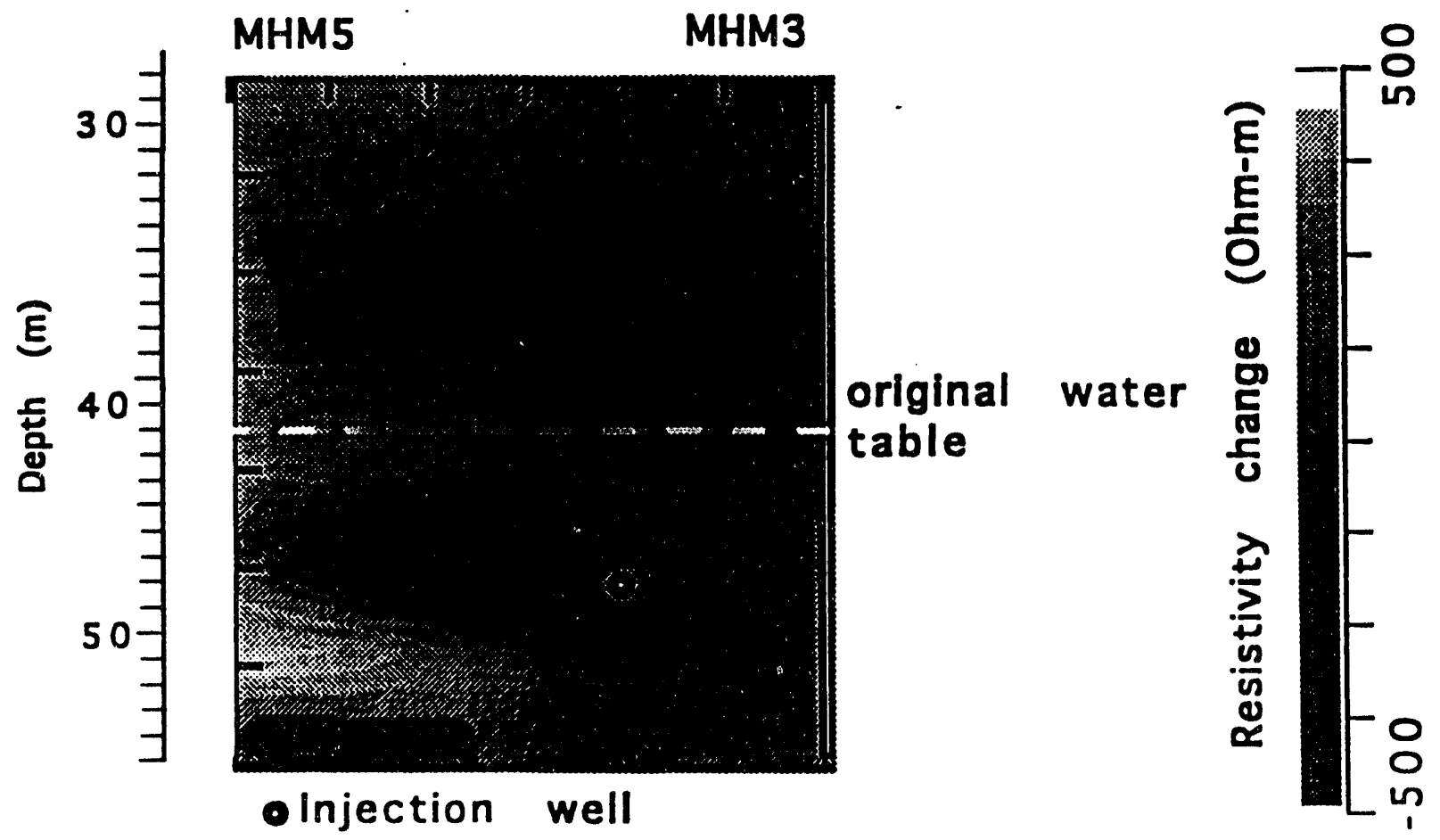

Figure 8. Differntial resistivity tomograph representing changes in resistance observed during the high-rate air injection phase (The approximate location of the injection well is shown for comparison.) 
- The sensors are cheap and robust, made of stainless steel that can be buried in the ground to depths of hundreds of feet; they can be placed in boreholes, pushed into the ground at the surface (thereby reducing the need for drilling), or both.

- True 3-D imaging of the subsurface is possible.

- The technology can be used to map the movement of liquids in the subsurface to verify the emplacement and performance of surface and subsurface barriers.

- The technology can be applied to a wide range of conditions (e.g., saturated, unsaturated) and sites (e.g., SRS, LLNL).

ERT can be used to monitor the progress of subsurface environmental clean-up processes (e.g., air injection, steam injection, radio frequency and low frequency heating) so that the processes can be adjusted and optimized in almost real time.

Plans for technology transfers are being discussed with a few potential industrial partners at the time of writing. Remaining development work includes a 3-D inversion algorithm and development of induced polarization tomography for the possible detection of hydrocarbons.

Additional development and demonstration activities have advanced the state of ERT since the completion of this manuscript. These activities have included the demonstration of ERT as a tool to monitor subsurface processes such as steam injection, radio-frequency heating, ohmic heating, air sparging, and water infiltration of the vadose zone. Additional information this work by Daily and Raimerez can be found in the Bibliography section.

A Cooperative Research and Development Agreement (CRADA) has been negotiated with RIM Tech, Inc. (Westminster, $\mathrm{CO}$ ) and is in the final stages of the approval process.

\section{Colloidal Borescope}

\section{Background}

The accurate measurement of groundwater flow in a well is a significant priority for improvement of subsurface flow and transport analyses. Methods that stress the aquifer such as bail, slug, and single-well pumping tests are used to measure aquifer hydraulic conductivity. Borehole flowmeters to measure the hydraulic conductivity of individual zones in test wells have been developed by Hess (1986) and Moltz et al. (1989). Directly assessing seepage velocities from flow velocities in a well is feasible based on theoretical and experimental evidence. Potential flow theory solutions describing uniform flow through a cylinder of infinite permeability surrounded by a porous media of finite permeability are presented by Carslaw and Jaeger (1959) and Wheatcraft and Winterberg (1985). Numerous researchers including Drost et al. (1968) have experimentally shown by laboratory tracer tests that groundwater flow in a porous medium with a cylinder of infinite permeability behaves as predicted by potential flow theory. Based on these theoretical predictions and experimental evidence, researchers have explored methods to measure flow velocities in wells in order to predict seepage velocities in the adjacent porous media. Borehole dilution methods (Halevy et al. 1967, Drost et al. 1968, Grisak et al. 1977), K-V heat-pulsing flow meter (Kerfoot 1988), and the laser doppler velocimeters (Momii et al. 1993) are all attempts to measure the groundwater velocity in a well.

The colloidal borescope developed by Oak Ridge National Laboratory is another instrument designed to measure groundwater velocity in a well. The borescope consists of 2 CCD cameras, a ball compass, optical magnification lens, illumination source, and stainless steel housing. The device is approximately $60-\mathrm{cm}$ long and has a diameter of $44 \mathrm{~mm}$, thus facilitating insertion into a monitoring well with a diameter of $5 \mathrm{~cm}$ (Figure 9). Upon insertion into a well, an electronic image magnified $140 \mathrm{X}$ is transmitted to the surface where it is viewed and analyzed. The compass is viewed by one of the $C C D$ cameras in order to align the borescope in the well. A frame grabber and associated software analyzes the video image every four seconds recording particle size, number, speed, and direction.

The colloidal borescope has been field tested at several sites across the United States. Particles as small as $1 \mu \mathrm{m}$ can be observed. The number of particles often changes with time. Disturbances caused by the insertion of the borescope into the well results in the release of hundreds of particles ranging in sizes of $1 \mu \mathrm{m}$ to over $50 \mu \mathrm{m}$. After a few minutes, the numbers and sizes of particles generally decrease. In certain aquifers, particularly sandy moderately-permeable aquifers with low organic material content, visible particle numbers may decrease to one to two per minute.

Consistent horizontal laminar flow has been observed in wells for a period of 48 hours. Flow is sensitive to pressure changes such as precipitation, surface water fluctuations, pumping, and nearby heavy traffic. Groundwater flow directions generally agree with potentiometric maps for the area. However, variations in flow direction from the potentiometric map and different flow directions within the same well are observed. 
The most significant difference in observed versus expected results is the magnitude of groundwater velocity. Measurements of flow velocities based on particles observed by the colloidal borescope are 5 to 15 times higher than seepage velocities calculated using Darcy's Law.

\section{Operations and Methods}

Seven wells were selected at the Integrated Demonstration Site (IDS) for observations using the colloidal borescope and a borehole inspection camera. In six monitor wells, groundwater flow direction and velocity were measured at five separate intervals within the well screen using the colloidal borescope. Each well screen was also inspected with the borehole inspection camera.

\section{Results}

The colloidal borescope was used to asses flow patterns in six of the D-series monitoring wells (wells screened above and into the water table aquifer) at the IDS. Turbulent effects from operation of the air/methane injection system were observed in three of the six wells. Data taken with the colloidal borescope indicate fast, rotational flow of micro-particles in wells MHT-13D and MHT-14D. Additionally, a flashing, strobe light effect is associated with recorded data. This phenomena may be caused by gas bubbles passing through the field of view. The turbulent flow patterns are cause significant mixing within the wells and no distinct flow direction is apparent during operation of the injection/extraction system. These wells appear to be serving as preferential flow conduits for the gas phase transport induced from the air/methane injection system.

Flow in monitoring well MHT-6D is also turbulent. The directional compass image associated with the downhole camera appeared to bounce around indicating the equipment was being buffeted by turbulence. The fine grained, reddish clay found in the well and the apparent turbulence resulted in extremely murky conditions in the well that precluded observation of micro-particles with the colloidal borescope.

Laminar, directionally consistent flow patterns were observed at all depths of investigation in monitoring wells MHT-4D, MHT-10D, and MHT-7D. It appears that effects from the air/methane injection are not as pronounced in these wells. Flow fields were recorded in each of these three wells at two $\mathrm{ft}$. intervals from the bottom of the screened interval to the water table (Figure 10). All of the flow zones in wells MHT-4D and MHT-10D appear to be flowing in a north (magnetic) to northwesterly direction with the exception of southwesterly flow in MHT-10D at a depth of $148 \mathrm{ft}$ below casing level. The flow direction in
MHT-7D appears to be southwesterly except at a depth of $142 \mathrm{ft}$ below casing level where northwesterly flow was observed.

Site specific calibration data, necessary to relate the magnitude of observed flow velocities in the well bore to specific discharge in the surrounding aquifer, has not yet been compiled. A qualitative analysis of data indicates that the magnitude of the flow velocity in MHT-4D and MHT-10D is two to three times greater than the magnitude of the flow velocity in MHT-7D.

A borehole inspection camera from RJ Electronics was used to observe wells at the integrated demonstration facility. For wells that showed turbulent flow conditions using the colloidal borescope, air bubbles were observed entering the well through the screen slots. The bubbles were due to the operation of the air/methane system.

\section{Conclusions}

Colloidal borescope measurements of groundwater in monitoring wells that exhibit laminar flow shows flow directions outward from the air/methane injection line. Flow directions are consistent with the assumed groundwater flow in response to gradient alteration from the air/ methane injection system. These results agree with earlier field work showing the colloidal borescope yields reliable groundwater flow directions under forced gradient flow conditions. Wells exhibiting turbulence suggest preferential air flow is occurring in the aquifer. This observation was confirmed with the borehole inspection camera that showed air bubbles entering the well screen.

In summary, the borescope can rapidly and cost-effectively determine groundwater velocities at hazardous waste sites. Future plans call for a fully automated borescope that is capable of measuring hundreds of depth specific flow zones simultaneously without moving the borescope. In addition, modeling work is planned to fully describe three-dimensional flow in and surrounding a cylinder of infinite permeability. It is hoped that the effects of well design and varying lithologies can be accurately assessed using the model.

The colloidal borescope is commercially available from RJ Electronics, Inc. (OR) and an instrument has been transferred to personnel at SRS for use in the environmental restoration site characterization program.

Additional information by Kearl on this technology can be found in the publications listed in the Bibliography section. 

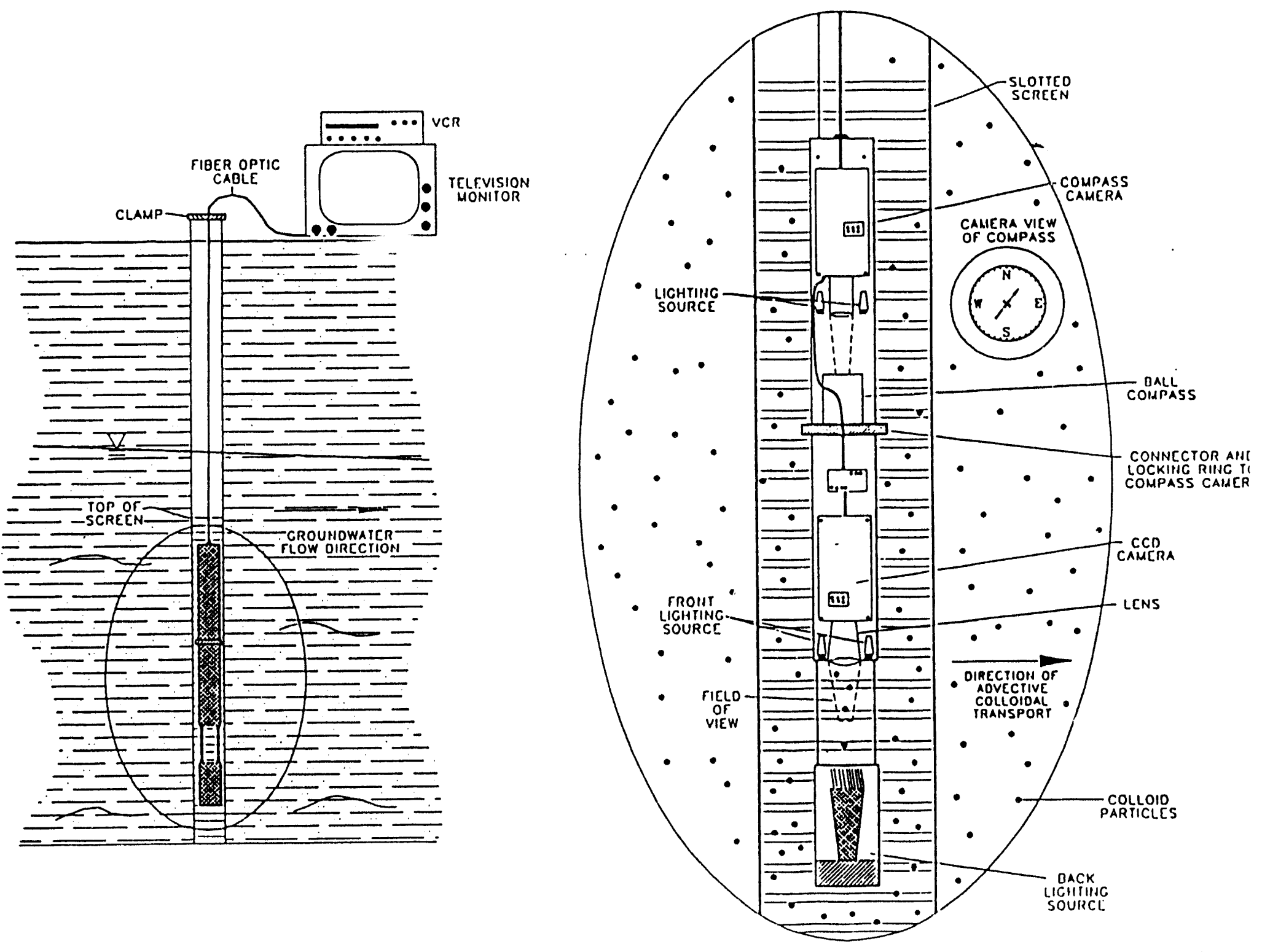

Figure 9. Diagram of the Colloidal Borescope 


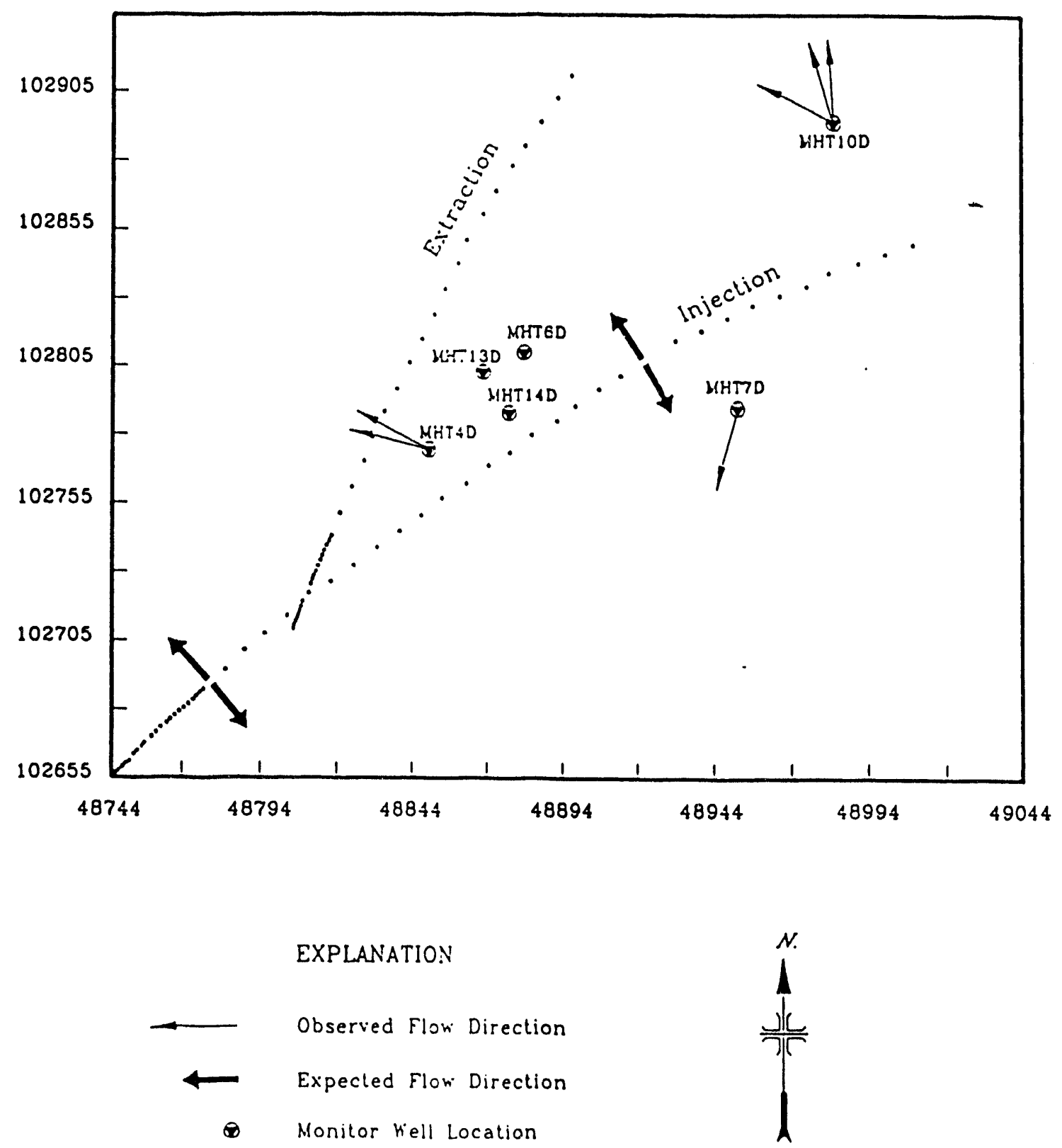

Figure 10. Groundwater Flow Directions at the Integrated Site Demonstration as Measured by the Colloidal Borescope 


\section{Chemical Sampling and Monitoring}

By 1995 it is estimated that DOE will generate one million samples requiring analysis under RCRA/CERCLA regulations, which will cost more than $\$ 200$ million using standard methods. New chemical analysis technologies are needed to reduce the cost of hazardous waste site characterization and monitoring while providing equivalent or superior performance to standard methods.

Instrumentation capable of detecting broad classes of hazardous materials and specific compounds is needed to monitor the progress of remediation. Without accurate monitoring of remediation systems, excessive volumes of soil and water must be treated to guarantee compliance so that small pockets of contamination are not missed. Real-time analysis is especially important for monitoring the progress and effectiveness of remediation. With real-time analysis capabilities, site investigation and remediation activities can proceed rapidly in response to new information rather than following a predetermined plan which may be based on old and/or inaccurate data. This rapid response saves money by avoiding the placement of wells in clean areas and by precisely targeting the most contaminated zones. In addition, in situ sampling methods are needed to obtain a more accurate representation of the subsurface geology, geochemistry, and contamination.

Site investigation and remediation require considerable planning and laboratory support. There are a large number of toxic chemical species, both inorganic and organic, that have been identified in environmental samples. The use of conventional offsits laboratories [Environmental Protection Agency's National Contract Laboratory Program (CLP)] can be expensive and often time consuming. The CLP goal was to provide a range of analytical chemistry services of known quality on a high-volume, cost-effective basis providing legally-defensible data. Because of the large demand for analyses and the effort to maintain high quality, turnaround time at labs can exceed two months. Long sample turnaround times can stop work during characterization, monitoring, or remediation efforts, which can dramatically increase the cost of these projects. In addition, the high quality but expensive CLP data may not be necessary or appropriate for all analyses.

Development of field analytical equipment is necessary to provide real-time analytical capabilities for screeninglevel and/or decision quality data. Effective site characterization and monitoring start with inexpensive screening technologies before using more expensive, contaminant specific technologies. A suite of technologies must be used in various sequences (phases). The technologies used in the later phase are determined based on the results of analyses conducted in the earlier phase, (e.g., a shallow soil gas survey precedes a large scale drilling and sampling activity). Often a technology may be used for both site characterization and monitoring.

The chemical sampling and monitoring technologies demonstrated at the SRIDS can be divided into four basic categories:

- sampling technologies

- compound selective technologies

- class selective technologies

- broadly applicable technologies 
Each of these categories will be preceded by a brief description of the field-portable technologies and their niche in environmental activities.

The use of these field-portable instruments and techniques could provide near real-time analytical results. This would allow the technical staff to (1) make decisions concerning the location of wells and sampling devices, or (2) take additional characterization data for a more accurate plume definition, all during the investigation. During restoration, the near real-time results could be used to limit costly standby time by the restoration contractors. In addition, there are indications that the shorter holding times may significantly improve the results of certain analyses. Field screening methods can also be implemented in compliance monitoring to reduce the number of samples sent to CLP laboratories, thereby saving money and time spent by the laboratories analyzing clean samples. During site characterization or monitoring, the number of samples taken must be based on the data quality objectives or reliability needs, urgency, and cost. Field screening methods provide a value-added method of achieving data quality objectives while minimizing cost in real-time. 


\section{Sampling Technologies}

Three sampling technologies were demonstrated at the SRIDS to address the need for depth-discrete information on contaminant concentration and subsurface flow. All three devices were deployed in wells. A mechanical sampler developed by Brookhaven National Laboratory (BNL) used several remotely controlled chambers to capture water from different depths for laboratory analysis. A membrane sampler, also developed by BNL, was used to obtain horizontal specific discharge data in a well with a borehole dilution technique. Oak Ridge National Laboratory (ORNL) developed an arrayed sampler for determining depth-discrete, vapor-phase concentrations in vadose zone wells. All three methods are inexpensive and provide necessary information to construct concentration or flow depth profiles at contaminated sites.

\section{Passive Groundwater Sampling}

Two passive, multilayer groundwater monitoring and sampling devices that collect data simultaneously at small vertical intervals in the same well, were demonstrated at the SRIDS. One system uses a stacked series of membranes, the other uses remotely-operated stainless steel cylinders connected in tandem. These devices can be used in several wells to collect sufficient information to allow a 3-D characterization of contaminants and flow in the aquifer at a substantially lower cost than standard techniques. The systems were used during November 1991 field trials to collect water quality and flow data in two wells over a 3-m interval below the water table.

\section{Background}

Available groundwater sampling and monitoring devices are limited in their ability to characterize the subsurface. For example, bailers and pumps of various kinds take samples from a single fixed depth within a single well, or from specified depths within a cluster of wells located within close proximity to one another. Samples are usually collected at the surface only after a relatively large volume of water is removed from the well using some type of pump. This purging process disturbs the aquifer being sampled and provides information at only a few depths. At best the chemical properties of a given sample are used to represent a large (and often uncertain) portion of the aquifer presumably in need of remediation. In addition, the sample and purge water must often be collected and disposed of as hazardous waste.
BNL personnel have shown that substantial changes in groundwater composition and horizontal specific discharge occur over small depth intervals. These effects can be profound. In one study, the horizontal component of the specific discharge in the first $50 \mathrm{~cm}$ below the water table was more than an order of magnitude lower than that at depths of $100-240 \mathrm{~cm}$. Clearly, if floating contaminants were present, their transport could have been seriously under- or over-estimated. This is especially true for aquifers containing contaminants with densities that are markedly different from the ambient water. In this situation, chemical gradients or even chemoclines are possible.

\section{Operation and Methods}

During FY 92, laboratory tests were performed at BNL to determine the diffusion-related properties of several types of membranes (e.g., polypropylene, Teflon, cellulose acetate, nylon). Other laboratory experiments determined that the operating characteristics of a commercially available discrete liquid sampler were similar to those of a BNLdesigned mechanical sampler. This obviated the need to fabricate such devices at BNL; modifications were made to the commercial product for use at SRS. Field experiments at BNL demonstrated the feasibility of both types of samplers to provide vertical profiles of flow and chemistry in the saturated zone. This information was derived from measurements in an existing shallow monitoring well downgradient of an oil spill at a steam generation plant.

Field trials of membrane and mechanical multilevel samplers were conducted at the SRIDS during November 1991. Samples came from two wells that were specially designed and installed within approximately $4 \mathrm{~m}$ of each other. A small amount of each sample collected with the mechanical apparatus was transferred to a VOC collection bottle for headspace analyses of trichloroethylene (TCE) by SRTC personnel. Measurements of inorganic constituents were made in the field and at BNL (using atomic absorption spectroscopy). Samples collected from the membrane apparatus were shipped to the U.S. Geological Survey in Reston, Virginia, for measurements of the concentrations of ${ }^{18} \mathrm{O}$ and deuterium, which were injected for tracers of groundwater flow.

\section{Results}

Mechanical difficulties with the gas chromatograph apparatus and problems related to quality assurance caused 
long delays between the time samples were collected in November 1991 and when they were analyzed during March 1992. During this time, all samples were refrigerated at $4^{\circ} \mathrm{C}$. Maskarinec et al. (1989) found that VOC samples show no degradation when kept at this temperature for months.

Several interesting results were obtained from measurements on samples taken with the mechanical sampler. BNL personnel determined that the water table aquifer at the SRIDS requires approximately 24 hours until initial disturbances from inserting the samplers can settle. Furthermore, the mechanical samplers need only stay opened about one hour, during which time they come to equilibrium with surrounding water via diffusive-dispersive processes. Figure 11 (preliminary data) indicates the existence of weak vertical profiles in dissolved oxygen, temperature, and $\mathrm{pH}$ over the 3-m sampling interval below the water table.

As seen in Figure 12, measurements made using the membrane apparatus indicate a horizontal specific discharge of about $6 \mathrm{~cm} /$ year over a sampling interval of $3 \mathrm{~m}$. There does not appear to be any statistically significant vertical structure to flow. An important observation was that deuterium worked as effectively as a tracer as did ${ }^{18} \mathrm{O}$-depleted water. This implies substantial cost savings; ${ }^{18} \mathrm{O}$-depleted water cost about $\$ 3300$ per experiment compared to $\$ 50$ per experiment for deuterium (or a factor of 66 ).

\section{Conclusions}

The feasibility of using both mechanical and membrane multilevel samplers was demonstrated based on laboratory tests and samples taken during a field trial at SRTC in 1991. Important cost savings can be implied solely on the basis of vertical profiles obtained thus far in single wells. For example, strong vertical profiles measured at BNL will have a strong bearing on an earlier decision to use a pump-and-treat system for remediation, where groundwater will be sprayed into the atmosphere and volatiles (e.g., benzene, toluene, xylene) stripped. Based on concentrations of organics found using submersible pumps and bailers, remediation pumps would likely be placed at the bottom of wells. This would lead to longer and costlier remediations, since multilevel samplers have indicated that pumping should instead focus on several feet below the water table.

At the SRIDS, the horizontal specific discharge of $6 \mathrm{~cm} / \mathrm{yr}$, measured using the membrane multilevel sampler, is higher than previously expected. While this information has not yet been used in numerical models of contaminant transport, it is clear that previous calculations made with models using much lower values of flow would indicate a contaminant movement that is slower than what may have actually been occurring.

Discussions have begun with the manufacturer of the commercially available discrete liquid sampler to enter into a Cooperative Research and Development Agreement (CRADA) as a proposed route to transfer the multilevel mechanical sampler technology. Should this CRADA come into existence, a suitably modified, commercially available system will be available soon after. Technology transfer for the membrane sampler can also be accomplished relatively quickly depending on the result of ongoing negotiations for an exclusive manufacturing and distribution agreement between the holders of a patent on a similar device and a U.S. environmental engineering company. One very important caveat relates to both sampling systems: their ultimate use in the commercial sector depends to a very large extent on their being tested by the EPA. While the EPA does not officially certify or otherwise accredit any specific sampling technologies, its review of the results of this project will be crucial toward the eventual use of these non-invasive samplers at actual field sites.

\section{Arrayed Vadose Zone Sampler}

This section describes briefly the development and initial field demonstrations of an arrayed, multisorbent sampler for in situ collection of VOCs at depths up to 125 feet in the vadose zone. This sampler, which can be controlled from the surface, was successfully deployed and demonstrated at the SRIDS in January and March 1992. Numerous vadose zone samples were collected, and data acquired during the sampling yielded a wide range of apparent soil gas concentrations for both target (TCE) and non-target species. Although recommendations for system modifications are made herein, it is clear that in its current configuration, the system can provide spatially resolved chemical information concerning the impact and effectiveness of, and zone of influence for, candidate remediation technologies.

\section{Background}

Conventional approaches to the acquisition of a soil gas sample at depths of more than a few feet involve the implantation of a tube, and withdrawal of a soil gas sample to the surface. There are a number of potential problems with such an approach. First, in geologic strata with low permeability, the volume of gas which needs to be pulled to the surface may be greater than that which can be replenished by diffusion through the surrounding soil. Extraction of a large sample can disturb the subsurface 


(n)

Figure 11. Mechanical sampler results indicating the existence of weak vertical profiles in dissolved oxygen, temperature, and $\mathrm{pH}$

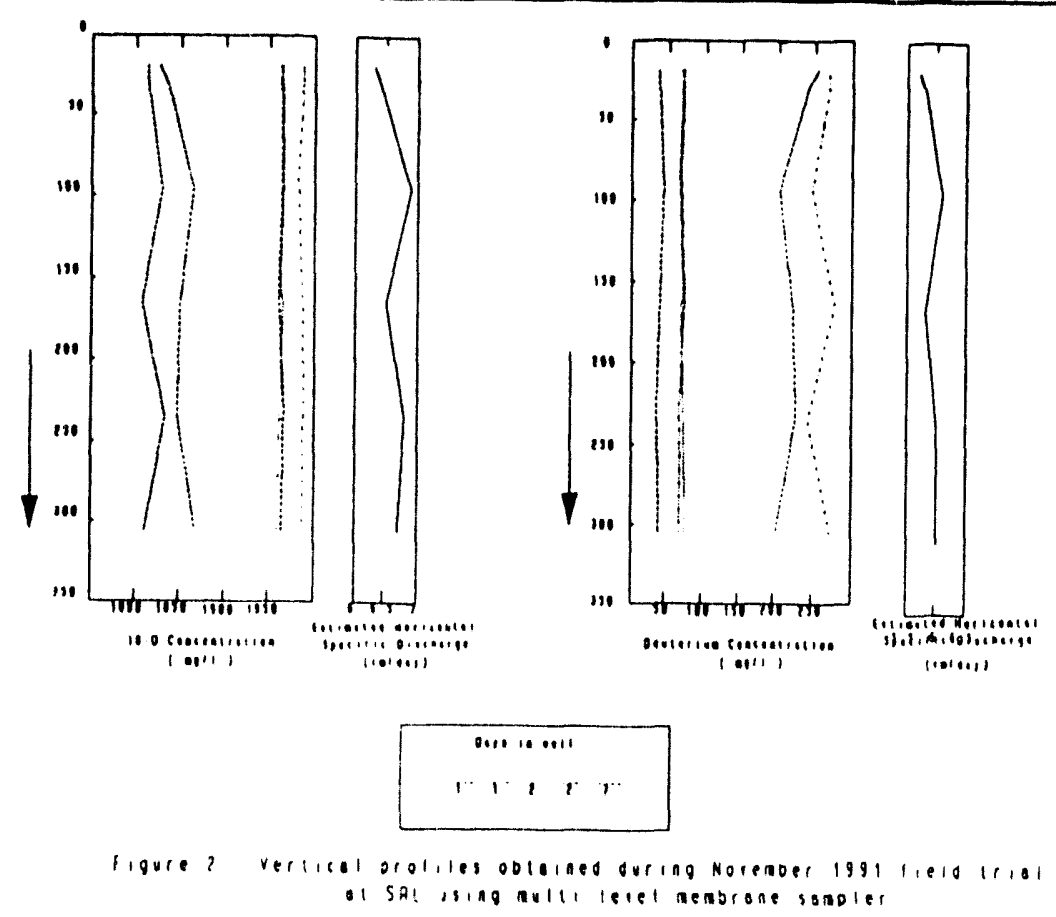

Figure 12. Membrane apparatus results indicating a horizontal specific discharge of about $6 \mathrm{~cm} /$ year 
equilibrium, and gas not representative of that present in the soil can be withdrawn. Secondly, there can be significant losses of organic vapors through permeable tubing, such as Teflon, especially when considerable lengths of tubing are involved. Even in nonporous tubing, organic vapors may adsorb on or react with tubing surfaces, or dissolve in water vapor condensed on the walls of the tubing.

There is also a need for subsurface sampling in the vadose zone for a broad range of VOCs at contaminated sites, either during site characterization or remediation. One approach to the determination of a broad range of VOCs is to collect them on sorbent cartridges and subject them to analysis using sensitive, high-resolution technology. Such types of cartridges, filled with solid sorbents (e.g., Tenax), have been used for a number of years for ambient air sampling. Studies performed at Oak Ridge National Laboratory (ORNL) and elsewhere have demonstrated that packing multiple solid sorbents sequentially in tubes could extend the range of VOCs collected and retrieved, quantitatively. Pilot studies in 1989 and 1990 at ORNL suggested that such multisorbent traps could retain VOCs even in very high humidity environments, such as those likely to be encountered in the vadose zone.

The multi-sorbent arrayed sampler addresses the aforementioned deficiencies in conventional approaches to soil gas sample acquisition by enabling the user to acquire samples at the immediate point of their generation. And because of its ability to concentrate a wide variety of VOCs, the arrayed sampler has a very wide dynamic range.

\section{Operation and Methods}

The sampler consists of an array of six traps each packed with sequential beds of sorbent materials (see Figure 13). One end of each trap can be opened to a screened space. The sampler can be lowered into a 4-inch diameter screened borehole and controlled from the surface. Air samples of nearly any volume and/or time duration can be passed through the traps while the VOCs are retained. The arrayed sampler is then returned to the surface and the traps analyzed. Inflatable packers can be used to isolate the geologic zone being sampled if appropriate.

The sampler body is a 3 inch diameter cylindrical stainless steel assembly approximately 16 inches in length. It houses an array of 13 micro-miniature solenoid valves in a mounting structure to accept six multi-sorbent traps connected into the system via standard $1 / 4$-inch tube fittings. As mounted in the body, solenoid valves are connected to each end of each trap for isolation or sampling, as desired. The outlet of each trap is connected (via a solenoid valve) to a common sample conduction manifold. A vacuum source at the surface draws an accurately metered sample of air through any selected trap via the manifold. An additional solenoid valve is used in the sampler head to provide for rapid direct evacuation of the residual air in the vicinity of the sampler prior to sampling through a trap, if deemed appropriate. The system may also be used to draw soil gas samples directly to the surface. Each end of the sampler body is fitted with an inflatable donut-shaped bladder, which serves to secure the body at any given vertical location in a well. When a desired location for sampling is reached by manipulation of the composite cable, low pressure nitrogen from the surface control panel is applied to the bladders through one of the $1 / 4$-inch polyethylene tubes and the bladders inflate to "fix" the vertical location of the sampler in the well or borehole. Later removal of the pressure and application of vacuum collapses the bladders and again permits vertical positioning as desired.

The sampler body is connected to a control panel at the surface by 160 feet of a composite cable consisting of two 1/4-inch polyethylene tubes and a 12-conductor electrical control cable bundled together with a high strength, 1/8inch stainless steel wire rope. The sampler body is connected by the composite cable to a control assembly used at a suitable surface location. This assembly consists of all the necessary electrical and pneumatic circuitry to deploy and activate the sampler body. Pressure and vacuum gages, a 0-500-cc/min. mass flow meter, power supplies, and all necessary switches and valves are contained in a compact $17 \times 21 \times 8$ inch portable case. The control assembly requires 120 -vac electrical power, a source of low pressure nitrogen or other inert gas, and a source of moderate vacuum. The latter is provided by a small portable diaphragm pump. At a site without permanent electrical power, a small ac generator can be substituted.

The multisorbent traps used in the sampler at the SRIDS were constructed using $6 \mathrm{~mm}$ od (4 mm id) stainless steel tubing, $76 \mathrm{~mm}$ in length. The traps are sequentially filled with equal bed volumes of Carbotrap C, Carbotrap, and Carbosieve S-III. [These traps are similar in const uction to those marketed by Supelco as Carbotrap 300 traps. The primary differences are (a) a larger proportion of Carbosieve SIII, (b) no use of glass wool between adjacent sorbent media, and (c) tubes made of stainless steel rather than glass.] The multisorbent traps were routinely analyzed using thermal desorption gas chromatography with photoionization detection. Alternatively, the traps can be analyzed using thermal desorption gas chromatography/ mass spectrometry (GC/MS) or by thermal desorption direct sampling ion trap mass spectrometry (DSITMS). 


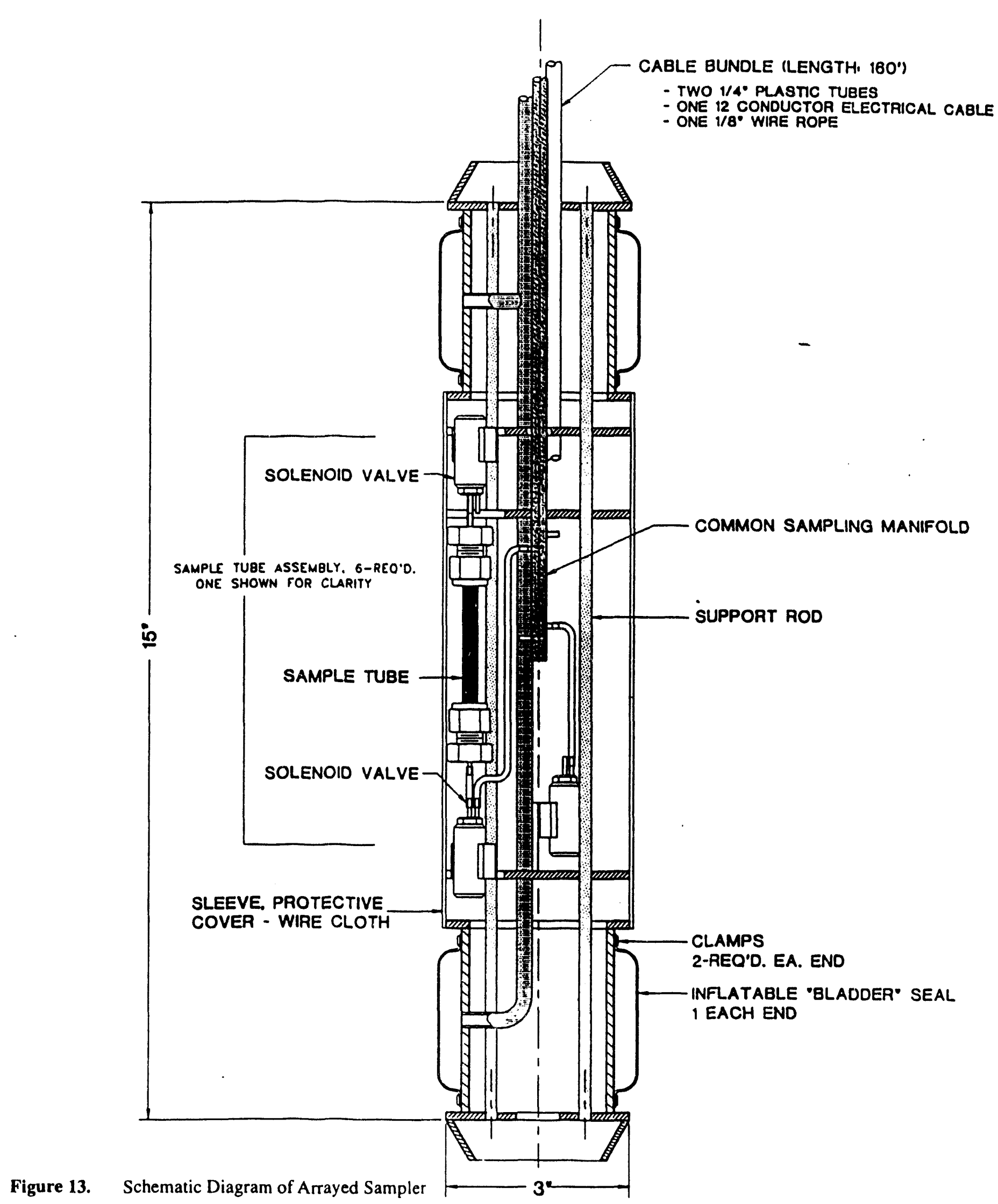


Fabrication and laboratory evaluation of the sampler was completed in the fall of 1991. The following issues were addressed during that phase of the effort:

- compactness of sampler design

- fool-proof operation under field conditions

- absolute sealing of traps while in the sampler

- procedures for pretreatment of the sorbent cartridges

- reproducible sorbent performance under high humidity conditions

- offgassing of trace constituents from sampler system materials

Upon completion of fabrication, the arrayed sampler was then field tested twice at the SRIDS, once in January 1992. and then in March. The purpose of the first field test was to determine the performance of the sampler, and to determine if adequate sensitivity could be achieved collecting samples as small as $15 \mathrm{~mL}$. The determination of any differences in soil $g$ concentrations in the vadose zone was considered to be additional information, and not critical to the determination of sampler performance.

The purpose of the second field test (March) was to interface the sampler with the DSITMS-based ORNL Real Time Monitor (DSITMS currently under development and discussed later; see Broadly Applicable Technologies) and to identify those problem areas or difficulties related to the use of such an integrated system under field conditions. The DSITMS is a device based on ion-trap technology; it permits direct introduction of a sample into the mass spectrometer, obviating the need for a separation-based sample introduction system, such as a GC.

\section{Results}

The mechanical and electrical performance of the sensor was exact and without incident. Despite the 150-foot length of cable, the sampler can be easily be deployed by one person. The surface control unit is easy to operate, and once the sampler is loaded with traps and the control system has warmed up (usually 10 minutes or less are required to achieve good stability of the digital flow meter), the sampler can be deployed, the packers inflated, and samples acquired in a matter of minutes. Some difficulties were, however, noted with the operation of the system. First, the compact design of the sampler requires that care be employed while changing sorbent traps to ensure an air-tight seal at the coupling point. Also, some zero drift in the digital readout for the sampling flow measurement system was observed.

Table I lists a few selected soil gas concentrations of TCE and $\mathrm{PCE}$ in the vadose zone monitoring boreholes deter- mined using the arrayed sampler. A cursory examination of all of the data revealed no consistent patterns of soil gas concentrations. It is clear that there is considerable variation in both the absolute concentrations and the TCE:PCE ratios. Some of the airspace samples collected were as small as $2 \mathrm{~mL}$. This result, combined with the widely ranging concentrations, suggest the presence of spatial heterogeneities of contaminants over short distances within the well airspace. There may be a number of explanations for these observations. First, in several of the experiments, the volume isolated by the packers of the sampler $(\approx 700 \mathrm{~mL})$ was evacuated several times prior to sampling. While some time was permitted to pass for equilibrium to be reestablished in the zone, it is possible, and even likely, that equilibrium may not have been achieved in the zone being sampled, especially in relatively low permeability strata. Also, well design, air removal rate from the horizontal extraction well, and barometric pressure fluctuations appear to all play an important role in determining the apparent concentrations of VOCs in the well airspace. For example, in the second field trial, experiments performed with the sampler interfaced to the DSITMS indicated that it is possible to withdraw all of the air contaminated with TCE from both the packed off zone in the well plus a substantial amount of the surrounding sand and gravel backfill behind the well screen. Thus, only traces of TCE and PCE remain in the air drawn through the sorbent traps. The results suggest that more data about vadose zone and borehole transport of contaminants must be collected to establish meaningful sampling and monitoring protocols.

\section{Conclusions}

Results from the initial field trials of the arrayed sampler indicated that it functions as expected. It is clearly capable of being deployed by one operator to depths of over 100 feet, and it is adequately rugged in its current configuration. Soil gas samples as small as $15 \mathrm{~mL}$ can be concentrated on the multisorbent traps and returned to the surface for analysis, with quantitative results. 
Table 1. Selected Vadose Zone Well Airspace Concentrations of Trichloroethylene and Tetrachloroethylene using Multisorbent Arrayed Sampler (January and March, 1992)

\begin{tabular}{|c|c|c|c|c|}
\hline \multirow[t]{2}{*}{ Well } & \multirow[t]{2}{*}{$\begin{array}{c}\text { Sample } \\
\text { Depth (ft) }\end{array}$} & \multicolumn{2}{|c|}{$\begin{array}{c}\text { Concentration } \\
\left(\mu \mathrm{g} / \mathrm{m}^{3}\right)\end{array}$} & \multirow[t]{2}{*}{$\begin{array}{l}\text { Mass Ratio } \\
\text { TCE:PCE }\end{array}$} \\
\hline & & TCE & PCE & \\
\hline MHV-6 & 88 & 5330 & 2780 & 1.92 \\
\hline MHV-7 & 88 & 50 & 17,000 & 0.003 \\
\hline MHV-6 & 65 & 20 & 27 & 0.75 \\
\hline MHV-6 & 88 & 130,000 & 122,000 & 1.07 \\
\hline MHT-14D & NS & $254^{*}$ & $55^{*}$ & 4.6 \\
\hline MHT-ID & NS & $12,500^{*}$ & $677^{*}$ & 18.5 \\
\hline MHT-ID & NS & $318^{*}$ & $3^{*}$ & 106.0 \\
\hline
\end{tabular}

* Quantification performed with DSITMS in field. All others determined using lab-based GC/PID.

NS Not specified.

Several modifications were made in the fall of 1992 to improve the operation of the sampler in deep vadose zone wells. These modifications include the following:

- expansion of the spacing of the packers to permit isolation of 2-foot long screened intervals

- addition of a water sensor alarm system

- independent operation of the packer cuffs

- stabilization of the flow meter readout at low flows

Due to funding restrictions, the modified prototype was not field tested in 1993. Current plan involves conducting field tests at the 200 West Area of the Hanford Site in late spring or summer of 1994.

The arrayed vadose zone sampler is intended for use in at least two scenarios. In the first, where relatively large concentrations of contaminants exist (ppm levels), the sampler can be employed to collect samples so small (10-20 $\mathrm{mL}$ ) that there is essentially no disturbance of the subsurface equilibrium. This is especially important in strata of low permeability. In the other scenario, where permeabilities are higher, the sampler can be used to concentrate very large samples of soil gas. Typically, such a capability would be important when very strict regulatory levels have been imposed. For example, if $1 \mathrm{ng}$ of TCE can be sorbed on a trap and accurately quantified, then collection of soil gas at the rate of $200 \mathrm{~mL} / \mathrm{min}$ for eight hours on a single trap would permit the observation of TCE concentrations of two parts-per-trillion. In general, the capabilities of the sampler are such that it may be useful in a number of scenarios, or concentration ranges.

\section{Tech Transfer}

Initial discussions have been held with a candidate partner to co-develop and commercialize the technology. The potential partner is a small company with interests in developing sub-surface sampling and analytical systems, and would like to become familiar with sorbent sampling technology. This could be gained through an alliance with the PI and the development team.

Additional information on this work can be found in publications by Jenkins and Maskarinec listed in the Bibliography section. 
WSRC-TR-93-671 


\section{Compound Selective Technologies}

At present, the organic chemical analysis technologies acceptable to state and federal regulatory agencies are limited to conventional methods such as gas chromatography amd mass spectrometry. Owing to their ability to unequivocally identify chemical compounds, these methods will continue to be the cornerstone of environmental characterization and monitoring programs. Unfortunately, these classical approaches achieve sensitivity and resolution at the expense of speed, and they are usually labor intensive. This has kept the cost-per-analysis high, and often the time required for sampling, transport, and chemical processing impedes investigations and removal actions by .

DOE has recognized that in many cases initial qualitative detail can be greatly augmented by timely quantitative data from class-specific and compound-specific chemical sensors. The concept is to follow detailed chemical characterization with installation of appropriate sensors in wells, treatment equipment, or other matrices of interest, that can be interrogated automatically at arbitrary intervals without manual operation. Chemical "sensors" may use spectral characteristics of target species or derivatives, changes in acoustical properties, micro-balance phenomena, or a variety of electrical phenomena to detect chemical compounds. Owing to the wide variety of materials that we would like to be able to monitor, and the extremes of their chemical properties, sensor systems may range widely in apparent complexity and may include reagent delivery subsystems, optical spectroscopy, and high frequency signal analysis. Research programs in all these directions are being supported by DOE, and some have progressed sufficiently enough to be operated in the field in conjunction with the DOE's Integrated Demonstration experimental sites. One such program involves the fiber optic TCE sensor developed by Lawrence Livermore National Laboratory (LLNL). This sensor can perform in situ measurements of vapor phase TCE in wells or in conjunction with the cone penetrometer.

For chemical sensors to be useful in a given application, they must meet definable criteria. Sensitivity of a particular compound-specific chemical sensor is usually restricted to only one or two members of a class; the range of sensitivity must be known, and any alteration of sensitivity when mixtures of related compounds are present must be understood. Note that compound selectivity is often exploited when the detected species have behaviors that can be used to predict the behavior of other related compounds.
The sensor must reliably detect its target compounds within a range of concentration that is useful for environmental applications (A sensor that may be practical as a process monitor, when its analytes are present in percent quantities, may be unable to detect its target when present in part per million concentrations in soil or groundwater.) Optimally, the response of chemical sensors to target analytes will be unmodified, or at least predictively shifted by (non-target) materials present in likely environmental matrices (i.e., high relative humidity, high çoncentrations of carbon dioxide, low oxygen tension, nitrous oxide, etc.). Sensor response should not drift excessively, or some provision should be made to characterize response by means of automated introduction of standards at appropriate intervals.

Finally, many sensors have the promise of being mass-produced at low cost, with relatively low-cost support modules that are sufficiently rugged as to be placed in the field for long-term, unattended operation. Ideally, compoundspecific sensors should incorporate sufficient on-board analysis software so that their routine output is a tabular record of time and concentration. At present, the systems being developed by researchers within DOE may have more extensive real-time display, diagnostic, and control capability than systems that would be commercially manufactured for routine monitoring applications.

\section{Fiber Optic TCE Sensor}

Researchers from LLNL have developed fiber optic sensor technology for the remote detection of TCE and chloroform. In laboratory studies, sensitivity below the EPA drinking water compliance level has been demonstrated for both contaminants. The efficacy of this technology for remediation activities has been evaluated at SRS. Instrumentation has been developed and field tests of the TCE sensor in vadose zone and groundwater monitoring wells have been successfully conducted. A cone penetrometer was used to install and deploy the TCE sensor. The technology was transferred to SRS during FY 93 for long-term testing.

\section{Background}

Researchers at LLNL have been developing fiber optic sensor technology for environmental applications since 1985. Some of the advantages of using fiber optic based 
technology for environmental monitoring include the following:

- Minimal invasiveness-Small size of the fibers and sensors has little impact on the sensing environment.

- Inertness-Optical fibers generally do not react with the analytes or the environment.

- Sensitivity-Many different spectroscopic methods can be utilized with fiber optics and many of these methods or combinations of them can provide very low detection limits.

- Ruggedness-Fiber optic cable is as strong as electrical cable and can be deployed in the subsurface indefinitely without corroding.

Because of their widespiead use within DOE facilities, chlorinated hydrocarbons were among the many compounds targeted for in situ monitoring in subsurface soils and groundwater. In 1988, the feasibility of detecting TCE and chloroform with useful sensitivity and accuracy was established by LLNL. During 1990, with internal LLNL funding, the technology was reduced to practice in the laboratory. This research was subsequently funded by the DOE's OTD for continued development and evaluation at the SRIDS.

\section{Operation and Methods}

With the SRIDS having been chosen as the initial location for field demonstration of LLNL fiber sensor technology, sensors and instrumentation that were significantly into or through the development stage were evaluated as to their applicability to SRS. Initial target compounds were VOCs and fuels. The following three sensor placement modalities were evaluated:

- screened vadose zone well installation

- water well headspace measurement

- penetrometer placement

The basis of the TCE sensor technology is the irreversible development of color in a specific chemical reagent upon its exposure to various target molecules. Target molecules (e.g., TCE) diffuse through a semipermeable membrane on a fiber optic sensor and react with a sequestered chemical reagent, thereby forming light-absorbing products. This absorbance, which is measured against time and over optical fibers, provides a remote and nearly instantaneous measure of TCE concentration.

The basic components of the technology (Figure 14) are as follows:
- a pumping system that consists of a computer controlled syringe for renewing the chemical reagent

- an electro-optic read-out device that consists of an incandescent lamp, suitable filters, and silicon diode detectors for measuring the sensor transmission

- the fiber optic sensor itself

The sensor allows consecutive measurements to be taken at short intervals on an on-demand basis, with control and monitoring executed remotely. It consists of a semipermeable, flexible tube connected at both ends by stainless steel micro-capillaries. One capillary contains the input optical fiber and a reagent fill tube while the other contains the output optical fiber and a reagent drain tube. The components are potted in their respective capillary using epoxy.

\section{Results}

The most significant data to date is the corroboration of fiber optic sensor analyses with independent, EPAapproved sampling and analysis techniques. Forty wells were sampled in duplicate during the LLNL monitoring program and analyzed by an independent analytical measurements contractor (Brown and Caldwell). The concentration was determined immediately by using a headspace application of the fiber optic sensor. The contractor samples were sent to their offsite laboratory and analyzed for TCE content by using EPA method 601 . Figure 15 is a scatter plot comparing the results of the two measurements. The coefficient of correlation between the two techniques is 0.89 . In laboratory measurements, the fiber optic sensor has demonstrated a sensitivity of $1 \mathrm{ppb}$ for both TCE and chloroform. Routine variance in replicate measurements is $8-12 \%$.

Self-contained instruments have been developed for placing the sensor and reagent delivery system in 4-inch-diameter, cased monitoring wells and in 1.5-inch-diameter penetrometer cones. This development gives the analyst the ability to make measurements at depths of up to 200 feet and to a vertical resolution of at least 12 inches, with or without a monitoring well. The instrumentation has been successfully field tested at the SRIDS in a screened vadose zone monitoring well and in the headspace of a groundwater monitoring well. Tests using a cone penetrometer to deploy the sensor to a depth of 120 feet were performed in May 1992. Measurements were made under ambient conditions (static), then the pump was used to pull air from the formation to the probe (dynamic), and finally measurements were made under ambient conditions (static 2). The results from this test are shown in Figure 16. 


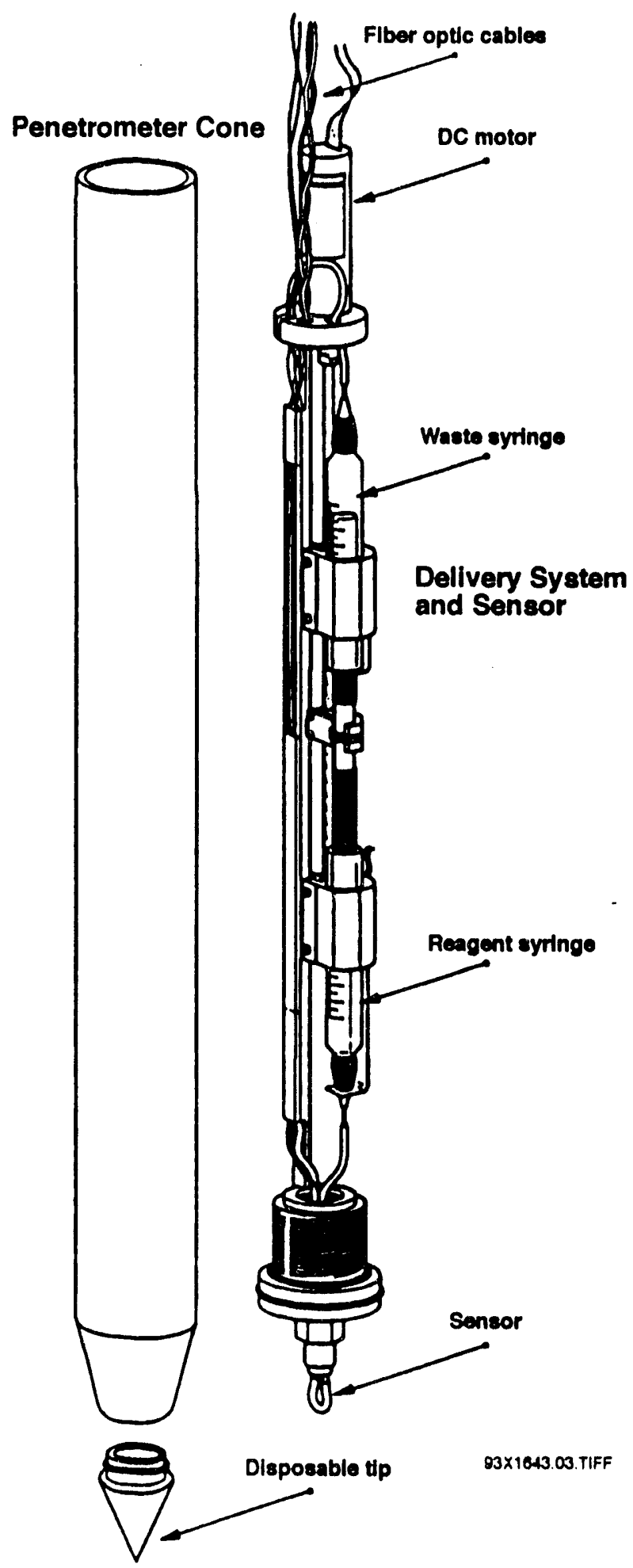

Figure 14. Fiber optic TCE sensor design 


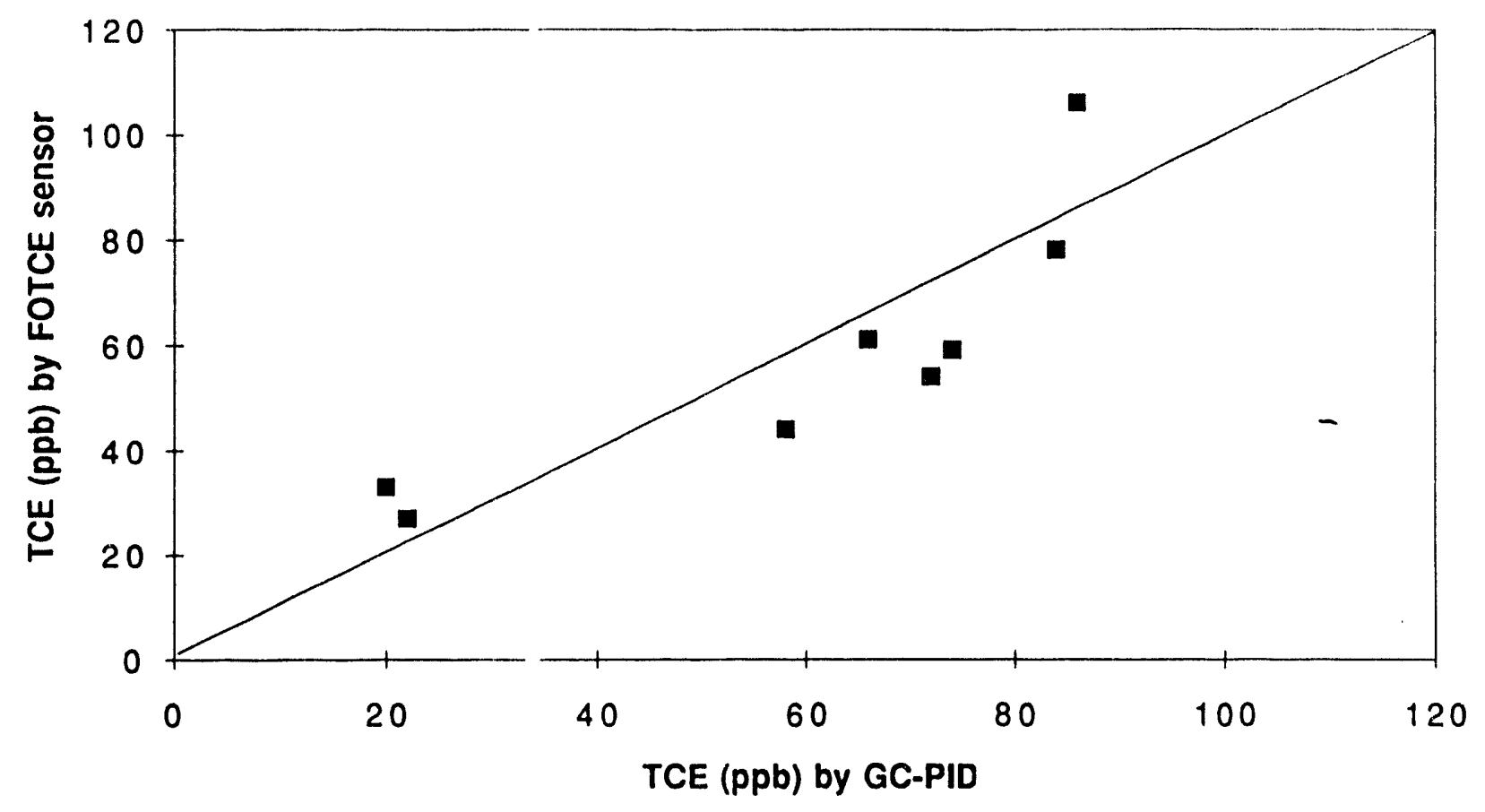

Figure 15. Scatter plot comparing results of fiber optic sensor analyses with independent, EPA-approved sampling and analysis techniques

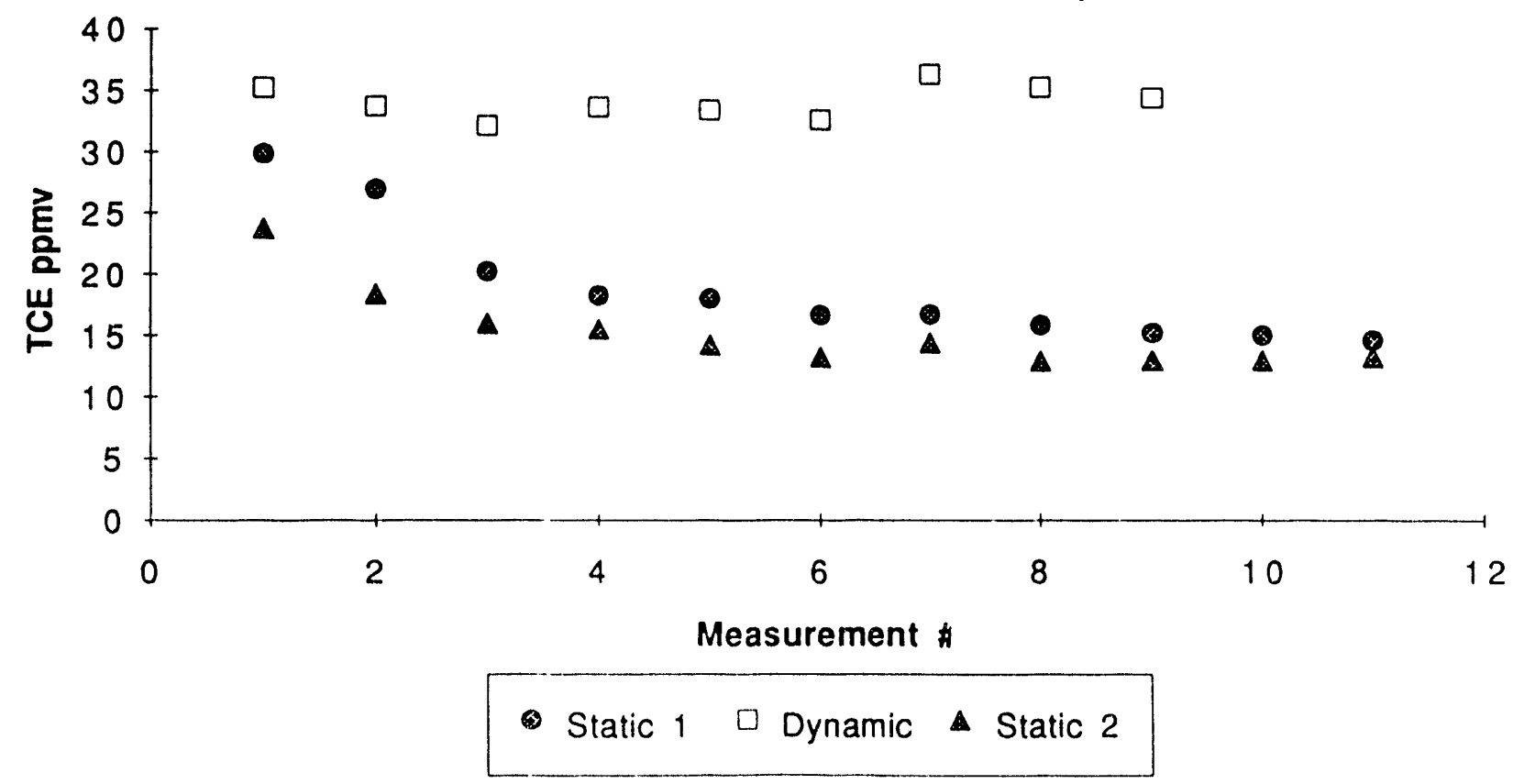

Figure 16. Results from penetrometer insertion test performed in May 1992 


\section{Conclusions}

Cost benefits of the fiber optic TCE sensor technology will come in several ways. The ability to make measurements on-demand and at impromptu locations can save costs indirectly by increasing the efficiency of characterization and monitoring. The costs of reagent per measurement is less than $\$ 1.00$, which in volume application represents significant savings over sample and GC analysis. (Typical charge per analyte is $\$ 15-300$, depending on matrix.) The manufactured cost of the sensor is less than $\$ 25.00$, which is well under the cost of most electrochemical sensors. The instrumentation cost competes favorably with the cost of a water sampling system and a field-portable GC. There are also indirect savings in sample chain-of-custody accounting and sample disposal fees. In applications where a penetrometer installation is adequate, thus mitigating the need for a cased well and pump, the cost savings per monitoring point is in the $\$ 10,000-100,000$ range. If these savings are amortized over the lifetime of the DOE remediation activities, then cost savings into the hundreds of millions can be expected from the widespread application of this technology to TCE and other applicable target compounds.

Several technology transfer activities are under way. A field-of-use license was obtained by Purus Corp. of San Jose, California. The license covers three LLNL patents and patents pending. This field-of-use license is for aboveground applications as an ancillary component to Purus ultra-violet lamp, vapor-phase organic destruction equipment. Burge and Associates of Tempe, Arizona, have entered into a joint development with LLNL to build a prototype submersible sensor assembly. A license for subsurface and groundwater applications of this technology is being negotiated. SRS is the first DOE laboratory equipped with the fiber optic measurement equipment.

Additional information on this work can be found in publications by Milanovich, Colston, and Angel which are listed in the Bibliography section. 
WSRC-TR-93-671 


\section{Class Selective Technologies}

Chemical analysis methods used during site remediation activities must cover a wide range of requirements for sensitivity and selectivity. Generally, methods used to characterize recovered samples must be highly selective to provide information concerning the compositions of the sample media. These analyses are typically performed in analytical laboratories using widely accepted, standardized methods such as GC/MS and ion chromatography. However, the cost of these methods often limits the number of samples that can be analyzed. New laboratory techniques or rapid field screening methods may provide economic relief.

At the other end of the spectrum of field screening needs are methods which for reasons of safety must be broadly responsive. For example, during hazardous waste investigations, portable photoionization (PID) or flame ionization (FID) detectors are used for personnel monitoring the breathing zone. These detectors respond to a wide range of organic and some inorganic vapors, making them ideal early-warning devices for the presence of virtually any hazardous vapor. PIDs are most commonly used because they are relatively inexpensive ( $\$ \$ 5000$ per unit), light weight, portable, rugged, and reasonably sensitive (typical lower detection limit of about $1 \mathrm{ppmv} / \mathrm{v}$ ). PIDs cover a reasonably wide dynamic range from about 1 to 1000 ppmv/v. The principal disadvantages of the PID are its sensitivity to humidity, limited linearity, widely variable responses to various compounds, and the need for the use of multiple lamps having different excitation energies to optimally cover all possible compounds.

Between the extremes represented by highly selective methods (i.e., GC/MS) and broadly selective methods (i.e., PID or FID) lies a heightened interest for methods that are better suited for use at a large number of sites where the contamination setting is narrowly defined. A number of efforts focus on the need to develop newly emerging chemical sensors. These types of sensors find broad applicability in situations where the contamination issue or contamination potential is reasonably unambiguous. For example, if early warning is required for a potentially leaking underground storage tank containing gasoline, the sensor used should respond to a range of indicator species present in gasoline (e.g., the BTEX fraction). A similar situation occurs during remediation of a well-characterized site (e.g.. the SRIDS), where TCE and PCE are clearly established as the dominant groundwater and vadose zone contaminants. In this case, a detector capable of monitoring total organic chlorinated compounds ( $\mathrm{TOCl}$ ) in real time and over a wide dynamic range is clearly beneficial.

The two systems described below. Portable Acoustic Wave Sensor (PAWS) and HaloSnifm, have similar characteristics in that both are capable of measuring $\mathrm{TOCl}$ in real time on an extracted gas sample; however, completely different transduction mechanisms are used (quartz microbalance vs. optical emission) and a true head-to-head comparison has not yet been made. In addition, a third system, the Odyssey 2001, is also under evaluation at both Hanford and SRS. The Odyssey 2001, manufactured by Transducer Research Inc. (Naperville, IL), is a field-portable TOCl detection system that has recently become commercially available. The Odyssey 2001 employs an electrochemical sensor, and thus represents a baseline technology for comparison purposes. Other commercially available baseline technologies include the PID systems discussed above, various kinds of portable infrared analyzers, and field-portable automated GCs.

\section{Portable Acoustic Wave Sensor}

Under separate OTD funding, a PAWS system was developed for continuous,-on-line, industrial monitoring of contaminant concentrations in offgas streams produced during vacuum extracticn processes and in gas samples pulled from monitoring wells. This simple and inexpensive system has an easy-to-use software program for system operation and data acquisition/analysis. The PAWS incorporates an automatic system for evaluating sensor baseline, and therefore can be used for long-term, on-line monitoring. A field demonstration of this system at the SRIDS demonstrated rapid, reversible, and quantitative evaluation of the concentration of chlorinated hydrocarbon contaminants.

\section{Background}

Acoustic wave devices are simple, durable, and inexpensive instruments consisting of a quartz substrate and a thin metal layer patterned into two interdigitated transducers. Application of an alternating voltage to one transducer results in an alternating strain in the quartz. This strain launches an acoustic wave that travels along the quartz substrate. A common analogy of this effect is throwing a rock into water to launch a wave that travels along the surface of the water. These devices can be made into chemi- 
cal sensors by applying a chemically sorbent coating to the surface of the device. Since the coating moves with the wave, changes in the wave properties can be used to detect changes in film properties that occur when chemical species are sorbed into the coating. These changes are detected by converting the wave back into an electrical signal using the second transducer. The sensitivity of these devices to mass changes accompanying species uptake is sufficient to detect as little as $10 \mathrm{pg}$ of mass.

There are two wave properties that can be altered by sorption of chemical species, wave velocity and wave attenuation (i.e., loss of acoustic power). The ability to advantageously use both of these responses has been demonstrated by researchers involved in this project. Using elastomeric polymers as the chemically sorbent layers. researchers found that the relative magnitudes of these two responses depends on the chemical species being absorbed into the polymer. This enables the use of a single sensor to determine the identity of an isolated species as well as its concentration. Alternatively, if there are two known species (e.g.r TCE and PCE at SRS), these two responses should enable the simultaneous evaluation of the concentration of both species. For more complicated mixtures, arrays of these dual output sensors could be combined with pattern recognition schemes to enable the evaluation of the concentrations of the multiple species that are present. A patent covering the various applications of this novel technique has been filed and granted (G. C. Frye and S. J. Martin, Dual Output Acoustic Wave Sensor for Molecular Identification, U.S. Patent $\$ 5,076,094$, Dec. 31, 1992).

\section{Operation and Methods}

Of the variety of coatings that have been evaluated to date, two were chosen for more detailed study for this application-polyisobutylene and polyisoprene. For both polymers, rapid (few-second response times) and reversible detection of CVOCs was observed. Both polymers were capable of discriminating between the responses due to CVOCs from those due to nonchlorinated species and, in addition, they both exhibited differences in the dual output responses for PCE and TCE. These differences are needed to evaluate the concentrations of these two species simultaneously. The calibrations demonstrated that the device sensitivity is about four times higher for PCE than for TCE. This difference in sensitivity is mainly due to the lower volatility of PCE, which results in greater absorption in the polymer coatings.
The PAWS system consists of a coated acoustic wave device in a test case containing gas inlet and outlet ports. This case enables quick changing of devices based on pressure electrical contacts, which are automatically made when the test case lid is bolted into place. To operate the acoustic wave device, this test case is mounted onto an radiofrequency uscillator board. The two outputs from this board are frequency, which tracks velocity, and a power detector voltage, which tracks attenuation. These outputs are monitored using frequency counter and $A D D$ boards in an IBM-compatible portable computer. This computer contains a user-friendly routine operating in the LabWindows software to control the sensor module and to analyze the data to determine concentrations. System control consists of switching a three-way solenoid value on an operator input protocol to direct the sample gas through a carbon-based scrubber. This periodic scrubbing enables the sensor baseline to be evaluated on line, which is a critical capability for continuous monitoring because it minimizes the effect of long-term drift. An external pump is used to continuously pull a gas sample into the sensor module and through the test case.

System capabilities were evaluated using a $300-\mathrm{nm}$ thick polyisobutylene-coated device. Short-term noise is on the order of two $\mathrm{Hz}(0.02 \mathrm{ppm}$ for these $100 \mathrm{MHz}$ devices) for frequency and about $0.004 \mathrm{mV}$ (out of a $2 \mathrm{mV}$ signal level) for the power detector signal. The response that results from activating the scrubber with no chemical present is about $20 \mathrm{~Hz}$. (This value determines the lower detection limit since it determines how accurately the sensor baseline can be evaluated.) Using this $20 \mathrm{~Hz}$ response to indicate the detection limits gives $12 \mathrm{ppm}$ for TCE and $2.5 \mathrm{ppm}$ for PCE. The ratio of the attenuation response to the frequency response is -1.12 for TCE and -0.96 for PCE. These values are similar because of the similar nature of the chemicals; however, they are distinct enough to enable differentiation of these two species if the concentrations are high enough. Improvements in the signal-tonoise level for the attenuation measurement are needed before this evaluation can be performed at the concentrations levels typically observed at SRS.

\section{Results}

A two-day field demonstration of the PAWS system at SRS was performed. Tests were performed both days on the offgas stream and on sample gases drawn from monitoring wells (MHV-1, MHV-2, MHV-4, and MHV-8) at various depths. For the tests, the most recent GC measurements were used to estimate a PCE/TCE ratio; this ratio was then used to calculate the calibration coefficient based 
on the independently determined values for PCE and TCE. The offgas measurements showed a relatively constant concentration with time, providing average total CVOC concentration values of 268 and $322 \mathrm{ppm}$ on the first and second days, respectively. This was in good agreement with the GC values of 274 and 297 ppm. Measurements for the first day are shown in Figure 17.

Regarding absolute accuracy, a direct comparison with the GC was performed by using the grab sample taken for GC analysis as the sample gas to the device. In this test, a total concentration of $299 \mathrm{ppm}$ was obtained from the PAWS measurement, in excellent agreement with the value of 297 ppm obtained from the GC. In addition, onsite calibration with a 974-ppm TCE standard was performed both days with a reproducibility of within $2 \%$. These results show that the system is able to provide quantitative values if the gas composition is known.

Measurements from the monitoring wells yielded values from below the detection limit $(<20 \mathrm{ppm})$ to over 1000 ppm. It was also found that even when pulling greater than a liter per minute out of the well, several minutes were sometimes required before the chemical was detected (and beyond that to pull the sample from the well to the sensor). This delay may have been due to depletion of contamination in the gravel pack of the well as barometric pressure was rising during these tests and air was blowing into the wells. As shown in Figure 18, relatively constant values with some minor fluctuations were observed for a given well after this initial delay. Significantly less variation in the response in the beginning of the run (prior to the arrival of the contaminant) indicates that these fluctuations are most likely due to actual concentration fluctuations. These fluctuations would not be detected with conventional analytical methods since they generally do not provide rapid and continuous monitoring.

\section{Conclusions}

Based on laboratory experiments and the field demonstration, several key advantages of the PAWS system have been demonstrated. They are as follows:

- simplicity of use based on user-friendly software and a self-contained, easy-to-interface sensor module

- low maintenance (The system only requires infrequent changing of scrubber material.)

- rapid response (few seconds) allowing for rapid evaluations and the observation of concentration transients

- reversible response allowing for continuous monitoring without regeneration
- quantitative analysis (if composition known based on periodic GC analysis)

- potential for evaluating the concentration of both PCE and TCE based on the dual output technique.

The PAWS system has a relatively low cost and it should provide a rapid return on investment, even if based solely on decreasing the frequency of expensive analysis (e.g., by GC) (With some further development, a sensor module including the data acquisition capabilities to interface with any computer could be produced for about $\$ 1000$.). In addition, the PAWS system can provide more frequent or even continuous analysis. These sensors can also be used to improve the accuracy of periodic analyses [e.g., monitoring gas from wells (prior to taking a sample for analysis) to verify that the contaminant has reached the sample port].

This initial system has been optimized with a more precise temperature control system. Field demonstrations have been performed at the SRIDS and at Hanford. A system will be transferred to Hanford personnel for ongoing use. Further work includes optimizing the coating material to provide sensitive detection and discrimination of species of interest, these systems can also be applied to a wide variety of other applications. Discussions have been initiated with a variety of companies regarding licensing of the dual output patent, which will lead to the production of these systems for DOE, other government agencies, and industry.

Further information on this work can be found in the publications by Frye and Cemosek listed in the Bibliography section.

\section{HaloSnif ${ }^{\mathrm{TM}}$}

Pacific Northwest Laboratory (PNL) has developed a $\mathrm{TOCl}$ sensor for use in offgas and vadose zone monitoring of chlorinated hydrocarbon vapor. The PNL system employs an atomic emission sensor that is selective for chlorinated compounds in the gas phase, but cannot distinguish between chlorinated compounds. The HaloSnif'M is reasonably sensitive and it has a wide linear dynamic range that extends up to at least $10,000 \mathrm{ppmv} / \mathrm{v}$. The sensor is designed primarily for use on extracted gas samples and it has been successfully tested at Tinker Air Force Base (AFB), SRS, and Hanford. Field tests conducted at the three sites were very encouraging and it appears that the HaloSnif ${ }^{\mathrm{TM}}$ offers significant quality advantages relative to the baseline technologies for monitoring vaporphase CVOCs, particularly in the case of vacuum extraction offgas. The functionality of the system is similar to SNL's PAWS system. However, more field experience and 


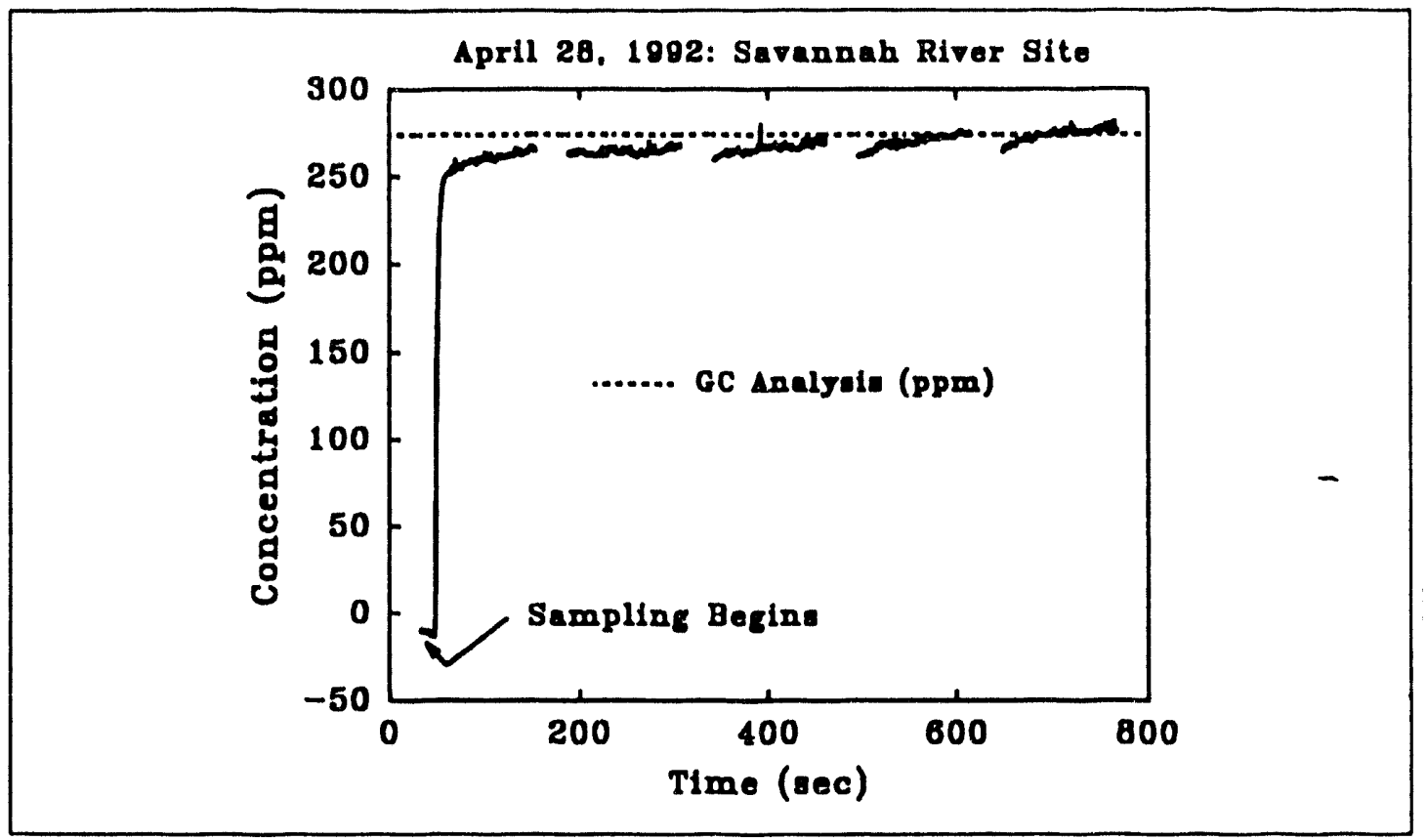

Figure 17. On-line analysis of contaminant concentrations in the offgas stream from the vacuum extraction process at SRIDS using the PAWS system. (Dashed line represents the value for the deay of the test obtained using an onsite GC. Gaps in the data represent periods where the scrubber was being used to establish baseline.

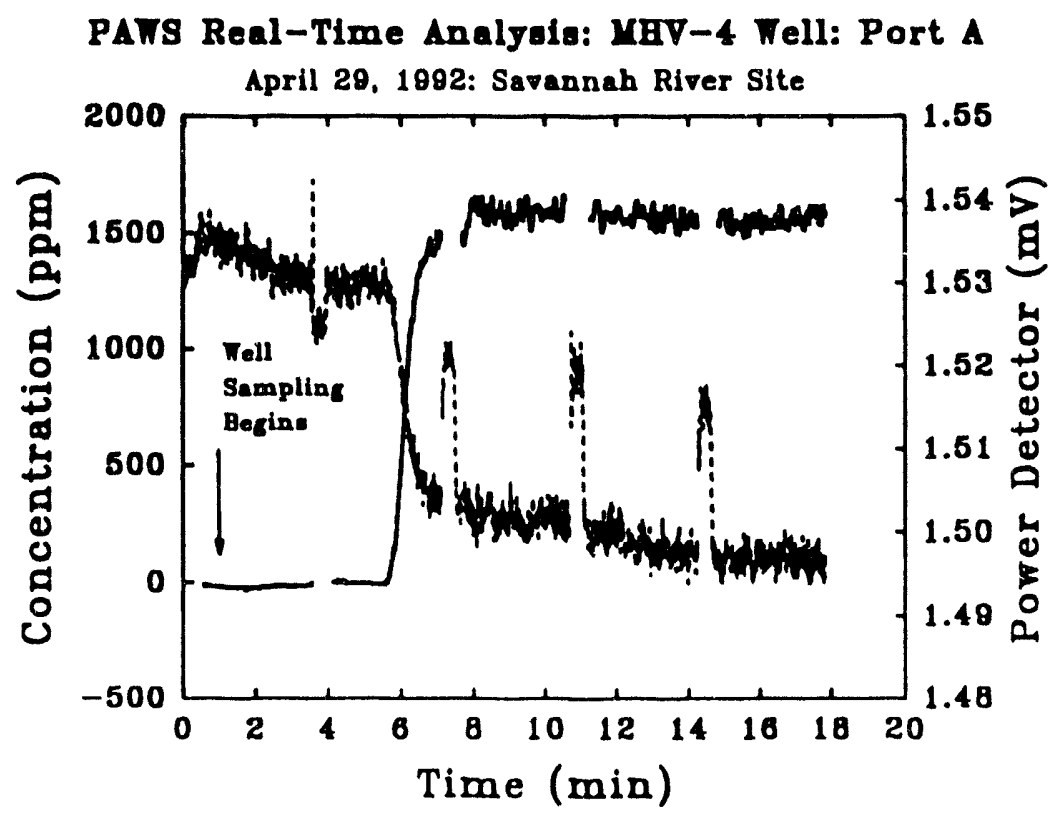

Figure 18. Monitoring of gas sample from monitoring u 
direct comparisons between the two systems are needed to evaluate the utility of these two approaches.

\section{Background}

In 1985, Rice, D'Silva, and Fassel published a paper entitled "A New He Discharge-Afterglow and its Application as a Gas Chromatographic Detector". Concurrent with the Rice publication, DOE's Office of Fossil Energy (DOE/ FE) was supporting a program at PNL entitled "Multi-element Detection of Gas Chromatography Effluents." The work by Rice suggested to PNL researchers that the RF excited detector may have several advantages over the standard microwave-induced helium plasma source being used at that time on the aforementioned DOE supported program. One specific advantage was the ability of the afterglow source to be more tolerant of contaminants in the plasma (i.e., chlorinated hydrocarbons or air). Because of the potential advantages of the afterglow source, a significant effort was made to characterize and improve the source. Two specific modifications were made to the original design: (1) axial viewing geometry, and (2) operation of the source at less than atmospheric pressure (both modifications are reflected in the current configuration of HaloSnif ${ }^{\mathrm{TM}}$ ). In FY 88, internal Exploratory Research funding was provided by PNL for "proof-of-concept" of a sensor specific for measuring the concentration of volatile organic compounds containing chlorine. A patent application was filed on September 2, 1988, based on the results of the Exploratory Research supported program for the halogen specific sensor using a radio-frequency induced helium plasma. In FY 90 PNL internal funding was used to modify and upgrade the system and to determine the response and behavior of the system to $\mathrm{CCl}_{4}$, a problem of particular importance in the subsurface environs of Hanford's 200-West Area. During the latter part of FY 91, limited support was provided through the characterizations system integration (CSI) task of the VOC-Arid Site Integrated Demonstration project. This support was used to upgrade the system into a field portable unit for use at the Hanford Site. An important technical enhancement added at that time was the use of a high-efficiency, narrow-band interference filter for spectral analysis of the chlorine emission line in place of the much bulkier and more expensive dispersive spectrometer. Additional field testing of HaloSnifrM in FY 91 was conducted at Tinker Air Force Base (AFB) in Oklahoma City, Oklahoma, and at the Savannah River VOC-Non Arid Integrated Demonstration Project. At Tinker AFB, HaloSnifrm was successfully interfaced with a cone penetrometer rig and used to determine TCE contaminations in soil gas as a function of depth. At Savannah Kiver, HaloSnifrm was used for measuring the TCE/PCE concentrations in vadose zone monitoring points and vapor extraction offgas. During FY 92 a
US Patent was issued (February 1992) and a commercial partner with possible interest in a manufacturing agreement was also identified (Quanta Physik, West Palm Beach, FL). Technical enhancements during FY 92 include the use of a background correction channel to provide a stable baseline, the addition of a computerized data logging system based on Labview software, and the receipt of the first commercial prototype power supply unit produced by Quanta Physik. The Quanta Physik unit was a complete redesign of the power supply assembly changing from a direct coupled to inductively coupled plasma. Supported by the VOC-Arid Site Integrated Demonstration project in FY 93, HaloSnifm has been successfully used at Hanford to monitor the concentration of carbon tetrachloride in the pre- and post- GAC soil gas from the vapor extraction system (VES), vadose zone monitoring wells around Z-1A crib, and during cone penetrometer monitoring around the Z-9 crib. In addition, longterm monitoring at several cone penetrometer installed ampling points has been conducted using the Quanta Physik power supply system during the summer of 1993. During late FY 93, a HaloSnif'M system was transferred to WHC personnel responsible for conducting monitoring at the VES around Z-1A or Z-9 crib.

\section{Operation and Methods}

The active element of the HaloSnif ${ }^{\mathrm{TM}}$ is a differentially pumped quartz tube containing a sustained flow of high purity helium gas. Helium is supplied at a flow rate of $\mathbf{4 0}$ $\mathrm{mL} / \mathrm{min}$ with pressure maintained at 20 Torr. A precision mass flow controller is used to maintain optimal flow conditions. Optimal vacuum conditions are controlled by a precision micrometer-operated steel bellows valve. A radio frequency-induced helium plasma is maintained in the tube by radio frequency (RF) excitation at $300 \mathrm{KHz}$. RF energy is supplied to the tube by an RF power supply operated at 23 watts forward power. The power supply is directly coupled with the plasma tube using small metallic electrodes at each end of the tube.

Air containing potential analyte is admitted to the system through a $50-\mu \mathrm{m}$ internal diameter quartz capillary tube. Alternately, a thin polysiloxane membrane has been successfully used as a diffusion barrier to exclude air and $\mathrm{HCl}$ while allowing rapid passage of $\mathrm{TOCl}$ analyte molecules. Analyte molecules entering the plasma tube are completely reduced to atomic form by high-energy transfer reactions within the helium plasma. The high excitation energies present in the plasma also produce efficient atomic excitation of the chlorine atoms causing light emission at $837.6 \mathrm{~nm}$. Emitted light is transmitted through a silica fiber optic cable to the analysis system, which consists of a narrow band interference filter, a miniature 
mechanical chopper, and photodiode. The signal is processed by a phase-lock amplifier and converted to a $0-10 \mathrm{~V}$ DC signal suitable for display or logging. An optical splitter is used to route part of the light to a second interference filter tuned to a wavelength just off the chlorine line which serves as a background correction channel. Data logging is performed with a Macintosh computer operating LabView software with a custom-coded display panel.

The HaloSnif ${ }^{\text {TM }}$ is reasonably sensitive, with a lower limit of detection for TCE. CCl4, and other related compounds of $1-5 \mathrm{ppmv} / \mathrm{v}$. A significant advantage of the system is its wide linear dynamic range, which extends up to at least $10,000 \mathrm{ppmv} / \mathrm{v}$. The sensor is fully reversible and responds rapidly to changes in analyte concentration. Baselines set with zero gas are stable for prolonged periods. The HaloSnif ${ }^{m}$ is designed primarily for use on extracted gas samples and does not lend itself well to true in situ application because of the heat load generated by the plasma.

\section{Results}

The HaloSnif ${ }^{\mathrm{m}}$ was first field tested at Tinker Air Force Base (AFB) in August 1991 in an area of known high levels of TCE contamination. A commercial cone penetrometer was used to emplace a soil gas sampling point at several depths. TOCl concentrations in excess of 10,000 $\mathrm{ppm} v / \mathrm{v}$ were encountered during the tests.

A series of soil vapor measurements were made at the SRIDS in September 1991. The tests were performed in borehole MHV 7, which has a continuous screen over its entire length to just above the water table. The screened portion is exposed to the formation through a sand pack. A sliding gasket system was used to isolate one-foot intervals in the well. Soil vapor was transported to the surface through a 1/4-inch copper transfer line. A stainless steel bellows pump operated at a flow rate of up to $5 \mathrm{~L} / \mathrm{min}$ was used to extract sample gas.

The HaloSnif ${ }^{\mathrm{M}}$ was operated continuously with CVOC concentration readings recorded at 5-foot intervals as the gasket system was lowered into the borehole. The system was calibrated with a dynamic gas calibrator employing a Type-D diffusion tube that was filled with high-purity TCE. Zero air drawn through a charcoal filter was used as a baseline reference. Test 1 (September 25, 1991) was performed during a period of low barometric pressure in which significant outgassing from the borehole was observed. Test 2 was performed the following day after passage of the pressure front and no detectable air flow in or out of the borehole was observed. The two sets of results are essentially identical except for a small difference near the surface that may be attributable to the baro- metric effect (Figure 19). A noticeable concentration break occurs just above the relatively impermeable clay layer at 45 feet, which is an area known to contain high concentrations of TCE and PCE. The range of concentrations found $(250-550 \mathrm{ppmv} / \mathrm{v})$ was similar to that found in previous measurements reported by SRS personnel using GC detection on grab samples.

In February and March of 1992, the HaloSnifm has been used in several short field tests at Hanford in which a small amount of offgas from the $\mathrm{CCl} 4$ vapor extraction system was routed to the HaloSnif ${ }^{T M}$ for continuous real-time measurement. The system performed well for that application with results reported in the $150-500 \mathrm{ppmv} / \mathrm{v}$ range at various points in the test series. A cross calibration made on a grab sample of the gas stream was analyzed by GC using a modification of EPA Method 502.2. The results of this analysis agreed very closely with the HaloSnif ${ }^{\text {TM }}$ measurement. The Hanford tests also provided a good opportunity to compare this detection system with the Transducer Research Inc., Odyssey 2001 total organic chloride sensor baseline technology. The Odyssey 2001 has a limited functional dynamic range, thus requiring large dilutions to obtain usable measurements in the region of interest for offgas monitoring. Similarly, PNL personnel found portable PID measurements to be unreliable because of the relatively poor response of the detector to CCL4, poor linearity, and high sensitivity to bulk gas composition.

\section{Conclusions}

Results from field tests conducted at Tinker AFB, SRS, and Hanford have shown that the HaloSnif ${ }^{\mathrm{M}}$ offers significant quality advantages relative to the baseline technologies for monitoring of vapor-phase CVOCs, particularly in the case of vacuum extraction offgas. The system is simple to operate and relatively inexpensive to produce. The individual system costs should not exceed $\$ 10,000$ to $\$ 15,000$ in routine production. Monitoring of multiple sampling points with a single system can be easily achieved through the use of appropriate gas sampling manifolds and automated valving. Addition of a compact and more rugged RF power supply (from Quanta Physics) has made the system more portable and suitable for commercial development.

The functionality of the HaloSnif ${ }^{\text {TM }}$ is very similar to that of the SNL's PAWS (see above). Sensitivity and dynamic range of the two systems are similar. However, the HaloSnif ${ }^{\mathrm{MM}}$ system is not as well suited to remote field or in situ applications because of its size and operational requirements. Further field experience and some actual direct comparisons between the two systems are clearly 


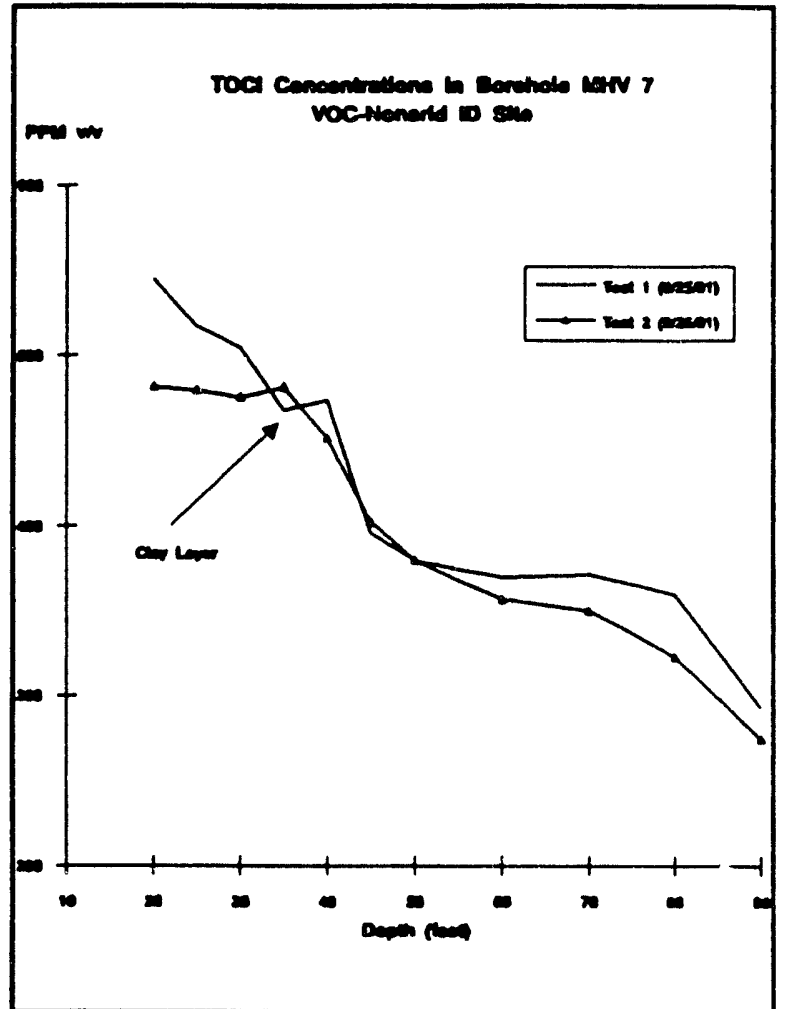

TOCL measurements in borehole MHV.7

conducted at Savannah River VOC-Non Arid Integrated Demonstration site in September, 1991.

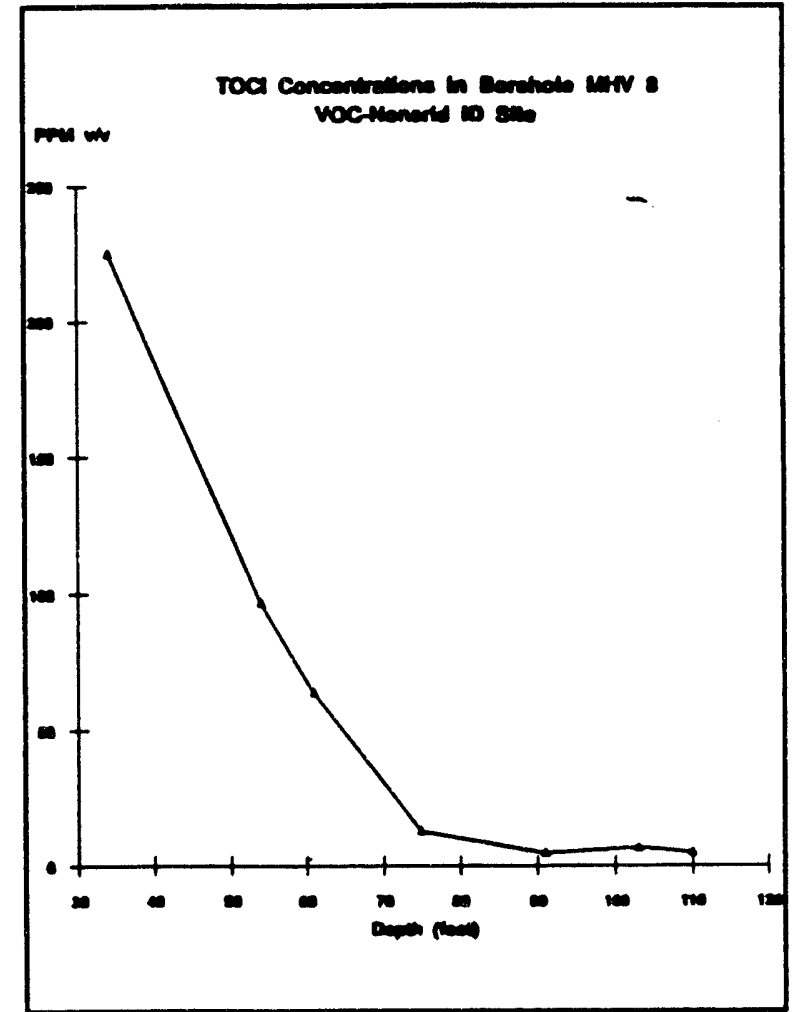

TOCL measurements in borehole MHV-8 conducted at Savannah River VOC-Non Arid Integrated Demonstration site in May, 1992.

Figure 19. Test I and II results using HaloSnifm 
needed to fully and objectively evaluate the long-term future utility of these two approaches.

PNL was recently issued a patent (February 1992) covering a number of related applications of spectrochemical optical emission detection techniques, including the HaloSnif ${ }^{T M}$. PNL is actively pursuing commercialization of this instrument.

Additional information on this work can be found in publications by Olsen listed in the Bibliography. 


\section{Broadly Applicable Technologies}

Broadly applicable technologies are those that can analyze multiple contaminant concentrations in several different phases. Environmental applications require information on contaminant concentrations in the solid, aqueous, liquid, and vapor phases. Technologies that can perform these analyses typically have a sample processing front end that can modify the sample in a way to allow a direct measurement of the contaminant in a single phase (usually vapor phase).

Many types of laboratory instruments are capable of analyzing contaminant concentrations in different phases but are dependent on the availablity of a sample introduction system (e.g., thermal desorption; purge and trap; direct injection). There are very few field-portable instruments with that capability. The need for rapid and accurate field characterization and monitoring instruments for environmental activities has been discussed throughout this document. Versatile instruments capable of multiple-phase, multi-contaminant field analyses can be critical for a costeffective site characterization and monitoring program.

\section{Direct Sampling Ion Trap Mass Spectrometer}

Direct Sampling Ion Trap Mass Spectrometry (DSITMS) has been under development at Oak Ridge National Laboratory for several years. This work is aimed at the development of instrumentation and methods for the rapid analysis of target analytes in environmental samples. Efforts have focussed especially on the analysis of volatile organic compounds in air, water, and soil samples. In order to maximize the utility of the technology, laboratory and fieldable versions of the DSITMS instruments have been developed. Both types of instruments are equipped with a capillary inlet and a set of quick connecting sample modules for the analysis of air, water, soil, and sorbent tubes. With this arrangement, the instrument can rapidly be converted from one sampling configuration to another without breaking vacuum to the instrument. Field testing of this instrument at a Savannah River Laboratory Integrated Demonstration Site (SRIDS) and other DOE sites has been highly successful and demonstrated the ability to quickly and easily perform measurements for volatile organics in a wide range of samples including soil gas, well headspace, drilling mud, and groundwater. High sensitivity, accurate quantification of target analytes, and fast analysis times have been demonstrated.

\section{Background}

DSITMS is a technology which addresses the need for faster and less expensive environmental analysis. This work has been jointly sponsored by the DOE Office of Technology Development and by the US Army Environmental Center. The term "direct sampling" describes the introduction of organic analytes directly into the mass spectrometer with minimal sample preparation and no chromatographic separation. This technique differs from conventional GC/MS methods in that the analytes are monitored in real-time with the ion trap at concentrations down to low part-per-billion (ppb) levels. The time required for quantitative analysis ranges from nearly instantaneous for air monitoring to approximately $3 \mathrm{~min}$ utes for water or soil samples. A limitation of DSITMS, which arises from the elimination of the chromatographic separation step, is the inability to fully characterize complex chemical combinations in samples. However, ion traps have several modes of operation that can help to identify targeted compounds in a sample without increasing the analysis time. These include the use of chemicat ionization methods, multiple stage MS (MS/MS), spectral subtraction, and pattern recognition. Even with the present limitation, in many cases, the mixtures of chemicals found in real-world samples are often simple enough to permit accurate quantification of the components based solely on the information contained in the full scan electron ionization and chemical ionization mass spectra. If isobaric interferences are suspected of being a problem, MS/MS can often be used to distinguish them. Further, for sample screening purposes, accurate quantification of each constituent in a sample is not necessary. Instead, it is sufficient to determine that target compounds are present at or above a threshold limit.

\section{Operation and Methods}

The present DSITMS instruments are modified versions of ion trap mass spectrometers which are manufactured by Finnigan MAT Corporation. The laboratory instrument is a model ITMS that is equipped with dual $330 \mathrm{~L} / \mathrm{sec}$ turbo pumps and the electronics necessary for selective mass storage, chemical ionization, and MS/MS. The field version of the DSITMS is based on a model ITS-40 Magnum ion trap (normally sold as a GC/MS) that has been modified and hardened in our laboratory. Specific modifications to the ITS-40 include mounting of the spectrometer on a shock absorbing base, replacing of the rotary vane oil 
filled vacuum pump with a Drytel-Micro (Alcatel)molecular drag/diaphragm pump for backing the $60 \mathrm{U} / \mathrm{sec}$ turbo pump, adding heat insulation to the vacuum chamber for cold weather operation, and replacing the commercial GC interface line with the direct sample introduction system developed in our laboratory. The field instrument is equipped with electronics for electron ionization and positive ion chemical ionization, although this instrument does not currently have MS/MS capability. Instrument control for both instruments is provided by 386 or 486 -based PCs using standard software provided by Finnigan MAT Corporation. Menu-driven key-sequence programs and FORTH programs are being developed at ORNL for easier instrument operation and faster data reduction.

The DSITMS sample introduction system can be interfaced with either the laboratory or fieldable ion trap. This provides consistency with respect to experimental parameters and analytical methods regardless of which instrument is used. The sample introduction system (Figure 20) consists of a fixed-orifice open/split fused-silica capillary restrictor interface and sample inlet modules for real-time air monitoring, water and soil purging, and thermal desorption of sorbent tubes. The samnle modules have quickconnect fittings which enable them to be interchanged within 1 minute without having to vent the mass spectrometer. The vent port of the splitter provides a means of attaching sorbent tubes which can collect and archive up to $99 \%$ of the volatile analytes from a sample while the remaining $1 \%$ is monitored with the ion trap. The archived samples can be analyzed later using conventional thermal desorption GC/MS for confirmation.

For the analysis of water samples and soil slurries, a needle sparger that accepts standard $40 \mathrm{~mL}$ VOA vials is used. Samples are purged with helium at a flow of $100 \mathrm{~mL} / \mathrm{min}$ at ambient temperature. This efficiently purges most VOCs except for aldehydes, ketones, alcohols, and other highly water soluble compounds. The laboratory ion trap is typically operated in a mode that rapidly alternates ionization conditions between conventional electron ionization and water chemical ionization. The field instrument presently requires sequential analysis using different ionization conditions. Electron ionization provides fragmentation spectra and is universal for the detection of all compounds. Chemical ionization provides enhanced sensitivity for water soluble compounds and also provides molecular weight information that is useful for distinguishing between compounds which have similar electron ionization fragmentation patterns such as alkyl-benzenes. In cases where isobaric interferences are present due to compounds of the same molecular weight such as xylenes and ethyl-benzene, MS/MS can be used to distinguish them.
Real-time direct air monitoring of VOCs at low to mid ppbv levels and higher can be performed using a direct air sampling module. This module consists of a $2 \mathrm{~L} / \mathrm{min}$ air sampling pump, a throttle valve on the pump, a sample transfer line connector, and a mechanism for pulsing helium into the sample stream. The helium is required as a buffer gas inside ion traps to collisionally stabilize the ions and improve mass resolution. Electron ionization is typically used for air monitoring applications although positive ion chemical ionization can provide specificity and improved sensitivity for some analytes.

The thermal desorption module is used for the analysis of volatile or semi volatile compounds that have been preconcentrated on sorbent tubes. It is designed to accept sorbent tubes that are 0.25 inches in diameter and 3 inches long. The sorbent tubes may be packed with any material that is thermally stable at temperatures of up to $250 \mathrm{C}$. During desorption, helium is passed through the sorbent tube at a rate of between 10 and $100 \mathrm{~mL} / \mathrm{min}$. Desorption times range from 10 seconds to 1 minute depending on the nature of the analytes and the type of sorbent used. The ion trap is typically operated in electron ionization mode and the scan range is usually at least 20 amu above the highest expected mass.

Quantification of targeted compounds by DSITMS is similar for each mode of operation and involves the integration of the response for one or more characteristic ions for a specific compound over a time window, which may vary from a few seconds for thermal desorption up to 3 minutes for water purge. The integrated response is compared with a working curve generated from a series of standards. Calibration of the instrument for direct air sampling is best achieved through the use of certified gas standards that can be obtained commercially at concentrations down to approximately $1 \mathrm{ppb}$. 
HEIUM INLT

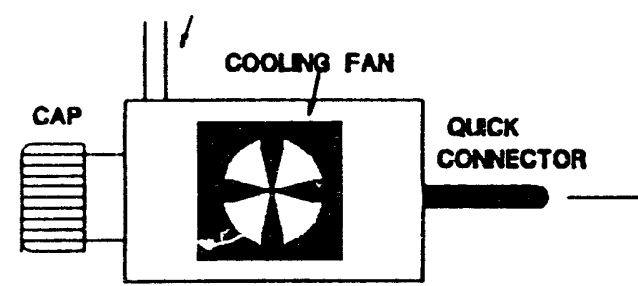

THERMAL DESORBER MODULE

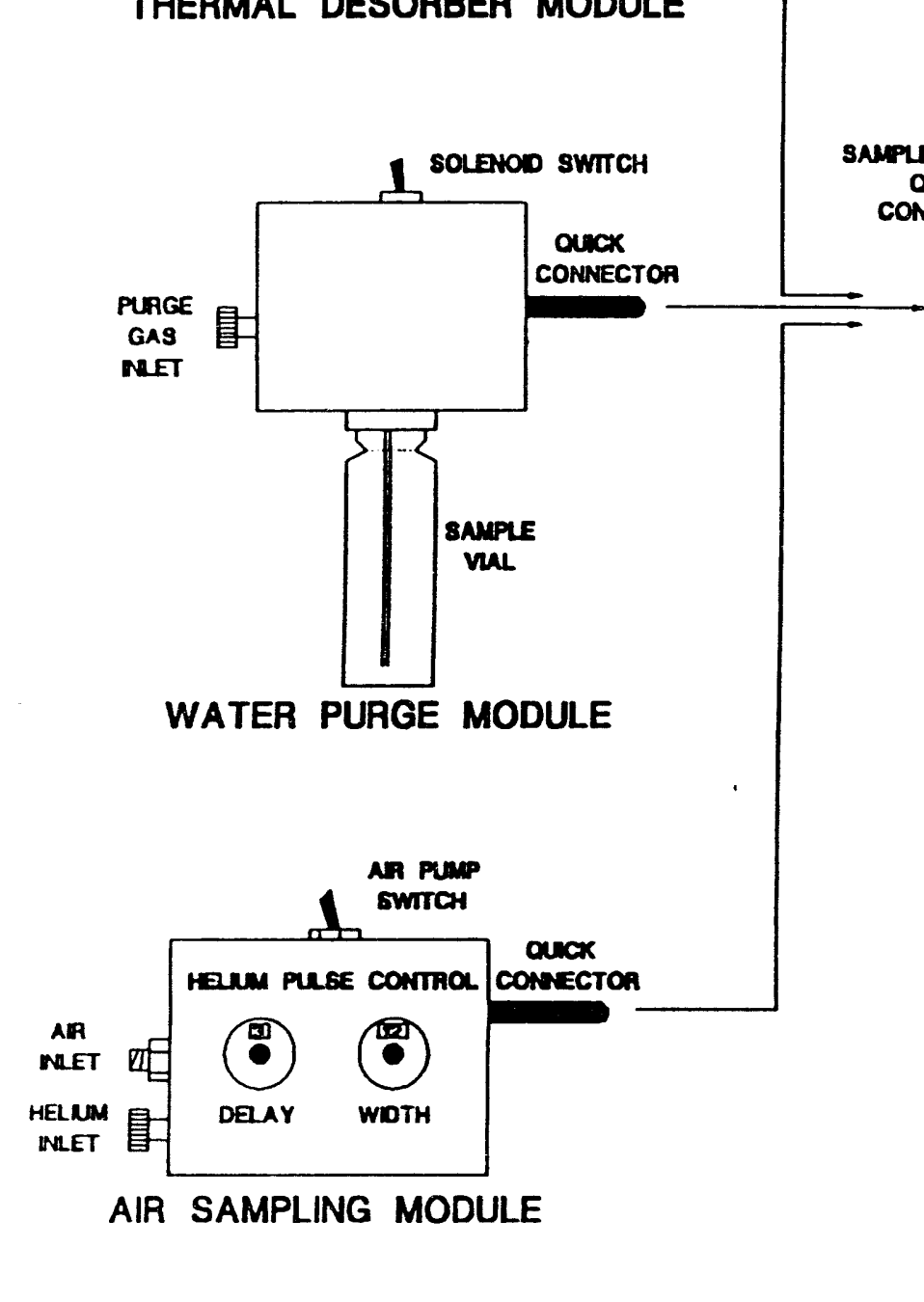




\section{Results}

Laboratory and field tests of the DSITMS have been quite successful, especially with respect to the analysis of VOCs in water samples and soil gas. Field tests at the SRIDS have been aimed primarily at the determination of trichloroethylene (TCE) and perchloroethylene (PCE) in a variety of different sample matrices. These field tests have successfully demonstrated the ability of the instrument to withstand vehicle transport, extreme environments, and versatile analytical performance of the DSITMS sample interface.

VOCs in Water: One of the most significant capabilities of the DSITMS is the ability to rapidly screen and/or quantify VOCs in water samples by direct purge into the ion trap. Method Detection Limits (MDLs) for the 34 VOCs on the EPA Target Compound List have been established using DSITMS and in most cases is less than 5 ppb. Analysis times are on the order of 3 to 4 minutes per sample, making it possible to screen or analyze large numbers of samples during a single working day. For example, during a field test at SRIDS, 52 groundwater samples were analyzed for TCE and PCE in approximately 2.5 hours. Sample throughput was approximately 24 samples per hour with simultaneous off-line data processing. Compared with EPA Method 8240 for VOCs in water, each analysis would have required 45 to 75 minutes, which clearly demonstrates the speed advantage of DSITMS. Table 2 is a comparison of some results for TCE in groundwater by field DSITMS and laboratory purge and trap GC and shows good comparison between the two techniques.

Table 2. Comparison of Results for TCE Analysis in Groundwater Samples Collected at the Savannah River Integrated Demonstration Site

\begin{tabular}{ccc} 
DSITMS & $\begin{array}{c}\text { Concentration in ng/ } \\
\text { (ppb) Sample \# } \\
\text { Laboratory EPA } \\
\text { Method }\end{array}$ & Field \\
\hline 1 & 64 & 63 \\
2 & 167 & 159 \\
3 & 257 & 254 \\
4 & 461 & 435 \\
5 & 738 & 666 \\
6 & 1,273 & 1,180 \\
7 & 9,000 & 4,178
\end{tabular}

VOCs in Soil Gas: Real-time air monitoring with the field DSITMS instrument was successfully accomplished at SRIDS during field testing of the instrumentation. Analyses conducted include the quantification of TCE and PCE in the headspace of groundwater wells, in soil gas using sampling tubes implanted in the vadose zone, and in the soil gas using a specially designed sampling head inserted at various depths in a vadose zone borehole. A 0.25 inch OD unheated teflon line was used as the sample transfer line in each case. The ion trap was located at a fixed location among the sampling weils and the length of the transfer line ranged from 100 feet to 350 feet in order to access various wells and the soil gas probes at the site. The throttle of the air sampling pump was adjusted to provide maximum flow through the tubing.

Sampling of the headspace of a groundwater well was accomplished by inserting the sample transfer line to the desired depth in the well and monitoring the response of the instrument for the presence of TCE and PCE. The mass spectrometer was continuously scanned over a range of 50 amu to $650 \mathrm{amu}$, and the real-time mass spectra were displayed along with a temporal profile of the response for $\mathrm{m} / \mathrm{z} 132$ (TCE) and $\mathrm{m} / \mathrm{z} 166$ (PCE) (Figure 21). Significant concentrations of other VOCs were not typically observed in the well headspace except near the surface, where alkyl aromatic compounds from vehicle exhaust were sometimes found to be present. Quantification of the TCE and PCE in the headspace air was determined by measuring the response relative to that of a 1 ppmv certified standard prepared in nitrogen. The concentrations of TCE and PCE were typically found to be in the low ppmv range in the headspace of the groundwater wells sampled. The realtime monitoring capability of DSITMS makes it possible to quickly and easily generate depth profiles of well headspace or soil gas strata depending on the type of well casing and sampling probe used. 


\section{Real-Time Measurement of VOCs in Air TCE and PCE in Well Headspace}

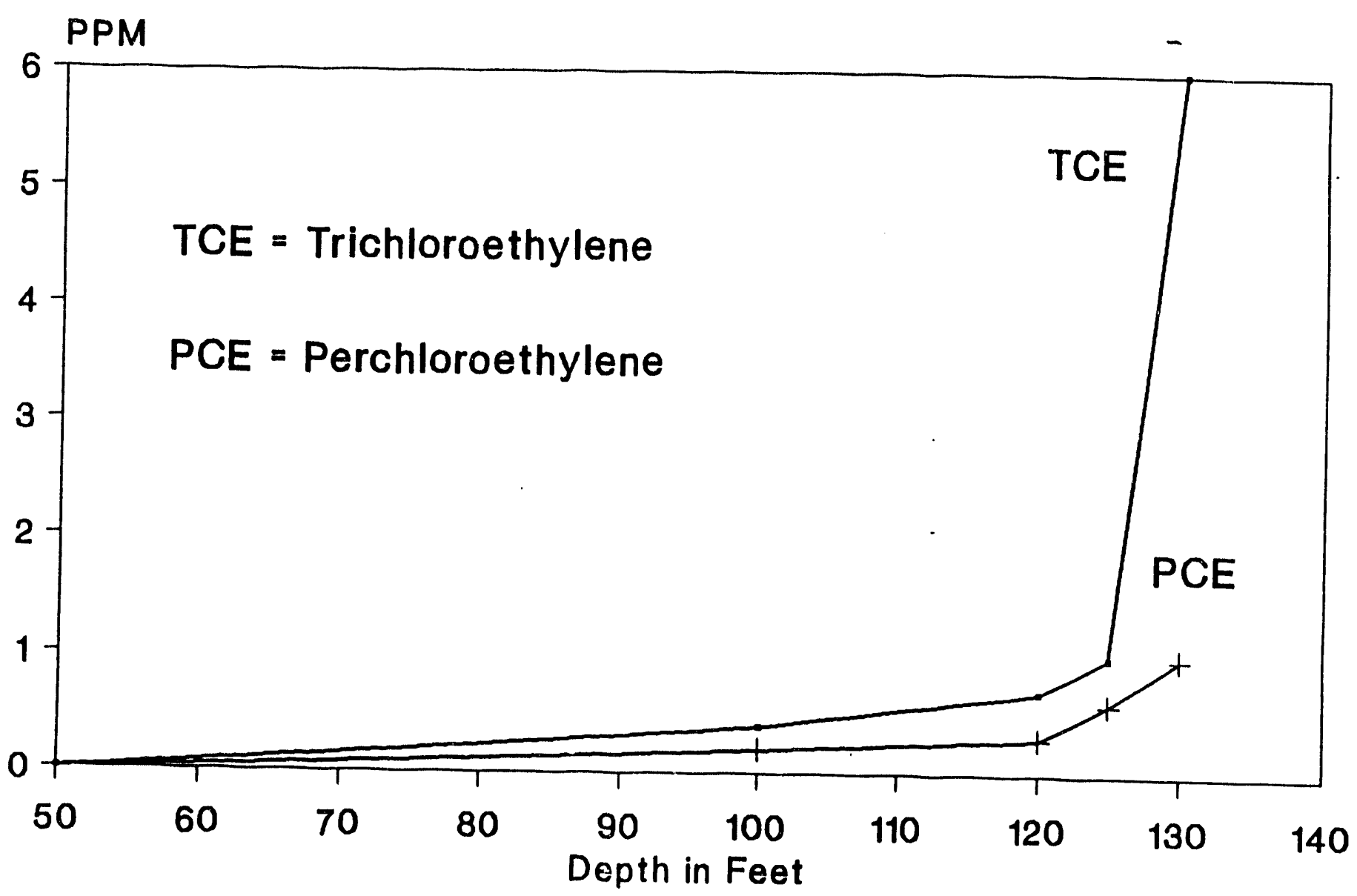

Figure 21. Real time Measurements of TCE and PCE in Well Headspace 


\section{Conclusions}

DSITMS has been successfully demonstrated in the laboratory and in the field for a variety of real-world applications including the determination of VOCs in soil gas, VOCs in groundwater and soil slurries, and target semi volatile organics in air and water. The ruggedness of the instrumentation has been demonstrated repeatedly in the field and very little adverse effects have been noted from the transport in the vehicle or extreme environmental conditions. Field testing has demonstrated the ability to quickly and easily convert the ion trap from one sampling mode to another using the quick connect sample modules. Hardware improvements are continuously being made as feedback is received from other users of the technology. For many applications, it is expected that DSITMS will provide the cost savings $75 \%$ or more compared with conventional laboratory analysis, resulting in considerable savings over long-term use. Furthermore, the high sample throughput for field screening can provide enhanced site characterization and additional cost savings by greatly reducing the number of non-contaminated samples submitted for full laboratory analysis.

Additional information on this work can be found in publication by Wise, Guerin, and Henricksen listed in the Bibliography. 


\section{Summary}

A number of innovative monitoring technologies have been demonstrated at the Savannah River Integrated Demonstration Site. These technologies have addressed the measurement of both physical and chemical parameters related to subsurface characterization and monitoring as well as in situ sampling methods. Several different platforms were targeted for the deployment of these sensors including placement directly in the subsurface, in wells, and at the surface. Many of the technologies are licensed to private industry and all are mature enough to begin technology transfer and to initiate progress toward regulatory acceptance. Not only are several of the technologies cost competitive with existing technologies, but they can provide information that is not obtainable by the existing methods.

The following three categories of instruments have been demonstrated as part of the DOE's OTD integrated demonstrations:

- instruments that monitor physical parameters by measuring surrogate parameters (i.e., colloidal particle movement for groundwater flow; electrical resistivity or seismic velocity for saturation changes).

- instruments that sample the subsurface with minimal invasiveness

- instruments that analyze chemical concentration in the vapor, liquid, or solid phases 
Table 3 provides an overview of the technologies developed as part of the Savannah River Integrated Demonstration.

Table 3. Overview of Technologies Developed as part of the Savannah River Integrated Demonstration Program

\begin{tabular}{|c|c|c|c|c|c|c|}
\hline Technology & Type & Platform & Niche & Issues & $\begin{array}{l}\text { Maturity/Labor } \\
\text { Level. }\end{array}$ & $\begin{array}{c}\text { Cost: } \\
\text { Instr., } \\
\text { Consumables. }\end{array}$ \\
\hline Flow Sensor & Physical & Borehole & $\begin{array}{l}\text { Dynamic, 3-D } \\
\text { flow direction }\end{array}$ & Sensitivity & $\begin{array}{c}\text { Negotiations under } \\
\text { way with commercial } \\
\text { producer. } \\
\text { I Technician. }\end{array}$ & $\begin{array}{l}\$ 5,000,8 \mathrm{hrs} \text { Com. } \\
\text { puter timel } \\
\text { measurement. }\end{array}$ \\
\hline $\begin{array}{l}\text { Seismic } \\
\text { Tomography }\end{array}$ & Physical & $\begin{array}{l}\text { Steel-cased } \\
\text { borehole }\end{array}$ & $\begin{array}{l}\text { 3-D geologic infor- } \\
\text { mation and moisture } \\
\text { content }\end{array}$ & $\begin{array}{l}\text { Sensitivity and } \\
\text { interferences }\end{array}$ & $\begin{array}{l}\text { Partially transferred } \\
\text { to commercial } \\
\text { producer. technician }\end{array}$ & \\
\hline $\begin{array}{l}\text { Electrical } \\
\text { Resistivity } \\
\text { Tomography }\end{array}$ & Physical & Borehole & $\begin{array}{l}\text { 3-D geologic infor- } \\
\text { mation } \\
\text { and moisture content }\end{array}$ & $\begin{array}{l}\text { Sensitivity and } \\
\text { interferences }\end{array}$ & $\begin{array}{l}\text { Negotiations under } \\
\text { way with commercial } \\
\text { organization to pro- } \\
\text { vide service. }\end{array}$ & $\begin{array}{l}\$ 10,000-20,000 \text { per } \\
\text { deployment. }\end{array}$ \\
\hline $\begin{array}{l}\text { Colloidal } \\
\text { Borescope }\end{array}$ & $\begin{array}{l}\text { Physical, } \\
\text { flow }\end{array}$ & Well & $\begin{array}{l}\text { Discrete, } 2-D \\
\text { groundwater flow } \\
\text { direction, magnitude } \\
\text { in single well }\end{array}$ & $\begin{array}{l}\text { Magnitude of } \\
\text { velocity }\end{array}$ & $\begin{array}{l}\text { Commercially } \\
\text { available. } \\
\text { I Technician. }\end{array}$ & $\begin{array}{c}\$ 20,000 \\
2 \text { hrs computer timel } \\
\text { measurement. }\end{array}$ \\
\hline $\begin{array}{l}\text { Multilevel } \\
\text { mechanical } \\
\text { sampler }\end{array}$ & $\begin{array}{l}\text { Liquid } \\
\text { samples }\end{array}$ & Well & $\begin{array}{l}\text { Multilevel water } \\
\text { sampling }\end{array}$ & $\begin{array}{l}\text { Effects of } \\
\text { instrument on } \\
\text { measurement. }\end{array}$ & $\begin{array}{c}\text { Negotiations under } \\
\text { way with commercial } \\
\text { producer }\end{array}$ & \\
\hline $\begin{array}{l}\text { Multilevel } \\
\text { membrane } \\
\text { sampler }\end{array}$ & $\begin{array}{l}\text { Liquid } \\
\text { samples }\end{array}$ & Well & $\begin{array}{l}\text { Discrete-level } \\
\text { specific discharge } \\
\text { measurements } \\
\end{array}$ & $\begin{array}{l}\text { Effects of } \\
\text { instrument on } \\
\text { measurement }\end{array}$ & $\begin{array}{l}\text { Negotiations under } \\
\text { way with commercial } \\
\text { producer }\end{array}$ & \\
\hline $\begin{array}{l}\text { Arrayed } \\
\text { Sampler }\end{array}$ & $\begin{array}{l}\text { Vapor } \\
\text { samples }\end{array}$ & $\begin{array}{l}\text { Well, } \\
\text { offgas }\end{array}$ & $\begin{array}{l}\text { Discrete-level vapor } \\
\text { sampling for volatile } \\
\text { compounds }\end{array}$ & Precision & $\begin{array}{l}\text { Negotiations under } \\
\text { way with commercial } \\
\text { producer. } \\
1 \text { Technician. }\end{array}$ & $\begin{array}{c}\$ 1,000 \\
\text { Thermal desorption } \\
\text { analysis. }\end{array}$ \\
\hline $\begin{array}{l}\text { Fiber optic } \\
\text { TCE Sensor }\end{array}$ & $\begin{array}{l}\text { Chemical, } \\
\text { vapor }\end{array}$ & Well, CPT & $\begin{array}{l}\text { True in situ } \\
\text { measurements of } \\
\text { TCE to below the } \\
\text { drinking water } \\
\text { standard }\end{array}$ & $\begin{array}{l}\text { Long-term } \\
\text { emplacement }\end{array}$ & $\begin{array}{l}\text { Commercial proto- } \\
\text { type available. } \\
1 \text { technician. }\end{array}$ & $\begin{array}{l}\$ 15,000-30,000 \\
\text { Reagent- } \$ 1 \\
\text { per analysis. }\end{array}$ \\
\hline PAWS & $\begin{array}{l}\text { Chemical, } \\
\text { vapor }\end{array}$ & Offgas & $\begin{array}{l}\text { Continuous acoustic } \\
\text { wave } \\
\text { sensing of chlori- } \\
\text { nated organics } \\
\text { in extraction systems }\end{array}$ & Selectivity & $\begin{array}{c}\text { License } \\
\text { negotiations under } \\
\text { way. } \\
\text { I Technician. }\end{array}$ & $\begin{array}{c}\$ 2,000-5,000 \\
\text { No } \\
\text { Consumables. }\end{array}$ \\
\hline HaloSnifTM & $\begin{array}{l}\text { Chemical, } \\
\text { vapor }\end{array}$ & Offgas & $\begin{array}{l}\text { Wide dynamic range, } \\
\text { atomic emission- } \\
\text { based sensor for } \\
\text { chlorinated vapors }\end{array}$ & Selectivity & $\begin{array}{c}\text { Patented, Commer- } \\
\text { cial prototype avail- } \\
\text { able. } \\
\text { I Technician. }\end{array}$ & $\begin{array}{c}\$ 10-15,000 \\
\text { He gas }-40 \mathrm{mV} / \mathrm{min}\end{array}$ \\
\hline DSITMS & $\begin{array}{l}\text { Chemical, } \\
\text { vapor, } \\
\text { solid, } \\
\text { liquid }\end{array}$ & $\begin{array}{l}\text { Samples, } \\
\text { offgas }\end{array}$ & $\begin{array}{l}\text { Direct sampling of } \\
\text { volatile organics in } \\
\text { solid, liquid, and } \\
\text { vapor samples in } \\
\text { real time }\end{array}$ & Portability & $\begin{array}{l}\text { EPA equivalency } \\
\text { testing under way. } \\
1 \text { highly trained tech- } \\
\text { nician. }\end{array}$ & $\begin{array}{l}\text { \$112,000. } \\
\text { \$30/sample. }\end{array}$ \\
\hline
\end{tabular}




\section{Physical Parameter Technologies}

Of the four instruments tested in this category, two measured flow velocity and direction and two measured subsurface moisture content and gross geologic structure by inference.

The in situ permeable flow sensor developed by SNL successfully measured flow velocity using a technique that analyzes the change in an induced temperature distribution around a device emplaced directly into the subsurface by hollow stem auger drilling. The change in temperature distribution caused by groundwater flow past the device can be related to the direction and magnitude of the groundwater flow velocity.

The geological structure and moisture content of the plane formed between two vertical wells was analyzed using multipoint seismic techniques and tomographic processing by researchers from SNL. This minimally invasive technique enables researchers to non-destructively image the subsurface.

Multipoint electrical resistivity measurements performed by LLNL also enabled the re-creation of subsurface planes by tomographic analytical techniques. The use of this technology, in conjunction with the SNL seismic technique, produces higher resolution images of subsurface geologic and hydrogeologic structure.

The colloidal borescope, a video camera that was lowered into wells at the SRIDS, is designed to image sub-micronsized particles present in the subsurface groundwater flow field at a discrete level. By analyzing the recorded video images of the direction and speed of the particles in the well bore, the magnitude and direction of groundwater flow in the aquifer can be inferred. This technique was developed at ORNL-Grand Junction.

\section{Sampling Technology}

Of the three samplers demonstrated, one sampled gas and two obtained liquid samples.

The arrayed sampler developed at ORNL was used to collect vapor samples under ambient conditions at discrete depths in vadose zone wells at the SRIDS. This sampler incorporates six solenoid controlled ports where subsurface air is passed through individual carbon traps under low flow rates to avoid disturbing steady-state subsurface conditions. The carbon traps are later analyzed at the surface for many compounds by conventional laboratory methods or using the DSITMS.
BNL developed two multilayer groundwater monitoring and sampling devices. The mechanical sampler was used to collect depth-discrete liquid samples in wells at the SRIDS. These samples were then analyzed by conventional means, and depth profiles of water quality parameters were constructed. The device obtains samples using remotely operated stainless steel cylinders connected along the vertical axis. The membrane sampler was used to obtain depth-discrete, horizontal specific discharge data at the SRIDS. The sampler uses a borehole dilution type technique through the membranes and employs deuterium or $\mathbf{1 8 0}$ depleted water as a tracer. Both devices can collect data simultaneously at small vertical intervals in the same well without disturbing the geohydrological environment.

\section{Chemical Analysis Technologies}

Of the four instruments tested in this category, one was TCE selective, two were sensitive to chlorinated organics, and one was mass selective.

A fiber optic sensor developed at LLNL for vapor-phase TCE detection using a reagent-based method was tested in two different configurations at the SRIDS. The first configuration deployed the sensor in a well at depth using inflatable packers to seal a specific zone; the second involved placing the sensor in a cone penetrometer to obtain true in situ, subsurface measurements of ambient vapor-phase concentrations of TCE. This sensor is capable of obtaining measurements below corresponding drinking water standard concentrations.

An inexpensive, real time, reversible sensor for monitoring contaminant offgas concentrations using an acoustic wave device was tested by measuring CVOC concentrations in the offgas of the horizontal vacuum extraction well. The PAWS system, developed at SNL, uses a chemically sorbent coating to detect responses from chemical species. The sensor has detection limits in the low ppm for TCE and PCE.

An atomic emission-based sensor developed at PNL for the detection of chlorinated vapors was used to monitor offgas from the horizontal extraction wells and gas samples taken from vadose zone wells at the SRIDS. The HaloSnif ${ }^{\text {MM }}$ uses a radio frequency-induced helium plasma to probe for concentrations of chlorinated compounds in a vapor sample. Depth-discrete samples are obtained from vadose zone wells with an inflatable packer assembly and vacuum pump. The HaloSnif ${ }^{\mathrm{m}}$ is functionally similar to SNL's PAWS systern.

The direct sampling ion trap mass spectrometer (DSITMS) developed at ORNL was used to analyze vapor, liquid, and 
solid samples at the SRIDS. The instrument has three modular sample introduction assemblies, which allow for analysis of vapor-phase samples directly, water and soil samples by helium purging, and samples obtained on a carbon trap by thermal desorption. The DSITMS is being used in a monitoring sample reduction program at SRS.

\section{Other Technologies}

Fiber optic temperature sensors developed by researchers at SRTC permitted real-time monitoring of subsurface temperatures during an in situ heating experiment using radio frequency energy. The sensors are immune to the electromagnetic interferences that ordinary temperature sensors are susceptible to.

A commercially available, solid-state sensor for detecting vapor-phase concentrations of CVOCs was used to monitor offgas at the SRIDS. PNL demonstrated this technology concurrently with the HaloSnifm experiments. The Transducer Research Incorporated (TRI) TOCl sensor reacts to contaminant concentrations by an electrical conductivity change.

Although not officially part of the Non-Arid Site Integrated Demonstration Program, the following sensors were also tested at the SRIDS:

- Portable GC-MS produced commercially by Viking Instruments (this instrument was recently purchased by SRS following a demonstration)

- Aqueous-phase fiber optic sensor for CVOCs developed by researchers from LLNL and the Nuclear Research Center at Karlsruhe

- Fiber optic absorption based nitrate/nitrite sensor developed by SRTC

- Fiber optic probe for DNAPL using Raman spectroscopy developed by LLNL

- Membrane-based gas sampler developed by USATHAMA

- Infrared, photoacoustic, spectrometer-based vapor analysis system commercially produced by Bruel and Kjaer and demonstrated by researchers at Ames Lab (This instrument was purchased by SRS following a demonstration).

A description of these sensors and the results of their experiments will be included in the summary report on monitoring technologies demonstration at the SRIDP.

\section{Technology Status}

Most of the technologies described in this report are in the final stages of field deployment. This step involves the transfer of field-tested, prototype technologies to SRS personnel for long-term testing and evaluation. Further development of the technologies based on the results from the initial field trials is also planned for several of the technologies. Those technologies that have not concluded commercial licensing agreements are actively seeking these. The transfer to the commercial sector will be facilitated by publication of both short- and long-term data on the performance of the technologies.

\section{Field Use Issues}

A critical issue in the use of field characterization and monitoring technologies is the ease of installation and daily operation of the particular instrument. Since all of the technologies tested were prototypes it is difficult to project this factor for the commercial version of the instrument. However, this issue will be significant in the execution of technical transfer of the technology to industry.

\section{Acquisition and Use of Data}

In addition to the accumulation of monitoring or characterization data, it is necessary to process this data to assess a contaminated site or the progress of a remediation effort. For the project manager it is very difficult to assimilate all the data from a hazardous waste site undergoing characterization, restoration, or monitoring. Therefore, it is essential that we have methods for data acquisition and graphical visualization that not only simplify site decisions, but also allow the project manager to make those decisions quickly and with little risk. Complete characterization and monitoring often requires multi-dimensional, graphical representation of data. Advances in the field of scientific visualization and animation will improve the interpretation of complex three-dimensional modeling of data. These methods will provide scientists, engineers, and managers with powerful tools for visualizing and monitoring complex hydrogeological and restoration phenomena and processes. This is especially true using real-time sensors for monitoring in situ restoration processes. Knowledge can then be applied to obtain optimal site restoration design and to maintain restoration process control to provide greatest efficiency and economy. 
Innovative Monitoring Technologies at the Savannah River Integrated Demonstration Site

\section{References}

Carslaw, H. S. and J. C. Jaegar. 1959. Conduction of Heat in Solids, 2nd ed., Clarendon Press, Oxford.

Daily. W. D., and A. L. Ramirez 1989, "Evaluation of Geophysical Tomography to Map In situ Water in Heated Welded Tuff", Water Resources Research 25(6), 1083-1096.

Drost, W., D. Klotz, A. Koch, H. Moser, F. Neumaier, and W. Rauert. 1968. Point Dilution Methods of Investigating Groundwater Flow by Means of Radioisotopes. Water Resources Research. 4(1): 125-146.

Eddy, C. A., B. B. Looney, and D. S. Kaback. 1992. "Comparison of Innovative Depth Discrete Sampling Technologies for Sediments and Groundwater for Environmental Characterization." Proceedings of the 1992 Waste Management and Environmental Sciences Conference, Puerto Rico, p. 124-133.

Eddy, C. A., B. B. Looney, J. M. Dougherty, T. C. Hazen, and D. S. Kaback. 1991. "Characterization of the Geology, Geochemistry, Hydrology and Microbiology of the In-situ Air Stripping Demonstration Site at the Savannah River Site." Westinghouse Savannah River Company, WSRC-RD-91-21.

Elbring, G. J. 1992. "Crosshole Shear-Wave Seismic Monitoring of an Air Stripping Waste Remediation Process." SAND91-2742, Sandia National Laboratories, Albuquerque, New Mexico.

Grisak, G. E., W. F. Merritt, and D. W. Williams. 1977. A Fluoride Borehole Dilution Apparatus for Groundwater Velocity Measurements. Canadian Geotechnica! J., 14: 554-561.

Halevy, E., H. Moser, O. Zellhofer, and A. Zuber. 1967. Borehole Dilution Techniques: A Critical Review. Isotopes is Hydrology, IAEA, Vienna, 531-564.

Hazen, T. C. 1992. "Tst Plan for In Situ Bioremediation Demonstration of the Savannah River Integrated Demonstration Project DOE/OTD TTP No.:SR056601 (U). WSRC-RD-91-23. Westinghouse Savannah River Company, Aiken, SC.

Hess, A. E. 1986. Identifying Hydraulically Conductive Fractures with a Slow-velocity Borehole Flowmeter. Can. Geotech J., 23: 69-78.

Kaback, D. S., B. B. Looney, J. C. Corey, L. M. Wright, and J. L. Steele. 1989. "Horizontal Wells for in Situ Remediation of Groundwater and Soils." National Water Well Association Third Outdoor Action Conference Proceedings, Orlando, FL.

Kerfoot, W. B. 1988. Monitoring Well Construction and Recommended Procedures for Direct Groundwater Flow Measurements using a Heat-pulsing Flowmeter.
Groundwater Contamination: Field Methods. eds., A. G. Collins and A. I. Johnson. 146-161. ASTM.

Looney, B. B., C A. Eddy, and W. R. Sims. 1993. "Evaluation of Headspace Method for Volatile Constituents in Soils and Sediments." Proceedings of the National Symposium on Measuring and Interpreting VOC's in Soils: State of the Art and Research Needs, Las Vegas, Nevada. 8 p.

Looney, B. B., D. S. Kaback, and J. C. Corey. 1991/1992. "Field Demonstration of Environmental Restoration Using Horizontal Wells." Third Forum on Innovative Hazardous Waste Treatment Technologies: Domestic and International, Dallas TX (EPA); Waste Management '91 Conference (DOE), Tucson AZ; Live Satellite Seminar sponsored by Air and Wasta Management Association.

Looney, B. B., J. Rossabi, D. M. Tuck, C. L. Bergren, R. Van Pelt, W. E. Jones, A. E. Stevenson, and B. S. Kristiansen. 1992. "Assessing DNAPL Contamination, AM Area, Savannah River Site: Phase I Results (U)." WSRC-RP-1302. Westinghouse Savannah River Company, Aiken, SC. pp. 1-85.

Looney, B. B., T. C. Hazen, D. S. Kaback, and C. A. Eddy. 1991. "Full Scale Field Test of the In Situ Air Stripping Process at the Savannah River Integrated Demonstration Test Site (U). WSRC-RD-91-22. Westinghouse Savannah River Company, Aiken, SC.

Marine, I. W. and H. W. Bledsoe, 1984. "M-Area Groundwater Investigation (Supplemental Technical Data Summary). Savannah River Laboratory Report DPSTD-84-112.Savannah River Plant, Aiken, SC.

Maskarinec, M. P., C. K. Bayne, R. A. Jenkins, L. H. Johnson, and S. K. Holladay, "Stability of Volatile Organics in Environmental Soil Samples - Final Report" ORNL/TM 12128, November 1992, Available from the National Technical Information Service, Springfield, VA 22 161

Moltz, F. J., R. H. Morin, A. E. Hess, J. G. Melville, and O. Guven. 1989. The Impeller Meter for Measuring Aquifer Permeability Variations: Evaluation and Comparison with other Tests. Water Resources Research. 25(7): 1677-1683.

Momii, K., K. Jinno, and F. Hirano. 1993. Laboratory Studies on a New Laser Doppler Velocimeter System for Horizontal Groundwater Velocity Measurements in a Borehole. Water Resources Research. 29(2): 283291.

Ramirez, A. L., W. D. Daily, and D. LaBrecque. 1992. "Electrical Resistance Tomography Used in Environmental Restoration." Lawrence Livermore National Lab, UCRL-JC-110356, Livermore, CA, Proceedings of the Information Exchange Meeting on Characterization, Sensors, and Monitoring Technologies, Dallas, TX, sponsored by US DOE. 
Rossabi, J. 1993. "The Savannah River Technology Center Environmental Monitoring Field Test Platform." Proceedings of the Third International Symposium-Field Screening Methods for Hazardous Waste and Toxic Chemicals, Las Vegas, Nevada.

Walton, T. L. 1991. "Integrated Demonstration for Cleanup of Organics in Soils and Groundwater at Non-Arid Sites." IDP-0566.

Wheatcraft, S. W. and F. Winterberg. 1985. Steady State Flow Passing through a Cylinder of Permeability Different from the Surrounding Medium. Water Resources Research. 21(12): 1923-1929. 


\section{Bibliography}

"Demonstration of a Utility Industry Horizontal Drilling System: Horizontal Well AMH-5 Installation Report." 1993. WSRC-TR-93-008.

"Demonstration of a Utility Industry Horizontal Drilling System: Horizontal Well AMH-5 Installation Report." 1993. WSRC-TR-93-008.

"Demonstration of Eastman Christensen Horizontal Drilling System Integrated Demonstration Site Savannah River Site." 1992. WSRC-TR-92-577.

"Demonstration of Eastman Christensen Horizontal Drilling System Integrated Demonstration Site Savannah River Site." 1992. WSRC-TR-92-577.

"Demonstration of River Crossing Technology for Installation of Environmental Horizontal Wells: AMH-6 and AMH-7 Installation Report." 1993. WSRC-TR93-387.

"Summary Report of the Drilling Technologies Tested at the Integrated Demonstration Site." 1993.

"Summary Report of the Drilling Technologies Tested at the Integrated Demonstration Site." 1993.

"The Summary of National Environmental Needs." 1993. WSRC-TR-93-388.

Andrews, G. F., S. G. Hansen, and W. C. Downs. 1993. "The Rate of TCE Degradation by Indigenous Methanotrophic Bacteria at the Savannah River Site." [abs] Invited Seminar Speaker, In Situ and On-Site Bioreclamation, The Second International Symposium, San Diego, CA. (paper in press).

Ballard, S. 1992 “An In Situ Permeable Sensor to Monitor Groundwater Flow." Sensors, 9(13): 20.

Ballard, S. 1992 "An In Situ Permeable Sensor to Monitor Groundwater Flow." Sensors, 9(13): 20.

Ballard, S. 1992. "In Situ Permeable Flow Sensors at the Savannah River Integrated Demonstration: Phase I Results." SAND92-1952, Sandia National Laboratories, Albuquerque, New Mexico.

Ballard, S. 1992. "In Situ Permeable Flow Sensors at the Savannah River Integrated Demonstration: Phase I Results." SAND92-1952, Sandia National Laboratories, Albuquerque, New Mexico.

Ballard, S. 1992. "Monitoring Groundwater Flow Around an Air-Stripping Waste Remediation Experiment at the Savannah River Site, SC." AGU 1992 Fall Meeting Program and Abstracts, p. 165.

Ballard, S. 1992. "Monitoring Groundwater Flow Around an Air-Stripping Waste Remediation Experiment at the Savannah River Site, SC." AGU 1992 Fall Meeting Program and Abstracts, p. 165.
Ballard, S., M. Thompson, L. Romero. 1991. "A New Device for the In-Situ Measurement of Groundwater Flow Velocity." AGU 1991 Fall Meeting Program with Abstracts, p. 216.

Ballard, S., M. Thompson, L. Romero. 1991. "A New Device for the In-Situ Measurement of Groundwater Flow Velocity." AGU 1991 Fall Meeting Program with Abstracts, p. 216.

Bentley, H., and B. I. Travis. 1991. "Modeling In-Situ Biodegradation in Unsaturated and Saturated Soils." Proceedings of US-EPA Symposium on Soil Venting, Houston, TX

Bergsman, T. M., J. S. Roberts, D. L. Lessor, and W. O. Heath. 1993. "Field Test of Six Phase Heating and Evaluation of Engineering Design Code." PNL-SA21537, Pacific Northwest Laboratory, Richland, WA 99352.

Bergsman, T. M., J. S. Roberts, D. L. Lessor, and W. O. Heath. 1993. "Six Phase Soil Heating to Enhance Removal of Contaminants." PNL-SA-21709, Pacific Northwest Laboratory, Richland, WA 99352.

Berry*, C. J., T. C. Hazen, M. M. Franck and J. Rossabi. 1993. "Methanotrophic Treatment of Contaminated Well Water Using a Pilot Scale Bioreactor." [abs] In Situ and On-Site Bioreclamation, The Second International Symposium, San Diego, CA. (paper in press).

Berry, C. J., M. M. Franck, K. Lombard, and C. B. Fliermans. "Degradation of Polycyclic Aromatic Hydrocarbons in Discarded Railroad Crossties." [abs].

Borthen, J., F. Meyer, K. Lombard, and T. Hazen. "Catalytic Oxidation of Trichloroethylene and Perchloroethylene Mixtures." AIChE 1993 Summer National Meeting, Control and Measurement of VOC Emissions.

Bowman, J. P., L. Jiminez, I. Rosario, T. C. Hazen, and G. S. Sayler. 1993. "Characterization of the Methanotrophic Bacterial Communities Present in a Trichloroethylene Contaminated Subsurface Groundwater Site." Appl. Environ. Microbiol. 59(8).

Bowman, J., L. Jimenez, I. Rosario, and G. S. Sayler. "Methanotrophic Bacteria from Contaminated Subsurface Sites: Characterization, Soluble Methane Monooxygenase Activity, Gene Probe Analysis, and TCE Degradation Studies." (In preparation)

Bratina, B. J., G. A. Brusseau and R. S. Hanson. 1992. "Use of 16S rRNA Analysis to Investigate the Phylogeny of Methylotrophic Bacteria." Int. J. Systematic Bacteriol. 42: 645-648.

Brockman, F. J., D. Workman, W. Sun, and A. Ogram. 1993. "Baseline Characterization of TCE Degradative Potential by Enrichment Techniques and DNA Probe Analysis." Abstracts of the Second International Symposium on In Situ and On Site Bioreclamation. 
Brockman, F. J., W. Sun, A. Ograrn, W. Payne, and D. Workman. 1993. "Baseline Characterization and Remediation-Induced Changes in TCE Degradative Potential Using Enrichment Techniques and DNA Probe Analysis." in press, In Situ Bioremediation.

Brookshire, D. S. and M. McKee. 1992. "A Conceptual Framework for Conducting Cost-Effectiveness Analysis of Competing Groundwater Contamination Remediation Strategies." (Report submitted to Linda Trocki, AET, LANL). LA-UR 92-3633, 9/1992. I strategies, (Report submitted to Linda Trocki, AET, LANL).

Brusseau, G. A., E. S. Bulygina and R. S. Hanson. 1993. "Phylogenetic Analysis and Development of Probes for Differentiating Methylotrophic Bacteria." Appl. Environ. Microbiol. (Submitted).

Carslaw, H. S. and J. C. Jaegar. 1959. Conduction of Heat in Solids, 2nd ed., Clarendon Press, Oxford.

Cernosek, R. W., G. C. Frye and D. W. Gilbert. 1993. "Portable Acoustic Wave Sensor Systems for RealTime Monitoring of Volatile Organic Compounds." Proc. ISE.

Cernosek, R. W., G. C. Frye and D. W. Gilbert. 1993. "Portable Acoustic Wave Sensor Systems for RealTime Monitoring of Volatile Organic Compounds." Proc. ISE.

Colston, Jr., B. W., S. B. Brown, P. F. Daley, K. Langry, F. P. Milanovich. 1992. "Monitoring Remediation of Trichloroethylene Using a Chemical Fiber Optic Sensor: Field Studies." in Proceedings of the International Topical Meeting on Nuclear and Hazardous Waste Management. 1: 393-396.

Colston, Jr., B. W., S. B. Brown, P. F. Daley, K. Langry, F. P. Milanovich. 1992. "Monitoring Remediation of Trichloroethylene Using a Chemical Fiber Optic Sensor: Field Studies." in Proceedings of the International Topical Meeting on Nuclear and Hazardous Waste Management. 1: 393-396.

Daily, W. D. and A. L. Ramirez, Electrical Resistance Tomography During In Situ TCE Remediation at the Savannah River Site, Lawrence Livermore National Laboratory, UCRL JC-112326, Livermore, CA. 1993.

Daily, W. D., and A. L. Ramirez 1989, "Evaluation of Geophysical Tomography to Map In situ Water in Heated Welded Tuff", Water Resources Research 25(6), 1083-1096.

Daily, W., A. Ramirez, D. LaBrecque and J. Natio, Electrical Resistivity Tomography of Vadose Water Movement, Water Resources Research, vol. 28, no. 5, pp 1429-1442, 1992.

Dougherty*, J. M., C. J. Berry, M. M. Franck, and T. C. Hazen. 1993. "Characterization of the Subsurface Microbial Community from a Trichloroethylene Contaminated Site." [abs] In Situ and On-Site Biorecla- mation, The Second International Symposium, San Diego, CA. (paper in press).

Dougherty*, J. M., M. M. Franck, C. B. Fliermans, and T. C. Hazen. 1992. "Characterization of the Subsurface Microbial Community from a Trichloroethylene Contaminated Site." American Society for Microbiology Annual Meeting, New Orleans, LA.

Drost, W., D. Klotz, A. Koch, H. Moser, F. Neumaier, and W. Rauert. 1968. Point Dilution Methods of Investigating Groundwater Flow by Means of Radioisotopes. Water Resources Research. 4(1): 125-146.

Eckenrode, B. A. and B. Owens. 1992. "On Site Well Screening with a Transportable GC/MS System." Environmental Lab 4(1): 42.

Eckenrode, B. A., B. Owens, and J. Rossabi. 1992. "On Site Well Screening with a Transportable GC/MS System." Environmental Lab 4(1): 42.

Eddy, C. A. and B. B. Looney. 1992. "Three-Dimensional Imaging of Environmental Data: Optimal Selection of Gridding Parameters for Volumetric Calculations." [abs]: EOS Transactions of the American Geophysical Union. 73(43): 230.

Eddy, C. A. and B. B. Looney. 1992. "Three-Dimensional Imaging of Environmental Data: Optimal Selection of Gridding Parameters for Volumetric Calculations." [abs]: EOS Transactions of the American Geophysical Union. 73(43): 230.

Eddy, C. A. and B. B. Looney. 1993. "Three Dimensional Digital Imaging of Environmental Data: Selection of Gridding Parameters." International Journal of Geographic Information Systems. 7(2): 165-172.

Eddy, C. A. and B. B. Looney. 1993. "Three Dimensional Digital Imaging of Environmental Data: Selection of Gridding Parameters." International Journal of Geographic Information Systems. 7(2): 165-172.

Eddy, C. A., B. B. Looney, and D. S. Kaback. 1992. "Comparison of Innovative Depth Discrete Sampling Technologies for Sediments and Groundwater for Environmental Characterization." Proceedings of the 1992 Waste Management and Environmental Sciences Conference, Puerto Rico, p. 124-133.

Eddy, C. A., B. B. Looney, and D. S. Kaback. 1992. "Comparison of Innovative Depth Discrete Sampling Technologies for Sediments and Groundwater for Environmental Characterization." Proceedings of the 1992 Waste Management and Environmental Sciences Conference, Puerto Rico, p. 124-133.

Eddy, C. A., B. B. Looney, J. M. Dougherty, T. C. Hazen, and D. S. Kaback. 1991. "Characterization of the Geology, Geochemistry, Hydrology and Microbiology of the In-situ Air Stripping Demonstration Site at the Savannah River Site." Westinghouse Savannah River Company, WSRC-RD-91-21. 
Eddy, C. A., B. B. Looney, J. M. Dougherty, T. C. Hazen, and D. S. Kaback. 1991. "Characterization of the Geology, Geochemistry, Hydrology and Microbiology of the In-situ Air Stripping Demonstration Site at the Savannah River Site." Westinghouse Savannah River Company, WSRC-RD-91-21.

Edwards*, N. T., B. T. Walton, T. A. Anderson, J. J. Beauchamp, L. W. Cooper, R. J. Luxmoore, E. G. O'Neill, G. S. Sayler, D. C. White, and T. C. Hazen. 1993. "The Use of Vegetation for Bioremediation of Surface Soils Contaminated with Trichloroethylene." [abs] In Situ and On-Site Bioreclamation, The Second International Symposium, San Diego, CA. (paper in press).

Elbring, G. J. 1991. "Using Crosswell Seismic Imaging to Monitor In-Situ Air Stripping Waste Remediation Processes." AGU 1991 Fall Meeting Program and Abstracts, p. 295.

Elbring, G. J. 1991. "Using Crosswell Seismic Imaging to Monitor In-Situ Air Stripping Waste Remediation Processes." AGU 1991 Fall Meeting Program and Abstracts, p. 295.

Elbring, G. J. 1992. "Crosshole Shear-Wave Seismic Monitoring of an Air Stripping Waste Remediation Process." SAND91-2742, Sandia National Laboratories, Albuquerque, New Mexico.

Elbring, G. J. 1992. "Crosshole Shear-Wave Seismic Monitoring of an Air Stripping Waste Remediation Process." SAND91-2742, Sandia National Laboratories, Albuquerque, New Mexico.

Elbring, G. J. 1993. "Crosswell Seismic Imaging of an InSitu Air Stripping Waste Remediation Process." Proceedings of the Symposium on Application of Geophysics to Engineering and Environmental Problems. 1: 55-63.

Elbring, G. J. 1993. "Crosswell Seismic Imaging of an InSitu Air Stripping Waste Remediation Process." Proceedings of the Symposium on Application of Geophysics to Engineering and Environmental Problems. 1:55-63.

Enzien*, M. V., F. W. Picardal, T. C. Hazen, and R. G. Arnold. 1993. "Biodegradation of Trichloroethylene and Tetrachloroethylene under Aerobic Conditions with Methane Addition in a Sediment Column." [abs] In Situ and On-Site Bioreclamation. The Second International Symposium, San Diego, CA. (paper in press).

Enzien*, M., F. Picardal, T. C. Hazen, and B. Arnold. 1992. "Effects of Trichloroethyene, Tetrachloroethylene, and Methane Exposure on Microbial Community Dynamics in a Sediment Column." [abs] American Society for Microbiology Annual Meeting, New Orleans, L.A.
Enzien, M. V., F. Picardal, T. C. Hazen, R. G. Arnold, and C. B. Fliermans. 1993. "Reductive Dechlorination of Trichloroethylene and Tetrachloroethylene Under Aerobic Conditions in a Sediment Column." [abs].

Fliermans*, C. B., J. M. Dougherty, M. M. Franck, P. C. McKinley and T. C. Hazen. 1993. "Immunological Techniques as Tools to Characterize the Subsurface Microbial Community at a Trichloroethylene Contaminated Site." [abs] Invited Seminar Speaker, In Situ and On-Site Bioreclamation, The Second International Symposium, San Diego, CA. (paper in press).

Grisak, G. E., W. F. Merritt, and D. W. Williams. 1977. A Fluoride Borehole Dilution Apparatus for Groundwater Velocity Measurements. Canadian Geotechnical J., 14: 554-561.

Halevy, E., H. Moser, O. Zellhofer, and A. Zuber. 1967. Borehole Dilution Techniques: A Critical Review. Isotopes is Hydrology, IAEA, Vienna, 531-564. 61

Hamming, R. W. 1973. Numerical Methods for Scientists and Engineers. 2nd Edition, McGraw-Hill, New York, NY.

Hanson, R. S., B. J. Bratina and G. A. Brusseau. 1992. "Phylogeny and Ecology of Methylotrophic Bacteria." Microbial Growth on One-Carbon Compounds (J. C. Murrell and D. P. Kelley editors) Andover Press. Hampshire, U. K. pp. 285-302.

Harrold, R. T., T. S. Snyder, and R. S. Kasevich. 1993. "In Situ Radio Frequency Soil Remediation Heating Demonstration." Westinghouse STC Report No. 939TDO-RFHET-R1.

Haselow, J. S. J. Rossabi, T. R Jarosch. 1992. "Emerging Technologies for Abatement of Atmospheric Chlorinated Volatile-Organic Compound Emissions." Proceedings of the 1992 Waste Management and Environmental Sciences Conference, San Juan Puerto Rico.

Hazen*, T. C., J. M. Dougherty, and B. B. Looney. 1992. "Stimulation of Ground Water and Sediment Communities at a Trichloroethylene Contaminated Site." American Society for Microbiology Annual Meeting, New Orleans, LA.

Hazen*, T. C., J. M. Dougherty, and C. B. Fliermans. 1993. "DOE/SRS Integrated Demonstration: In Situ Bioremediation of Soil and Groundwater at a Chlorinated Solvent Contaminated Site using Horizontal Wells to Inject Air and Methane." [abs] Invited Seminar Speaker, In Situ and On-Site Bioreclamation, The Second International Symposium, San Diego, CA. (paper in press).

Hazen*, T. C., J. M. Dougherty, C. B. Fliermans, and B. B. Looney. 1992. "Full Scale Underground Injection of Air, Methane, and Other Gases via Horizontal Wells for In Situ Bioremediation of Chlorinated Solvent Contaminated Ground Water and Soil." [abs] Invited 
Symposium Speaker, American Institute of Chemical Engineers annual meeting, Minneapolis, MN.

Hazen*, T. C., J. M. Dougherty, C. B. Fliermans, and B. B. Looney. 1993. "Bioremediation of Soil and Groundwater at a Chlorinated Solvent Contaminated Site using Horizontal Wells to Inject Air." [abs] Invited Seminar Speaker, In Situ and On-Site Bioreclartation, The Second International Symposium, Saa Diego, CA. (paper in press).

Hazen*, T. C., J. M. Dougherty, M. Enzien, M. M. Franck, C. B. Fliermans, C. A. Eddy, and K. H. Lombard. 1992. "DOE/SRS Integrated Demonstration: In Situ Bioremediation of Soil and Groundwater." [abs] DOE Technology Information Exchange: Remediation, Pleasanton, CA.

Hazen, T. C. 1992. "Test Plan for In Situ Bioremediation Demonstration of the Savannah River Integrated Demonstration Project DOE/OTD TTP No.:SR056601 (U). WSRC-RD-91-23. Westinghouse Savannah River Company, Aiken, SC.

Hazen, T. C. 1991. "Bioremediation at SRS." Invited Speaker, Annual Meeting of the Southeastern Society for Microbiology, Atlanta, GA.

Hazen, T. C. 1991. "Bioremediation/Biotechnology." Invited Keynote Speaker, Puerto Rico Conference on Advanced Technology/ InterAmerican University, San Juan, Puerto Rico.

Hazen, T. C. 1991. "Ex-Situ Bioremediation of SRS Waste Sites." Invited Speaker, US Department of Energy, Office of Environmental Restoration Technology Information Exchange Workshop, Augusta, GA.

Hazen, T. C. 1991. "In-Situ Bioremediation of SRS Waste Sites." Invited Speaker, US Department of Energy, Office of Environmental Restoration Technology Information Exchange Workshop, Augusta, GA.

Hazen, T. C. 1991. "SRS Integrated Demonstration: Bioremediation Tasks." Invited Seminar/Convener, Fourth International Institute for Gas Technology Symposium on Gas, Oil, Coal and Environmental Biotechnology, Colorado Springs, CO.

Hazen, T. C. 1991. "Test Plan for In Situ Bioremediation Demonstration of the Savannah River Integrated Demonstration Project DOE/OTD TTP No.: SR 0566 01 (U)." WSRC-RD-91-23. Westinghouse Savannah River Company, Aiken, SC.

Hazen, T. C. 1992. "Emerging Technologies in Bioremediation." Workshop Chairman, American Sceizty for Microbiology Training Workshop, New Orleans, LA.

Hazen, T. C. 1992. "In Situ Bioremediation Demonstrations at SRS." Invited Symposium Speaker, American Society for Microbiology Annual Meeting, New Orleans, LA.

Hazen, T. C. 1992. "In Situ Bioremediation Demonstrations at SRS." Invited Symposium Speaker, Interna- tional Symposium on the Implementation of Biotechnology in Industrial Waste Treatment and Bioremediation, Grand Rapids, MI. Sponsored by Michigan Biotechnical Institute.

Hazen, T. C. 1992. "Monitoring In Situ Bioremediation." Invited Symposium Speaker, International Symposium on In Situ Bioremediation '92, Niagara-on-theLake, Canada. Sponsored by Environment Canada.

Hazen, T. C. 1992. "SRS Bioremediation Technology Licensing Symposium." SRS Technology Transfer Symposium, Augusta, GA.

Hazen, T. C. 1993. "In Situ Bioremediation of Groundwater." Invited Seminar Chairman and Speaker, American Society for Microbiology Conference on Water Quality in the Western Hemisphere, San Juan, Puerto Rico.

Hazen, T. C. and C. Berry*. 1991. "Bioreactors." Invited Poster, US Department of Energy, Office of Environmental Restoration Technology Information Exchange Workshop, Augusta, GA.

Hazen, T. C. and L. Jimenez. 1988. "Enumeration and Identification of Bacteria from Environmental Samples Using Nucleic Acid Probes." Microbiological Sciences. 5(11): 340-343.

Hazen, T. C., B. B. Looney, M. Enzien, M. M. Franck, C. B. Fliermans, and C. A. Eddy. 1993. "In Situ Bioremediation via Horizontal Wells." I \& EC Special Symposium, American Chemical Society, Atlanta, GA.

Hazen, T. C., K. Lombard, and C. B. Fliermans. "FullScale Prepared Bed Bioremediation Facility for Petroleum-Contaminated Soil." [abs] Invited Seminar. SRS-DOE Supplier Information Exchange Forum, Augusta, GA.

Hazen, T. C., L. Jimenez, G. Lopez de Victoria, and C. B. Fliermans. 1991. "Comparison of Bacteria from Deep Subsurface Sediment and Adjacent Groundwater." Microb. Ecol. 22: 293-304.

Heath, W. 0., J. S. Roberts, D. L. Lessor, and T. M. Bergsman. 1992. "Engineering Scaleup of Electrical Soil Heating of Soil Decontamination." Presentation at Spectrum `92, Boise, Idaho.

Heath, W. 0., S. C. Goheen, M. C. Miller, R. L. Richardson. 1992. "Investigation of Electrical Fields for LowTemperature Treatment of Soils and Liquids." Presented at A\&WMA and EPA's International Conference In Situ Treatment of Contaminated Soil and Water, Cincinnati, Ohio.

Henricksen, A. D. and S. R. Booth. 1992. "Cost Effectiveness of an Innovative Technology for VOC Detection: The Direct Sampling Ion Trap Mass Spectrometer." Report LA-UR-92-3527.

Henricksen, A. D. and S. R. Booth. 1992. "Cost Effectiveness of an Innovative Technology for VOC Detection: 
The Direct Sampling Ion Trap Mass Spectrometer." Report LA-UR-92-3527.

Hess, A. E. 1986. Identifying Hydraulically Conductive Fractures with a Slow-velocity Borehole Flowmeter. Can. Geotech J., 23: 69-78.

Jenkins, C. E. Higgins, T. M. Gayle, G. W. Allin, and R. R. Smith, "Field Experiences with a Multisorbent Arrayed Sampler for the In Situ Collection of Vadose Zone Volatile Organic Compounds," presented at the Third International Symposium for Field Screening Methods for Hazardous Wastes and Toxic Chemicals, Las Vegas, Nevada, February 24-26, 1993.

Jenkins, R. A., C. E. Higgins, T. M. Gayle, G. W. Allin, and R. R. Smith, "A Multisorbent Arrayed Sampler for In Situ Collection of Vadose Zone Volatile Organic Compounds," Proceedings of the Information Exchange Meeting on Characterization, Sensors, and Monitoring Technologies. Dallas, Texas. July 15-16, 1992, DOE/CONF 920791.

Jimenez, L. 1989. "Molecular Analysis of Deep Subsurface Bacteria." WSRC-RP-89-1039. Thesis for Submission to the Intercampus Doctoral Committee Puerto Rico Resource Center for Science and Engineering.

Jimenez, L. 1990. "Molecular Analysis of Deep-Subsurface Bacteria." Appl. Environ. Microbiol. 56(7): 2108-2113.

Jimenez, L., I. Rosario, C. Werner, S. Koh, and G. S. Sayler. "Molecular Environmental Diagnostics of Contaminated Subsurface Sites." 92nd Annual Meeting of the American Society for Microbiology, May 1992. New Orleans, LA.

Jimenez, L., I. Rosario, C. Werner, S. Koh, R. Hanson, T. C. Hazen, and G. S. Sayler. "Molecular Environmental Diagnostics of Contaminated Subsurface Environments." Manuscript in review by Westinghouse Savannah River Co.

Jimenez, L., I. Rosario, J. Bowman, S. Koh, and G. S. Sayler. 1993. "Molecular Environmental Diagnostics of TCE Contaminated Subsurface Environments." In Situ and On-Site Bioreclamation, The Second International Symposium, San Diego, CA.

Kaback, D. S., B. B. Looney, C. A. Eddy, and T. C. Hazen. 1991. "Innovative Ground Water and Soil Remediation: In Situ Air Stripping Using Horizontal Wells." National Water Well Association Fifth Outdoor Action Conference Proceedings, Las Vegas, NV.

Kaback, D. S., B. B. Looney, C. A. Eddy, and T. C. Hazen. 1991. "Innovative Ground Water and Soil Remediation: In Situ Air Stripping Using Horizontal Wells." National Water Well Association Fifth Outdoor Action Conference Proceedings, Las Vegas, NV.

Kaback, D. S., B. B. Looney, C. A. Eddy, and T. C. Hazen. 1992. "Innovative Ground Water and Soil Remedia- tion Using Horizontal Wells." Innovative Technologies for Cleaning the Environment, Erice, Italy.

Kaback, D. S., B. B. Looney, C. A. Eddy, and T. C. Hazen. 1992. "Innovative Ground Water and Soil Remediation Using Horizontal Wells." Innovative Technologies for Cleaning the Environment, Erice, Italy.

Kaback, D. S., B. B. Looney, J. C. Corey, and L. M. Wright. 1989. "Well Completion Report on Installation of Horizontal Wells for In Situ Remediation Tests." WSRC-RP-89-784.

Kaback, D. S., B. B. Looney, J. C. Corey, and L. M. Wright. 1989. "Well Completion Report on Installation of Horizontal Wells for In Situ Remediation Tests." WSRC-RP-89-784.

Kaback, D. S., B. B. Looney, J. C. Corey, L. M. Wright, and J. L. Steele. 1989. "Horizontal Wells for In Situ Remediation of Groundwater and Soils." National Water Well Association Third Outdoor Action Conference Proceedings, Orlando, FL.

Kaback, D. S., B. B. Looney, J. C. Corey, L. M. Wright, and J. L. Steele. 1989. "Horizontal Wells for In Situ Remediation of Groundwater and Soils." National Water Well Association Third Outdoor Action Conference Proceedings, Orlando, FL.

Kaback, D. S., B. B. Looney, J. C. Corey, L. M. Wright, and J. L. Steele. 1989. "Horizontal Wells for In-Situ Remediation of Groundwater and Soils." in Proceedings of the Third National Outdoor Action Conference on Aquifer Restoration, Groundwater Monitoring and Geophysical Methods, Association of Ground Water Scientists and Engineers, Orlando, FL. pp. 121-135.

Kearl, P. M., N. E. Korte, and T. A. Cronk. 1992. "Suggested Modifications to Groundwater Sampling Procedures Based on Observations Using the Colloidal Borescope." Groundwater Monitoring Review. Spring: 155-161.

Kearl, P. M., N. E. Korte, and T. A. Cronk. 1992. "Suggested Modifications to Groundwater Sampling Procedures Based on Observations Using the Colloidal Borescope." Groundwater Monitoring Review. Spring: 155-161.

Kerfoot, W. B. 1988. Monitoring Well Construction and Recommended Procedures for Direct Groundwater Flow Measurements using a Heat-pulsing Flowmeter. Groundwater Contamination: Field Methods. eds., A. G. Collins and A. I. Johnson. 146-161. ASTM.

Koh, S., I. Rosario, C. Werner, A. Heitzer, L. Jimenez, and G. S. Sayler. "Comparative Molecular Analysis of Deep Subsurface Environments." [abs] 91 st Annual Meeting of the American Society for Microbiology, May 1991, Dallas, TX.

Koh, S., J. P. Bowman, and G. Sayler. 1993. "Soluble Methane Monooxygenase Production and Trichloroethylene Degradation by a Type I Methanotroph, 
Methylomonas methanica 68-1." Appl. Environ. Microbiol. 59: 960-967.

Korde, V. M., T. J Phelps, P. R. Bienkowski, and D. C. White. 1992. "Biodegradation of Chlorinated Aliphatics and Aromatic Compounds in a Recycle ExpandedBed Bioreactor." 14th Symposium on Biotechnology of Fuels and Chemicals, Gatlinburg, TN.

Korde, V. M., T. J. Phelps, P. R. Bienkowski, and D. C. White. 1993. "Biodegradation of Chlorinated Aliphatics and Aromatic Compounds in Total-Recycle Expanded-Bed Biofilm Reactors." Applied Biochemistry and Biotechnology. 39/40: 631-641.

Lackey, L. W., O. F. Webb, T. J. Phelps, P. R. Bienkowski, and D. C. White. 1992. "Utilization of Differential Volume Reactor Systems for Fate Analysis of Trichloroethylene in Subsurface Environments." (Manuscript submitted)

Lackey, L. W., T. J. Phelps, P. R. Bienkowski, and D. C. White. 1993. "Biodegradation of Chlorinated Aliphatic Hydrocarbon Mixtures in a Single-Pass Packed-Bed Reactor." Applied Biochemistry and Biotechnology. 39/40: 701-713.

Lackey, L. W., T. J. Phelps, S. Nold, D. Ringelberg, V. Korde, P. R. Bienkowski and D. C. White. "Feasibility Testing for the On-Site Bioremediation of Organic Wastes by Native Microbial Consortia." (Manuscript in press) [abs].

Lombard*, K. H., J. Borthen, and T. C. Hazen. 1993 "The Design and Management of System Components for in situ Methanotrophic Bioremediation of Chlorinated Hydrocarbons." In Situ and On-Site Bioreclamation, The Second International Symposium, San Diego, CA. (paper in press). WSRC-MS-92-454.

Looney, B. B., T. C. Hazen, D. S. Kaback, and C. A. Eddy. 1991. "Full-Scale Field Test of the In Situ Air Stripping Process at the Savannah River Integrated Demonstration Test Site." WSRC-RD-91-22.

Looney, B. B., C. A. Eddy, and W. R. Sims. "Evaluation of a Rapid Headspace Analysis Method for Analysis of Volatile Constituents in Soils and Sediments." Groundwater Monitoring Review. (in revision).

Looney, B. B., C. A. Eddy, and W. R. Sims. "Evaluation of a Rapid Headspace Analysis Method for Analysis of Volatile Constituents in Soils and Sediments." Groundwater Monitoring Review. (in revision).

Looney, B. B., C. A. Eddy, and W. R. Sims. 1993. "Evaluation of Headspace Method for Volatile Constituents in Soils and Sediments." Proceedings of the National Symposium on Measuring and Interpreting VOC's in Soils: State of the Ait and Research Needs, Las Vegas, Nevada. 8 p.

Looney, B. B., C. A. Eddy, and W. R. Sims. 1993. "Evaluation of Headspace Method for Volatile Constituents in Soils and Sediments." Proceedings of the National
Symposium on Measuring and Interpreting VOC's in Soils: State of the Art and Research Needs, Las Vegas, Nevada. 8 p.

Looney, B. B., D. S. Kaback, and J. C. Corey, 1991/1992. "Field Demonstration of Environmental Restoration Using Horizontal Wells." Third Forum on Innovative Hazardous Waste Treatment Technologies: Domestic and International, Dallas TX (EPA); Waste Management '91 Conference (DOE), Tucson AZ; Live Satellite Seminar sponsored by Air and Waste Management Association.

Looney, B. B., D. S. Kaback, and J. C. Corey. 1991/1992. "Field Demonstration of Environmental Restoration Using Horizontal Wells." Third Forum on Innovative Hazardous Waste Treatment Technologies: Domestic and International, Dallas TX (EPA); Waste Management ' 91 Conference (DOE), Tucson AZ; Live Satellite Seminar sponsored by Air and Waste Management Association.

Looney, B. B., J. B. Pickett and J. J. Malot. 1991. "Pilot Test of a Vacuum Extraction System for Environmental Remediation of Chlorinated Solvents at the Savannah River Site." WSRC-RD-91-19.

Looney, B. B., J. Rossabi, D. M. Tuck, C. L. Bergren, R. Van Pelt, W. E. Jones, A. E. Stevenson, and B. S. Kristiansen. 1992. "Assessing DNAPL Contamination, A/M Area, Savannah River Site: Phase I Results (U)." WSRC-RP-1302. Westinghouse Savannah River Company, Aiken, SC. pp. 1-85.

Looney, B. B., J. Rossabi, D. M. Tuck, C. L. Bergren, R. Van Pelt, W. E. Jones, A. E. Stevenson, and B. S. Kristiansen. 1992. "Assessing DNAPL Contamination, A/M Area, Savannah River Site: Phase I Results (U)." WSRC-RP-1302. Westinghouse Savannah River Company, Aiken, SC. pp. 1-85.

Looney, B. B., T. C. Hazen, D. S. Kaback, and C. A. Eddy. 1991. "Full Scale Field Test of the In Situ Air Stripping Process at the Savannah River Integrated Demonstration Test Site (U). WSRC-RD-91-22. Westinghouse Savannah River Company, Aiken, SC.

Looney, B. B., T. C. Hazen, D. S. Kaback, and C. A. Eddy. 1991. "Full Scale Field Test of the In Situ Air Stripping Process at the Savannah River Integrated Demonstration Test Site (U). WSRC-RD-91-22. Westinghouse Savannah River Company, Aiken, SC. pp. 1-18.

Lopez de Victoria, G. 1989. "Chemotactic Behavior of Deep Subsurface Bacteria Toward Carbohydrates, Amino Acids, and a Chlorinated Alkene." DP-1779. Thesis Submitted for Degree of Master of Science at University of Puerto Rico.

Lowry, W. E. and S. D. Dunn. 1993. "Seamist Depth Discrete Sampling and Monitoring of the Vadose Zone at the Savannah River Site." SEASF-FR-93-005. 
Innovative Monitoring Technologies at the Savannah River Integrated Demonstration Site

Lowry, W. E. and S. D. Dunn. 1993. "Seamist Depth Discrete Sampling and Monitoring of the Vadose Zone at the Savannah River Site." SEASF-FR-93-005.

Malachowsky, K., T. J. Phelps, A. B. Teboli, D. E. Minnikin, and D. C. White. "Aerobic Mineralization of Trichloroethylene, Vinyl Chloride, and Aromatic Compounds by Rhodococcus Species." [abs] (paper in press).

Malachowsky, K., T. J. Phelps, and D. C. White. 1991. "Aerobic Mineralization of Vinyl Chloride by Branched-Shaped Gram-Positive Bacteria." in Abstracts of the Annual Meeting of the American Society for Microbiology.

Malachowsky, K., T. J. Phelps, and D. C. White. 1992. "Aerobic Degradation of Trichloroethylene (TCE) Vinyl Chloride (VC) and Aromatic Compounds by Type IV Actinomycetes." American Society for Microbiology, 92nd General meeting, New Orleans, LA.

Marine, I. W. and H. W. Bledsoe, 1984. "M-Area Groundwater Investigation (Supplemental Technical Data Summary). Savannah River Laboratory Report DPSTD-84-112.Savannah River Plant, Aiken, SC.

Maskarinec, M. P., C. K. Bayne, R. A. Jenkins, L. H. Johnson, and S. K. Holladay, "Stability of Volatile Organics in Environmental Soil Samples - Final Report" ORNLTM 12128, November 1992, Available from the National Technical Information Service, Springfield, VA 22161

Milanovich, F. P., P. F. Daley, K. Langry, B. W. Colston, S. B. Brown, and S. M. Angel. 1991. "A Fiber Optic Sensor for Continuous Monitoring of Chlorinated Hydrocarbons." in Proceedings of the Second International Symposium on Field Screening Methods for Hazardous Wastes and Toxic Chemicals. EPA/600/9. 91/028. EPA, Las Vegas. pp. 43-48.

Milanovich, F. P., P. F. Daley, K. Langry, B. W. Colston, S. B. Brown, and S. M. Angel. 1991. "A Fiber Optic Sensor for Continuous Monitoring of Chlorinated Hydrocarbons." in Proceedings of the Second International Symposium on Field Screening Methods for Hazardous Wastes and Toxic Chemicals. EPA/600/9. 91/028. EPA, Las Vegas. pp. 43-48.

Moltz, F. J., R. H. Morin, A. E. Hess, J. G. Melville, and O. Guven. 1989. The Impeller Meter for Measuring Aquifer Permeability Variations: Evaluation and Comparison with other Tests. Water Resources Research. 25(7): 1677-1683.

Momii, K., K. Jinno, and F. Hirano. 1993. Laboratory Studies on a New Laser Doppler Velocimeter System for Horizontal Groundwater Velocity Measurements in a Borehole. Water Resources Research. 29(2): 283. 291.
Morrissey, C. M., S. E. Herbes, A. V. Palumbo*, T. J. Phelps, and T. C. Hazen. 1993. "Use of Laboratory Soil Columns to Optimize In Situ Biotransformation of Tetrachloroethylene." [abs] Invited Seminar Speaker, In Situ and On-Site Bioreclamation. The Second International Symposium, San Diego, CA. (paper in press).

Morrissey, C. M., S. E. Herbes, A. V. Palumbo, T. J. Phelps, and T. C. Hazen. 1993. "Use of Laboratory Soil Columns to Optimize In-Situ Biotransformation of Tetrachloroethylene." In Situ and On-Site Bioreclamation: The Second International Symposium, San Diego, CA. (paper in press).

Nichols, R. L., B. B. Looney, and J. E. Huddleston. 1992. "Three Dimensional Digital Imaging." Environmental Science and Technology. 26(4): 642-649.

Nichols, R. L., B. B. Looney, and J. E. Huddleston. 1992. "Three Dimensional Digital Imaging." Environmental Science and Technology. 26(4): 642-649.

Niedzielski, J. J., R. M. Schram, T. J. Phelps, S. E. Herbes, and D. C. White. 1989. "A Total-Recycle ExpandedBed Bioreactor Design which Allows Direct Headspace Sampling of Volatile Chlorinated Aliphatic Compounds." J. Microbiol. Methods. p. 1-7.

Nold, S., L. Lackey, D. Ringelberg, and D. White. 1992. "Changes in Community Structure and Physiological Status of a Bacterial Consortia During Degradation of Trichloroethylene (TCE)." [abs] American Society for Microbiology, 92nd General Meeting, New Orleans, LA.

Palumbo, A. V., P. A. Boerman, S. E. Herbes, G. W. Strandberg, T. L. Donaldson, A. J. Lucero, H. L. Jennings, T. J. Phelps, and D. C. White. 1991. "A CoMetabolic Approach to Groundwater Remediation." Environmental Remediation 1991: Cleaning Up the Environment for the 21st Century. pp. 95-99.

Palumbo, A. V., T. J. Phelps, C. M. Morrissey, S. E. Herbes, G. Sayler, and L. Jiminez. "Monitoring Microbial Activity and Biomass During the Methane Injection Campaign." In Situ and On-Site Bioreclamation, Second International Symposium, San Diego, California. (In preparation)

Palumbo, A. V., T. J. Phelps, G. S. Sayler, D. C. White, and S. M. Pfiffner. "Integrated Demonstration of TCE Degradation: Biological Monitoring of Critical Populations." [abs].

Pfaender, F. K. and S. C. Long. 1993. "Toxicity Changes Accompanying In Situ Bioremediation." [abs] Invited Seminar Speaker, In Situ and On-Site Bioreclamation, The Second International Symposium, San Diego, CA. (paper in press).

Pfiffner, S. M., R. Mackowski, D. C. White, and T. J. Phelps. 1993. "Monitoring of Microbial Populations and Activities from Groundwater for In-Situ Trichlo- 
roethylene Remediation." [abs] American Society for Microbiology, 93rd General Meeting, Atlanta, GA.

Phelps, T. J., D. B. Ringelberg, J. B. Guckert, and D. C. White. 1990. "Biochemical Markers for In Situ Microbial Community Structure of Subsurface Sediments." Abstracts of the American Geophysical Union.

Phelps, T. J., J. J. Niedzielski, K. Malachowsky, R. M. Schram, S. E. Herbes, and D. C. White. 1991. "Biodegradation of Mixed-Organic Wastes by a Microbial Consortia in Continuous-Recycle Expanded-Bed Bioreactors." Environ. Sci. \& Technol. 25: 14611465.

Phelps, T. J., J. J. Niedzielski, R. M. Schram, S. E. Herbes, and D. C. White. 1990. "Biodegradation of Trichloroethylene in Continuous-Recycle Expanded-Bed Bioreactors." Appl. Environ. Microbiol. 56: 17021709.

Phelps, T. J., J. Niedzielski, and D. C. White. 1991. "Biodegradation of Mixed Organic Wastes by Microbial Consortia Enriched from Subsurface Sediments." in Proceedings of the First International Symposium on Microbiology of the Deep Subsurface. (C. B. Fliermans and T. C. Hazen editors), WSRC Information Services, Aiken, SC. pp. 7-71-80.

Phelps, T. J., K. Malachowsky, R. M. Schram, and D. C. White. 1991. "Aerobic Mineralization of Vinyl Chloride by a Bacterium of the Order Actinomycetales." Appl. Environ. Microbiol. 57(4): 1252-1254.

Phelps, T. J., L. Lackey, V. Korde, J. J. Niedzielski, and D. C. White. 1990. "Bioremediation of Mixed Organic Wastes by Microbial Consortia Enriched from Subsurface Sediments." Abstracts of the American Institute of Corrosion Engineers, Summer Meeting.

Phelps, T. J., S. M. Pfiffner, R. Mackowski, D. Ringelberg, and D. C. White. 1993. "Application of Microbial Biomass and Activity Measures to Assess In-Situ Bioremediation of Chlorinated Solvents." [abs] In Situ and On-Site Bioreclamation: The Second International Symposium, San Diego, CA. (paper in press).

Ramirez, A. L, Daily, W. D., Owen, E., and D. LaBrecque (1991), High Frequency electromagnetic and Electrical Resistance Tomography of the Savannah River Integrated Demonstration Project, Lawrence Livermore National Laboratory, UCRL-JC-107780, Livermore, CA, submitted to Water Resources Research.

Ramirez, A. L. and W. D. Daily, Monitoring Radio-Frequency Heating of Contaminated Soils Using Electrical Resistance Tomography, Lawrence Livermore National Laboratory, UCRL-ID-115373, Livermore, CA. 1993.

Ramirez, A. L., W. D. Daily, and D. LaBrecque. 1992. "Electrical Resistance Tomography Used in Environ- mental Restoration." Lawrence Livermore National Lab, UCRL-JC-110356, Livermore, CA, Proceedings of the Information Exchange Meeting on Characterization, Sensors, and Monitoring Technologies, Dallas, TX, sponsored by US DOE.

Ramirez, A. L., W. D. Daily, and D. LaBrecque. 1992. "Electrical Resistance Tomography Used in Environmental Restoration." Lawrence Livermore National Lab, UCRL-JC-110356, Livermore, CA, Proceedings of the Information Exchange Meeting on Characterization, Sensors, and Monitoring Technologies, Dallas, TX, sponsored by US DOE.

Ramirez, A. L., W. D. Daily, E. Owen, D. LaBrecque. 1991. "Using High Frequency Electromagnetic and Electrical Resistance Tomography to Determine the Effectiveness of a Remediation Process." Lawrence Livermore National Laboratory, UCRL-JC-107780, Livermore, CA.

Ramirez, A. L., W. Daily, and D. LaBrecque, Electrical Resistance Tomography Used in Environmental Restoration, Proceedings of the Information Exchange Meeting on Characterization, Sensors and Technology, U.S. Dept. of Energy, CONF-920791, session C1, paper \#37, 1992.

Ramirez, A., W. Daily, K. LaBrecque, E. Owen and D. Chesnut, Monitoring an Underground Steam Injection Process Using Electrical Resistance Tomography, Lawrence Livermore National Laboratory, Water Resources Research, vol. 29, no. 1, 1993.

Rosenberg, N. D., B. J. Travis, J. D. Schroeder, B. B. Looney, C. A. Eddy, S. R. Booth, D. S. Brookshire and M. McKee. "Environmental Restoration Technology Demonstrations at DOE's Savannah River Site." To be presented at the American Geophysical Union fall meeting, San Francisco, CA (abstract published in EOS Transactions 73, p.225).

Rossabi, J. "In-Situ, Subsurface Monitoring of Vapor Phase TCE Using Fiber Optics." Proceedings of the Third International Symposium-Field Screening Methods for Hazardous Waste and Toxic Chemicals, Las Vegas, Nevada. (in press).

Rossabi, J. "The Savannah River Technology Center Environmental Monitoring Field Test Platform." Proceedings of the Third International Symposium-Field Screening Methods for Hazardous Waste and Toxic Chemicals, Las Vegas, Nevada. (in press).

Rossabi, J. 1992. "Fiber Optic Sensors for Environmental Application: A Brief Review." Westinghouse Savannah River Company, WSRC-RP-92-471.

Rossabi, J. 1993. "The Savannah River Technology Center Environmental Monitoring Field Test Platform." Proceedings of the Third International Symposium-Field Screening Methods for Hazardous Waste and Toxic Chemicals, Las Vegas, Nevada. 
Rossabi, J., B. A. Eckenrode, and B. Owens. 1992. "Onsite Well Screening with a Transportable Gas Chromatography/Mass Spectrometer System." Westinghouse Savannah River Company, WSRC-RP-91-603.

Rossabi, J., B. B. Looney, B. Riha, A. Ferrelli, and N. Smith. 1992. "The Influence of Surface Pressure Fluctuation on Surface/Subsurface Air Migration." [abs]: EOS Transactions of the American Geophysical Union. 73(43): 233.

Rossabi, J., J. S. Haselow. 1991. "Technology Status Report: Off-Gas Treatment Technologies for Chlorinated Volatile Organic Compound Air Emissions." WSRC-RP-91 0603.

Sayler, G. S. 1992. "Environmental Biotechnology's Future in Hazardous Waste Management." Third Pacific Rim Biotechnology Conference, Taipei, Taiwan.

Sayler, G. S. 1992. "Molecular Approaches for Diagnostics, Performance Monitoring and Optimization in Bioremediation." U. S. Environmental Protection Agency, Tel Aviv, Israel.

Schroeder, J. D., N. D. Rosenberg, E. P. Barnes-Smith, and S. R. Booth. 1992. "In-Situ Air Stripping: Cost Effectiveness of a Remediation Technology Field Tested at the Savannah River Integrated Demonstration Site." Los Alamos National Laboratory Report, LA-UR-921927. 6/1992.

Schroeder, J. D., S. R. Booth and L. K. Trocki. "Cost Effectiveness of the Site Characterization and Analysis Penetrometer System." Report LA-UR-91-4016. $12 / 1991$.

Schroeder, J. D., S. R. Booth and L. K. Trocki. "Cost Effectiveness of the Site Characterization and Analysis Penetrometer System." Report LA-UR-91-4016. $12 / 1991$.

Schroeder, J. D., S. R. Booth, L. K. Trocki, A. G. Turpin, R. B. Kidman and J. H. Pendergrass. "Cost Savings From Integration of a Demonstration Program: The Savannah River Integrated Demonstration Project (SRIDP)." Report LA-UR-91-1485.

Sims, W. R., B. B. Looney, and C. A. Eddy. 1991. "Evaluation of a Rapid Headspace Analysis Method for Analysis of Volatile Constituents in Soils and Sediments." Proceedings of the Fifth National Outdoor Action Conference on Aquifer Restoration, Ground Water Monitoring, and Geophysical Methods.

Sims, W. R., B. B. Looney, and C. A. Eddy. 1991. "Evaluation of a Rapid Headspace Analysis Method for Analysis of Volatile Constituents in Soils and Sediments." Proceedings of the Fifth National Outdoor Action Conference on Aquifer Restoration, Ground Water Monitoring, and Geophysical Methods.

Smythe, W. R. 1939. Static and Dynamic Electricity, 1st ed., 65-67, McGraw-Hill, New York.
SR 121106: Bioremediation

Steele, J. L., D. S. Kaback, and B. B. Looney. 1992. "Organics in Soils and Groundwater at Non-Arid Sites (A-1) Integrated Demonstration." Presented at Spectrum '92 Conference, Boise, ID.

Steele, J. L., D. S. Kaback, and B. B. Looney. 1992. "Organics in Soils and Groundwater at Non-Arid Sites (A-1) Integrated Demonstration." Presented at Spectrum '92 Conference, Boise, ID.

Sun, W., A. Ogram, W. Payne, and F. J. Brockman. 1993. "Assessment of TCE Degradative Potential in a Contaminated Aquifer by Gene Probe Analysis." Abstracts of the 93rd General Meeting of the American Society for Microbiology. p. 378.

Travis, B. J. and B. C. Trent. 1991. "Three Dimensional Computer Simulations of Bioremediation and Vapor Extraction." Proceedings of Environmental Remediation Conference, ER '91, Pasco, WA, LA-UR-912875.

Travis, B. J. and E. Nuttall. 1987. "Two-Dimensional Numerical Simulation of Geochemical Transport in Yucca Mountain." LA-10532-MS.

Travis, B. J. and K. Birdsell. 1990. "TRACK3D: A Model of Flow and Transport in Porous Media: Model Description and User's Manual." LA-11798-M.

Travis, B. J., N. D. Rosenberg and K. H. Birdsell. 1993. "Numerical Simulations of In Situ Bioremediation at the Savannah River Site."

U. S. Department of Energy Environmental Restoration and Waste Management Office of Technology Development. 1991. "Eleanup of VOCs in Non-Arid Soils The Savannah River Integrated Demonstration."

U. S. Department of Energy Environmental Restoration and Waste Management Office of Technology Development. 1991. "Cleanup of VOCs in Non-Arid Soils The Savannah River Integrated Demonstration."

Virden, J. W., W. O. Heath, S. C. Goheen, M. C. Miller, G. M. Mong, and R. L. Richardson. 1992. "High-Energy Corona for Destruction of Volatile Organic Contaminants in Process Off-Gas." PNL-SA-20741, Pacific Northwest Laboratory, Richland WA 99352.

Walton, T. L. 1991. "Integrated Demonstration for Cleanup of Organics in Soils and Groundwater at Non-Arid Sites." IDP-0566.

Walton, T. L. 1991. "Integrated Demonstration for Cleanup of Organics in Soils and Groundwater at Non-Arid Sites." IDP-0566.

Wear Jr., J. E. 1993. "Environmental Diagnostic Analysis of Ground Water Bacteria and Their Involvement in Utilization of Aromatic Compounds." WSRC-TR-93083. Thesis Submitted to the Graduate Faculty of Wake Forest University.

Westinghouse Savannah River Company Environmental Restoration. 1993. "M Area HWMF Fact Sheet." 
Westinghouse Savannah River Company. 1991. "Air Pollution Control Feasibility Study." Prepared in support of an Air Permit Application to the South Carolina Department of Health and Environmental Control.

Westinghouse Savannah River Company. 1992. "In-Situ Radio Frequency Heating Demonstration Field Test Plan." WSRC-RP-92-1428.

Westinghouse Savannah River Company. 1992. "Roadmap for the Integrated Demonstration for Cleanup of Organics in Soils and Groundwater at Non-Arid Sites at the Savannah River Site." SRT-EMP-92-0204.

Westinghouse Savannah River Company. 1992. "Roadmap for the Integrated Demonstration for Cleanup of Organics in Soils and Groundwater at Non-Arid Sites at the Savannah River Site." SRT-EMP-92-0204.

Wheatcraft, S. W. and F. Winterberg. 1985. Steady State Flow Passing through a Cylinder of Permeability Different from the Surrounding Medium. Water Resources Research. 21(12): 1923-1929.

Wilson, D. D. and D. S. Kaback. 1993. "Industry Survey for Horizontal Wells Final Report." WSRC-TR-93511.

Wilson, D. D. and D. S. Kaback. 1993. "Industry Survey for Horizontal Wells Final Report." WSRC-TR-93511.

Yamazaki-Nishida, S., H. W. Read, J. K. Nagano, T. Jarosch, C. Eddy, S. Cervera-March, and M. A. Anderson. 1992, in preparation. "Photodegradation of Volatile Chlorinated Compounds by Using TiO2 Pellets from a Soil Vapor Extraction Treatment Unit." 


\section{Appendix-Field Monitoring Test Platform}

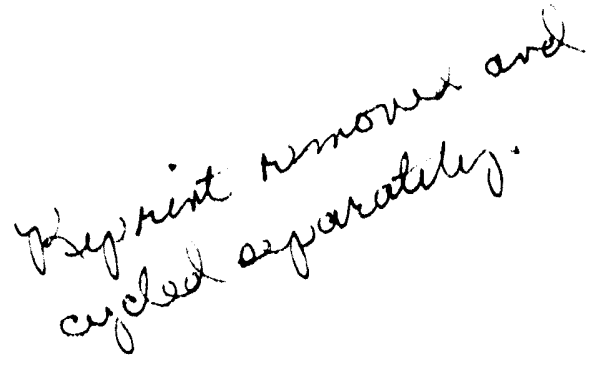


WSRC-TR-93-671

74

$92 \times 1017$ FMK 
11
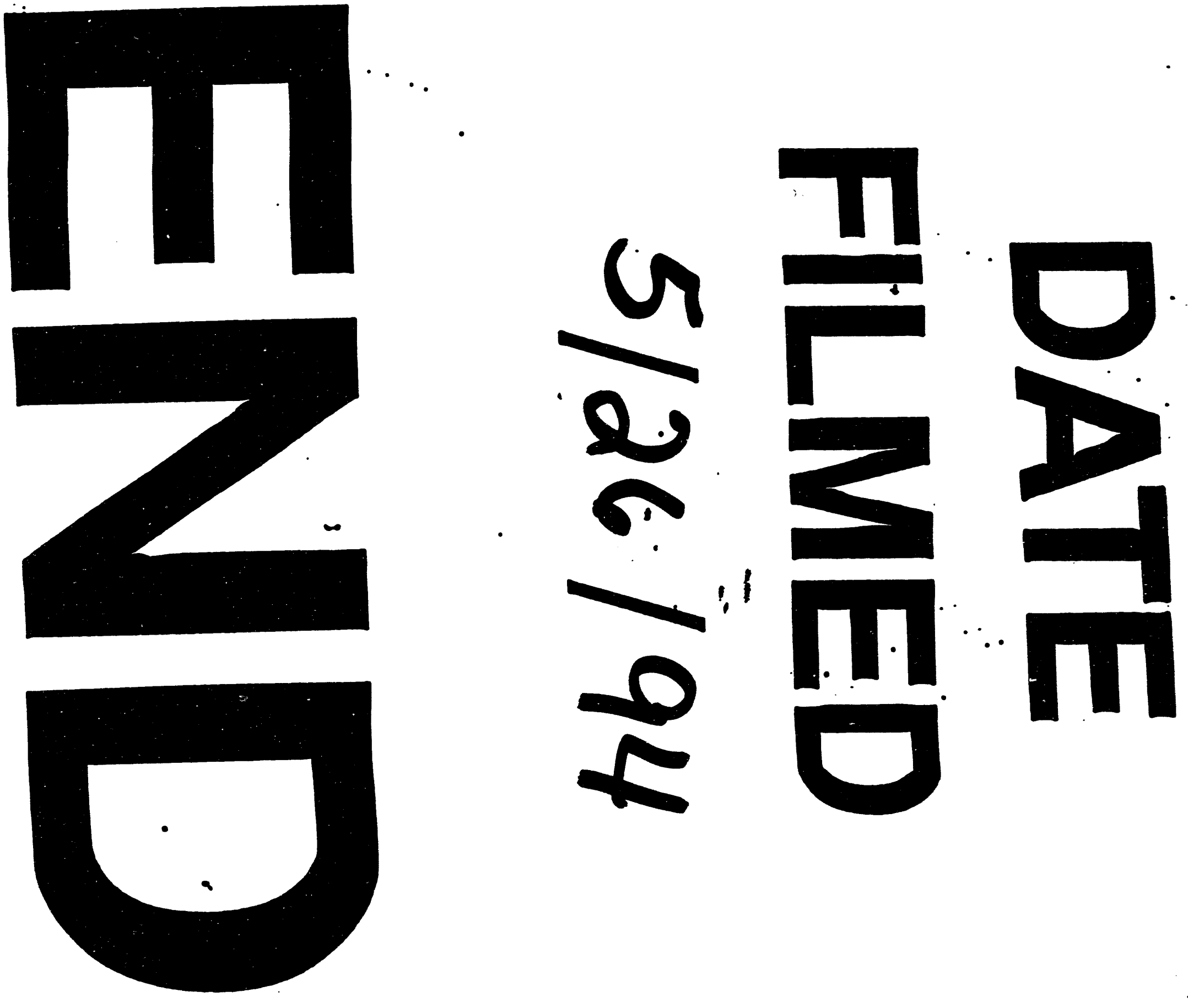